\title{
KINETIC FABRIC SAMPLES AS A NEW APPROACH TO INTERACTIVE FASHION ARTS
}

by

Daniela Ghanbari Vahid

A thesis submitted to the Faculty of Graduate and Postdoctoral Affairs in partial fulfillment of the requirements for the degree of

MASTER OF APPLIED SCIENCES

in

Human Computer Interaction

Carleton University

Ottawa, Ontario

(C) Copyright by Daniela Ghanbari Vahid, 2019 


\begin{abstract}
As technology is integrated into all aspects of our lives, researchers are working to explore emerging technologies — such as the creation of functional apparel — in the field of fashion design. The substantial growth in the field of functional apparel design - such as the use of smart textiles - encourages researchers and fashion designers to incorporate technology within their designs.

Literature shows that the field of interactive fashion design is new and requires interdisciplinary knowledge such as electrical engineering and computer science to be successful. Therefore, we created ready-to-use kinetic fabric samples for designers, to assess how convenient it could be for designers to implement emerging technologies into their designs. We explored this research gap through two preliminary user studies with seven experienced designers. The information gathered from this study could be used to identify design guidelines for kinetic fabric samples that would assist designers incorporating technology in their design.
\end{abstract}




\section{Acknowledgments}

I would first like to express the deepest appreciation to one of my Co-supervisors, Dr. Lois Frankel, who gave me the great opportunity to study with her. Lois made this work possible with her valuable comments and suggestions. I am forever grateful for her support throughout my journey at Carleton. I would also like to thank my other Co-supervisor Dr. Audrey Girouard, regarding her inputs and advice. I appreciate all her guidance and feedback, which helped me to improve this thesis.

Special thanks to the members of my defence committee, Chantal Trudel and, Elizabeth Stobert. I appreciate all your guidance and feedback, which will greatly help me to improve this thesis.

To my family, my loving mom and my brother, and to my Martin, for their unending love and support, for always believing in me and giving me the opportunity to follow my dreams. 


\section{Table of Contents}

Abstract......................................................................................................... ii

Acknowledgments ...................................................................................... iii

List of Tables ........................................................................................... vii

List of Illustrations ................................................................................. ix

List of Appendices..................................................................................... xii

Chapter 1: Introduction................................................................................

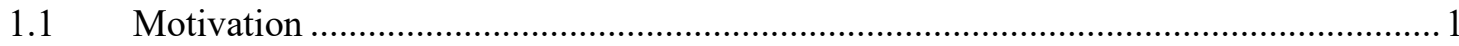

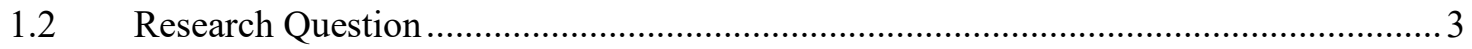

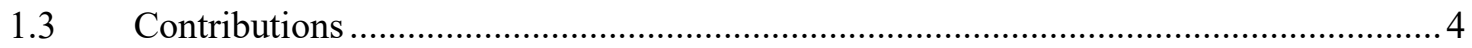

$1.4 \quad$ Thesis Outline

Chapter 2: Related Work ..........................................................................6

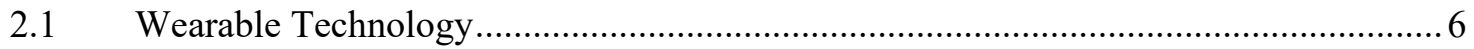

2.1.1 E-Textile

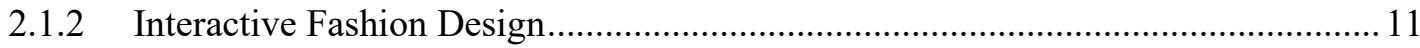

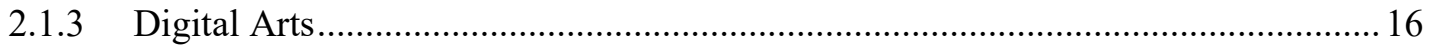

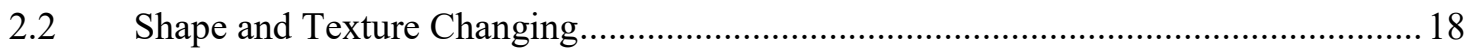

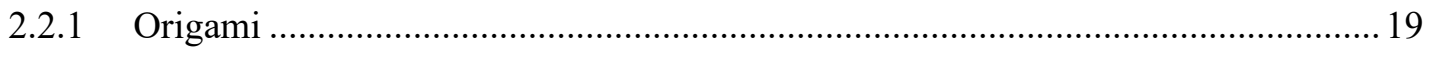

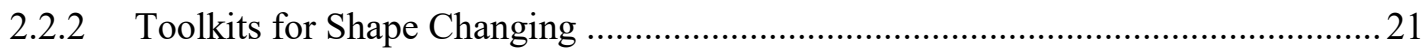

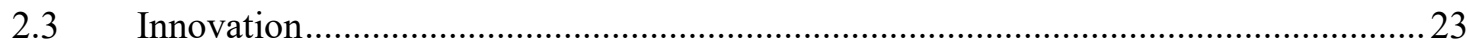

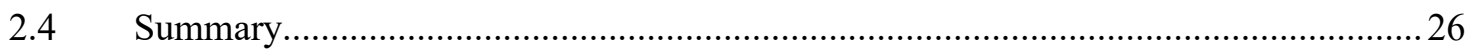

Chapter 3: The Prototypes .........................................................................................28

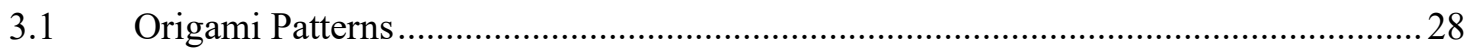




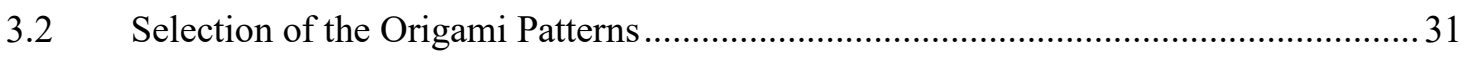

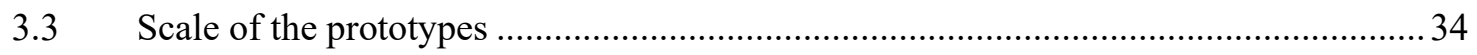

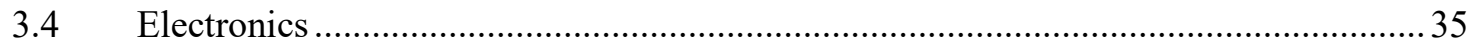

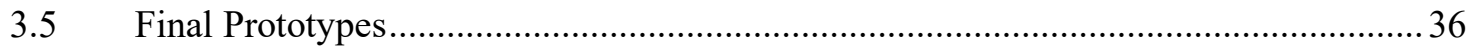

Chapter 4: Methods........................................................................................................39

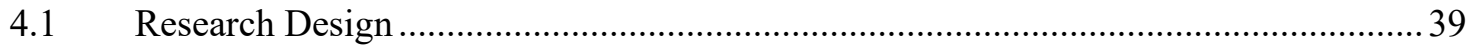

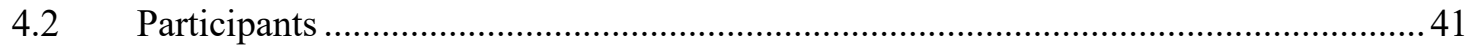

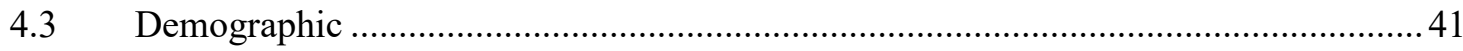

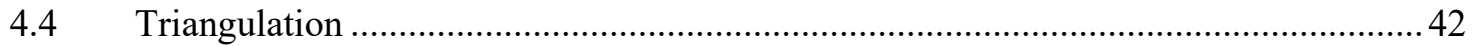

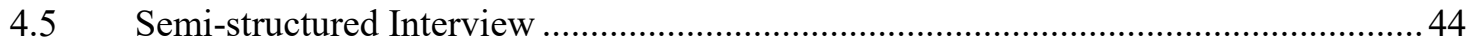

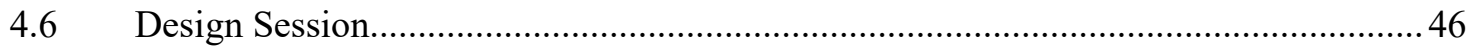

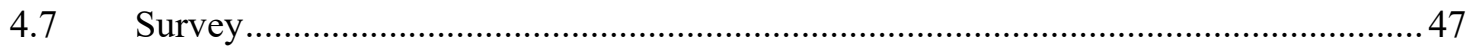

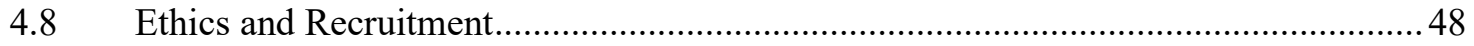

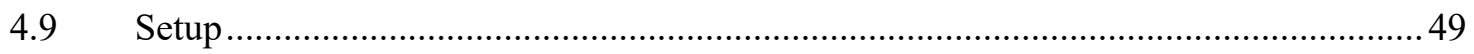

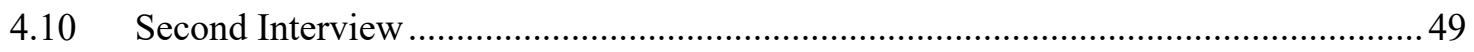

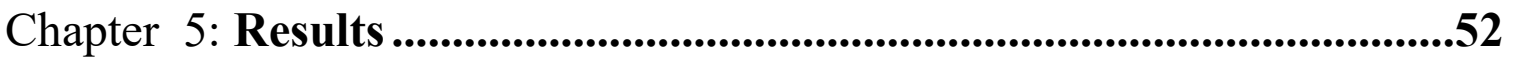

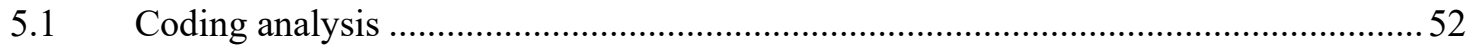

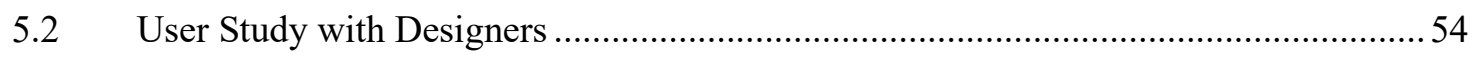

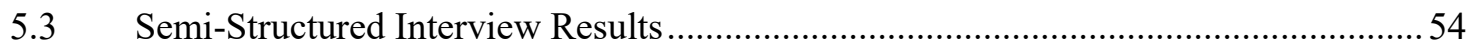

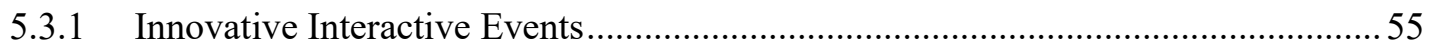

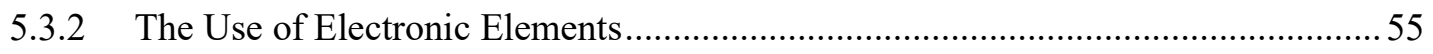

5.3.3 The Wearers' and Audience's Experience ........................................................... 56

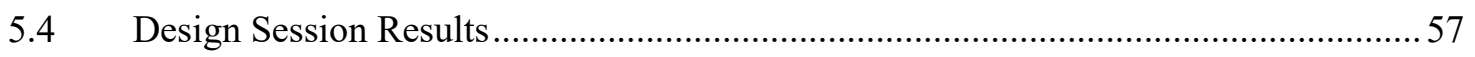

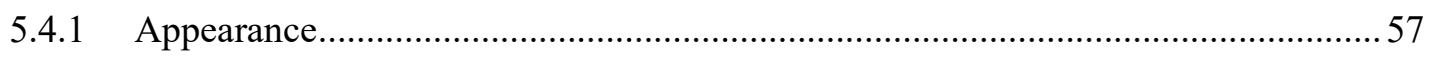

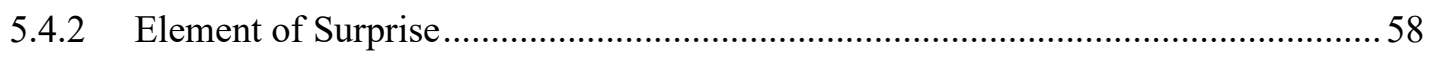




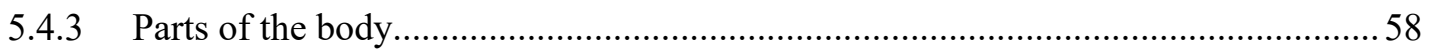

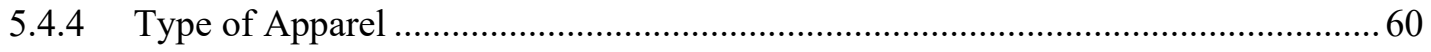

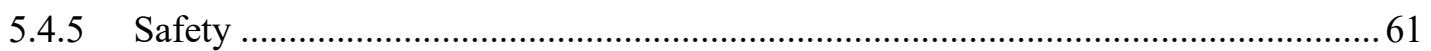

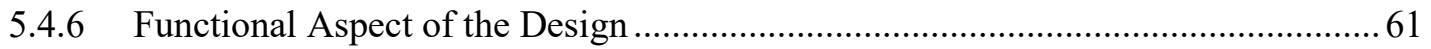

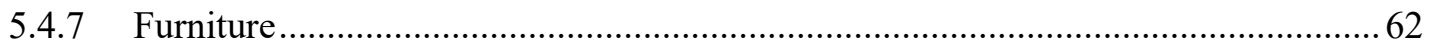

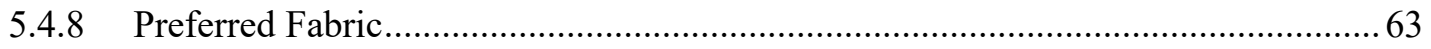

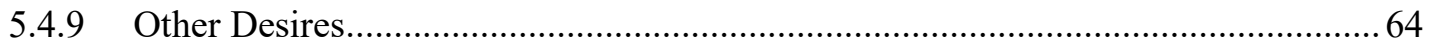

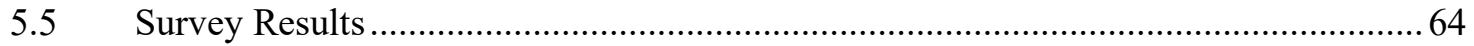

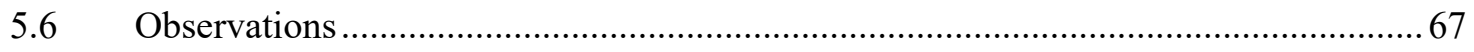

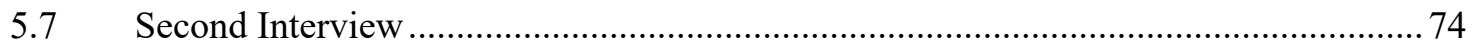

Chapter 6: Discussion ................................................................................................77

6.1 Designers' Awareness and Collaboration................................................................. 77

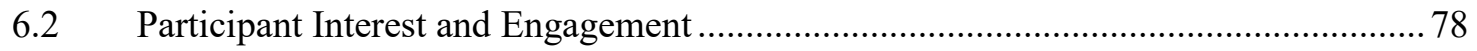

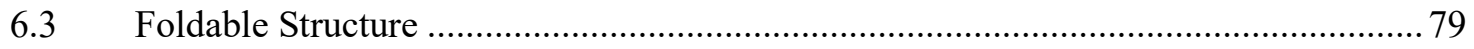

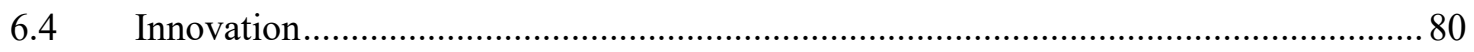

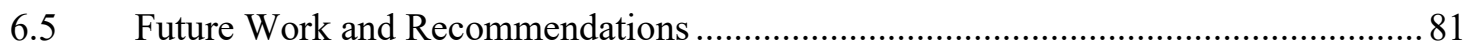

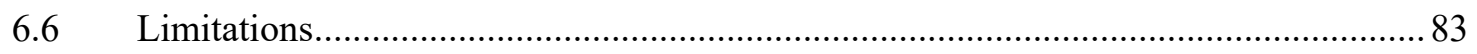

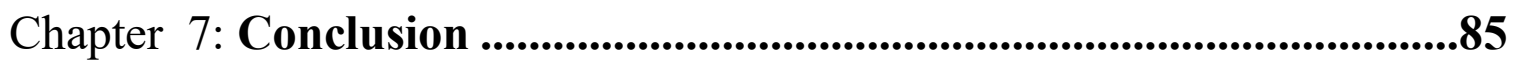

Appendices.............................................................................................................88

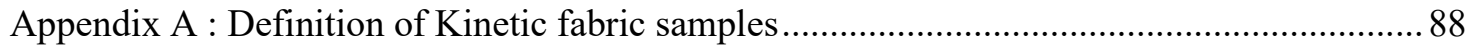

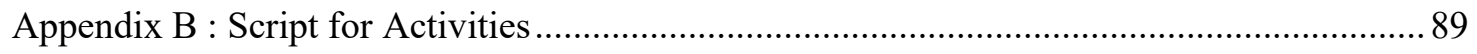

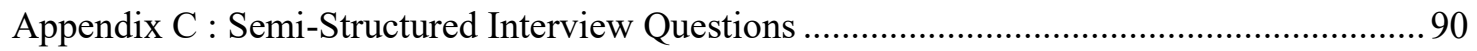

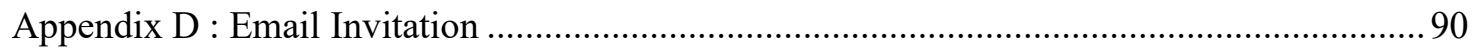

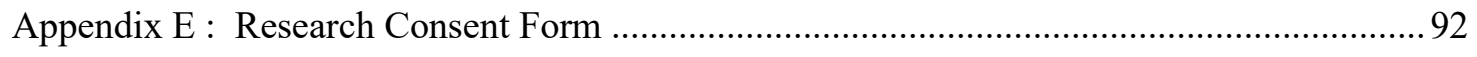

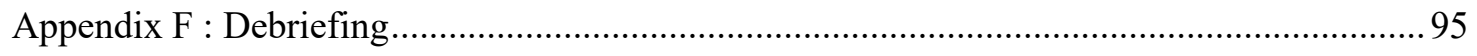


Appendix G : Survey

Appendix H : Semi-Structured Interview for the Second Study

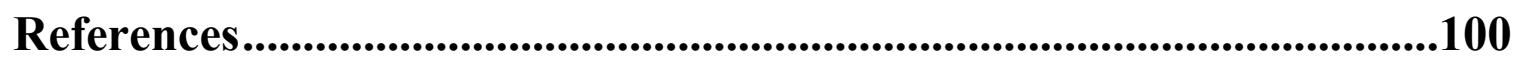




\section{List of Tables}

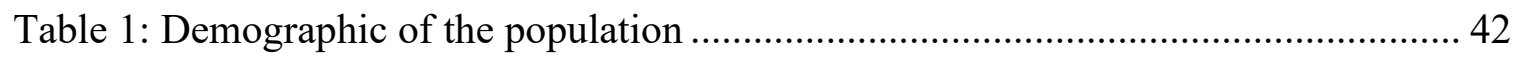

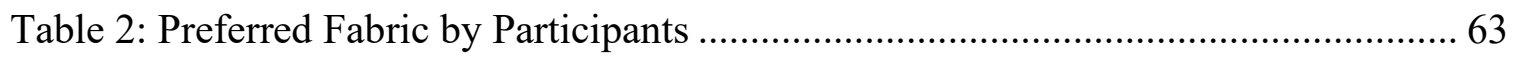




\section{List of Illustrations}

Figure 1: Head-Mounted Displays (DARPA, 2019).................................................. 7

Figure 2: Printed demonstrator showing two electroluminescent lamps and one proximity sensor with associated connector at the edge of the fabric (Torah et al., 2019). 9

Figure 3: Fabrication of Actuating Cellular Auxetic Structures Using SMAs and 3D

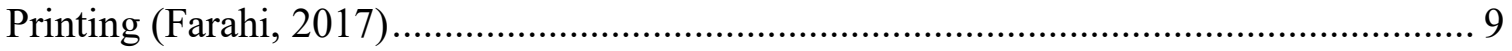

Figure 4: Forster Rohner Wearable LED \& Solar Tech Fashion (Forster Rohner, 2019) 10

Figure 5: Jellyfish dress, one of the (No)where Now(here) dresses by Ying Gao (Pailes-

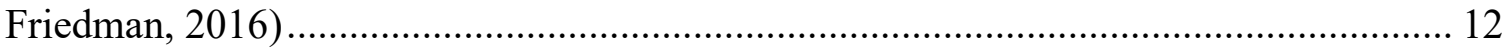

Figure 6: Intimacy dress by Daan Roosegaarde (Pailes-Friedman, 2016)...................... 13

Figure 7: The Spider Dress by Anouk Wipprecht (Wipprecht, 2019) ........................... 14

Figure 8: Inner embedded mechanism of the interactive garment (Ozkan, 2015)........... 15

Figure 9: Borderless World, MORI Building, Tokyo (TeamLab, 2019)........................ 16

Figure 10: "A Visionary Artist Takes on the Smart Home” by Anouk Wipprecht. (Angela

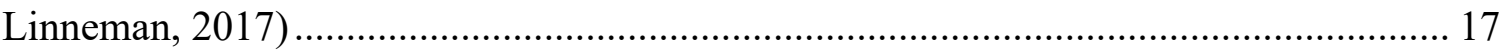

Figure 11: Awakened Apparel skirt (Perovich et al., 2013) ........................................ 19

Figure 12: (a) Food Box (Derrick Lin, 2012) (b) Solar arrays (Timothy Yeung, 2017) (c)

Origami dress designed by Yuki Hagino (Issam Yousef, 2015) ................................... 20

Figure 13: Oribotics, Hand push: robot opens. Hand pull: robot closes (Gardiner \&

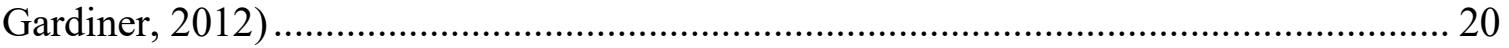

Figure 14: Polygonal Self- folding (Ou, Skouras, et al., 2016) ................................... 22

Figure 15: Pneuduino from MIT Lab (MIT Media Lab, 2019) .................................... 23 
Figure 16: Gartner Hype Cycle (Gartner, 2019)

Figure 17: Two Waterbomb bases and their tessellations. (a) The Eight-Crease

Waterbomb base; $(b)$ one of its tessellations forming the Resch pattern; $(c)$ partially

folded Resch pattern model; $(d)$ the Six-Crease waterbomb base; $(e)$ its tessellation in unfolded and folded states and $(f)$ the tessellation can also be used to form a tube (Chen,

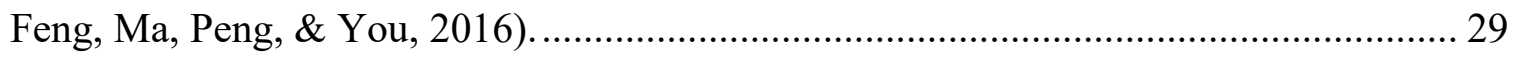

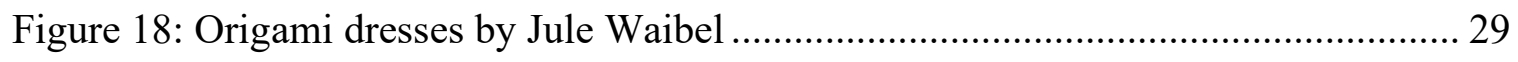

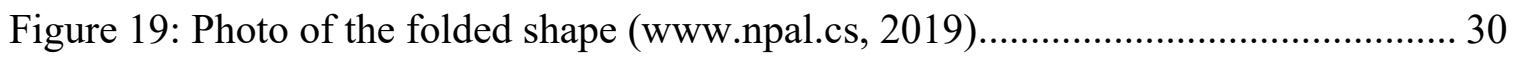

Figure 20: From left (1) Eight-Crease Waterbomb, (2) Six-Crease Waterbomb, (3)

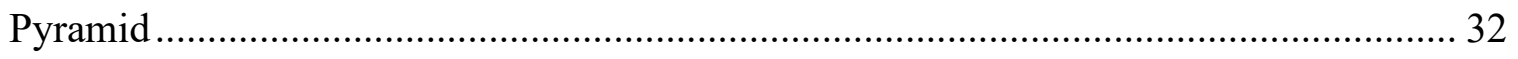

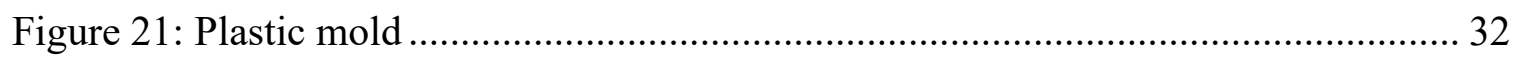

Figure 22: The fusible web cut and attached to the back of the fabric ........................... 33

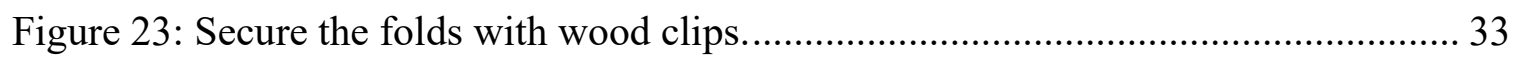

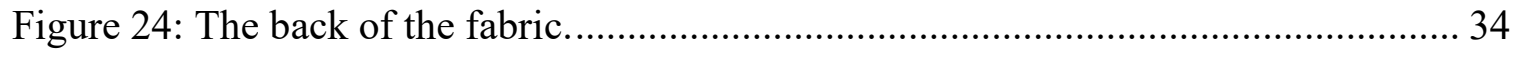

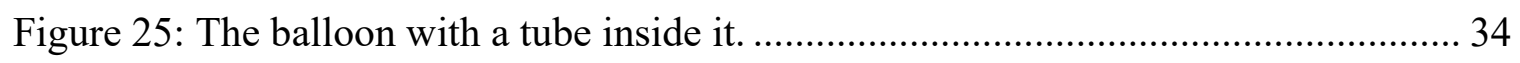

Figure 26: The material that were used to implement shape changing to the fabrics....... 36

Figure 27: Eight-Crease Waterbomb before and after air pressure is applied. View from

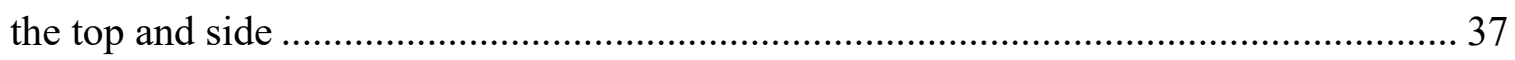

Figure 28: Six-Crease Waterbomb before and after air pressure is applied. View from the

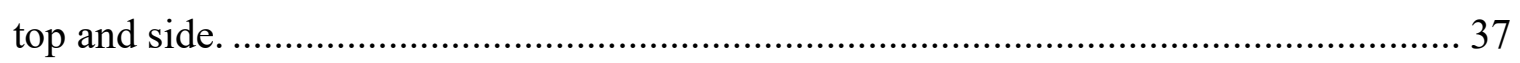

Figure 29: Pyramid before and after the air pressure is applied. View from the top and

side. 
Figure 30: Triangulation brings together different data sources to enrich the analysis

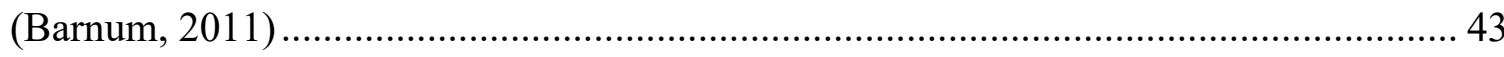

Figure 31: Demonstrations of the prototype to one of the participants ...........................46

Figure 32: The study was conducted in one of the participants' office.......................... 49

Figure 33: P7 made a pregnant lady on the mini manikin. ....................................... 59

Figure 34: Participants making a skirt on a mini manikin with the Six-Crease Waterbomb

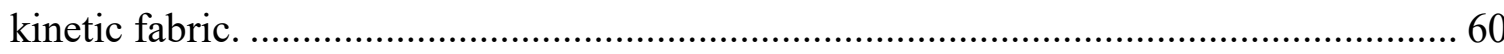

Figure 35: Participant two expected that Eight-Crease Waterbomb fabric changed the

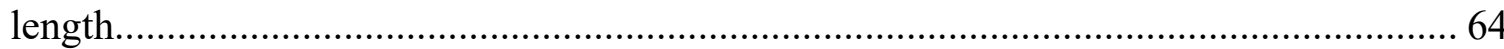

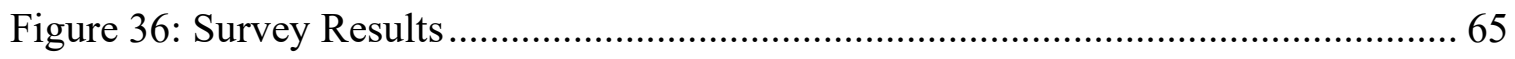

Figure 37: P1 wanted to stitch around the fabric and cut it as a corset.......................... 68

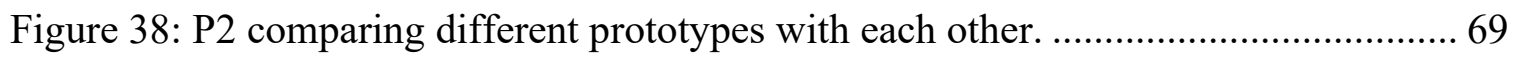

Figure 39: P2 squeezed the Six-Creased Waterbomb fabric to look at between the folds.

Figure 40: P2 showing the collar that she would make with the eight-crease fabric........ 70

Figure 41: P3 looking between the folds and at the back of fabric.............................. 70

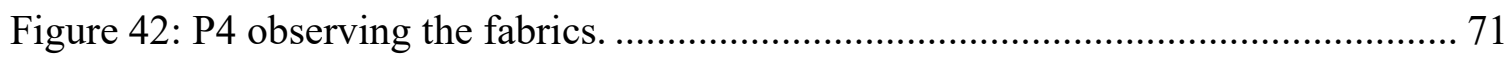

Figure 43: P5 touching the fabric and start designing based on the fabric quality.......... 72

Figure 44: P6 folding the Pyramid kinetic fabric.................................................. 72

Figure 45: P7 paying attention to the detail of the fabrics ...................................... 73

Figure 46: Kinetic Fabric Samples- The sample in this photo is closed ....................... 88

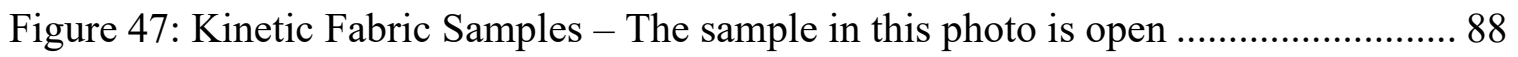




\section{List of Appendices}

Appendix A : Definition of Kinetic fabric samples..................... 88

Appendix B : Script for Activities................................. 89

Appendix C : Semi-Structured Interview Questions...................... 90

Appendix D : Email Invitation.................................... 90

Appendix E : Research Consent Form................................ 92

Appendix F : Debriefing ......................................... 95

Appendix G : Survey........................................... 97

Appendix H : Semi-Structured Interview for the Second Study............ 98 


\section{Chapter 1: Introduction}

\subsection{Motivation}

In recent decades, remarkable advances in the field of wearable technology have resulted in an interdisciplinary approach along with new challenges to designers and researchers (Pailes-Friedman, 2016). The accessibility of electronic devices has also increased lately; devices are smaller, more portable, mobile and their price has decreased which provides more opportunities for designers (Kumar \& Vigneswaran, 2015). This growth has created the potential for researchers and designers to explore different wearables with new functionalities.

Designing interactive garments and the integration of technology in design present many new challenges to researchers and designers because this field is still new (Hodges \& Link, 2019). Designers must be knowledgeable about technology to understand how to collaborate with engineers, to be able to integrate any new technology efficiently (McCann, J; Bryson, 2009). Interactive designers need to consider factors such as the garment fit, user comfort and aesthetics, along with technical aspects of the design such as visibility of electronic elements, and electronics reliability (Pailes-Friedman, 2016). These factors combined explain why it can be so complex to design interactive garments.

Based on our literature review, it is clear that in order to build interactive pieces fashion designers must collaborate with technology professionals to implement technologies within their designs (McCann, J; Bryson, 2009). Meanwhile, it is not always easy to collaborate with researchers or developers because there is often a communication asymmetry between the two; there exists a certain challenge for the technology researchers 
to understand designers' needs and to know how to solve their problems efficiently (PailesFriedman, 2016). Considering their different backgrounds, a lot of effort is required on both sides to understand each other.

As stated in the literature review in Chapter 2, we were unable to find any variety of examples of ready-to-use samples on the market; it could be one of the many factors that forces designers to interact and work with IT professionals who have the technical skills and knowledge. Our objective is therefore to give designers a sample that can be implemented within their design; this way the fashion designers won't need to focus on the technical aspects or look for help from professionals in that domain. We believe that there is an opportunity to create ready-to-use samples for designers, such as kinetic fabrics, to solve this problem. For the purpose of this research we are defining the term "kinetic fabrics" as fabrics that are able to change their shape. We wanted kinetic fabrics because of the aesthetic quality of movement. We also considered using sensors in the fabrics, however, due to the complexity of the programming tasks related to implementing sensors we decided to focus on the use of air pressure to suggest movement.

We created three different kinetic fabric samples based on origami patterns that change their shape by folding and unfolding. The samples were designed for this research in order to assess how useful and convenient it might be for designers to include emerging technology in their design. The aim of this research was to determine if fashion designers would appreciate such samples and find it useful to help them in their designs. 


\subsection{Research Question}

This research aims to answer the question: How can kinetic fabric samples help designers incorporate technology in their design? This question was explored through three sub-research questions:

1. What is the designer's perception of innovative interactive garments/art pieces?

2. How would designers use the kinetic fabric samples in their designs?

3. Would designers be likely to use kinetic fabric samples to inspire and explore design possibilities for their work?

To address the main research question, we created three sub-questions, each designed to provide insights to answer the main question. The first sub-question allowed us to understand designers' knowledge and perception of interactive design in the actual state (before seeing the prototypes) in order to better assess the impact of using samples and incorporating technology in their design. The second sub-question focused on the potential use of samples for design purposes which would give us insights into possible designs with samples and how those designs would impact the designers' experience. Finally, the last sub-question allowed us to determine if designers would be willing to use kinetic fabric based on their experience working with them and if that experience helped them to incorporate technology into their designs.

To answer our questions, we collected data by interviewing experienced designers to assess their knowledge and experience about innovative interactive design and incorporating technology in their designs. We gathered information about their previous experience and knowledge and asked if they are willing to incorporate technology into their design. We observed designers during the design session to determine how they would use 
the kinetic fabric samples, which helped us to find out the pros and cons of the samples. Finally, to understand how likely it would be for designers to consider working with kinetic fabric samples in the future, we asked the question in a survey. We also conducted a second study a few months after the initial one and asked questions. These methods allowed us to answer the three sub-questions and to acquire a better understanding of the use of technology in fashion and art.

\subsection{Contributions}

As discussed in the motivation section, the lack of access to ready-to-use samples forces designers to either work with IT professionals or learn the technology by themselves (Cass, 2016). Working with IT professionals can help fashion designers shape their vision into a product; the designers can explain their idea and vision to the IT professionals and depend upon them to make the technology work (Pailes-Friedman, 2016). However, this way of working is not always easy; difficulties can arise when trying to find the right partner for collaboration. It is also possible for designers to learn to work with electronic elements and programing, but it cannot be easy for people who do not have a technology education background. We created our prototypes because we believed that it would fill the gap that currently exists for the group of designers who were studied.

This thesis reports on a Case Study in which we provided kinetic fabric samples to seven designers, in their own individual design session, in order to identify the advantages and disadvantages of these samples. We expected these individuals to appreciate the kinetic fabric samples as a new approach to help designers who may be interested in working on interactive garments. The information gathered from the study would be used to identify 
design guidelines for kinetic fabric samples, which could assist designers who are interested in using electronics in garment design.

We wanted to understand the impact of the new prototypes in interactive fashion arts from the designers' points of view. It may also help to understand the fashion designers' point of view about a technology and how likely they would be to use it in the future. This could provide a better understanding of a technology's potential adoption within this group of designers. The different questions in our interviews focused on the tendency of designers to implement new technologies within their designs. This helped us to understand the adoption curve of new technology within the field of interactive fashion design.

\subsection{Thesis Outline}

This thesis includes seven chapters. This first chapter introduces the thesis topic and includes the motivation, why this research topic should be investigated, and its contribution to the field, followed by the main question. In Chapter 2, we present a literature review on different areas related to wearable technology, interactive fashion design and kinetic fabrics and origami. In Chapter 3, we present the design process of all the three new kinetic fabric samples, we also provide photos in different steps and the samples. The method used for this study is described in Chapter 4 and the results are displayed in Chapter 5. Chapter 6 discusses the results of the first and second study and compare them to the findings from the literature review. This chapter also explains the limitations of the study and makes recommendations for future research. Lastly, Chapter 7 is the conclusion where the main findings and results of the research are summarized. 


\section{Chapter 2: Related Work}

This literature review addresses different areas related to wearable technology, interactive fashion design and kinetic fabrics and provides insight into similar and related work in the field. This chapter explores the impact that fashion and technology have on each other and looks at specific examples of textiles and garments that have been developed by designers and engineers. We also address the samples and patterns that have been used.

\subsection{Wearable Technology}

In the mid-1990s, wearable computing was introduced as "data gathering and disseminating devices which enable the user to operate more efficiently" by the Defense Advanced Research Projects Agency (DARPA) (Kumar \& Vigneswaran, 2015). At this time, DARPA's definition stated three fundamental properties that had to be met for an object to be considered a wearable computer: it must be worn and not carried, it must be user controllable and finally, it must operate in real time.

DARPA had a mission to work with the inventors on past projects that had a major influence on people's lives today. They transformed revolutionary concepts not only for military projects but also for civilian applications such as the internet and voice recognition. In 1997, DARPA developed a head-mounted display (Figure 1) to improve soldiers' situational awareness. This tool was recognized as an early application of wearable computing (Belfiore, 2009). 


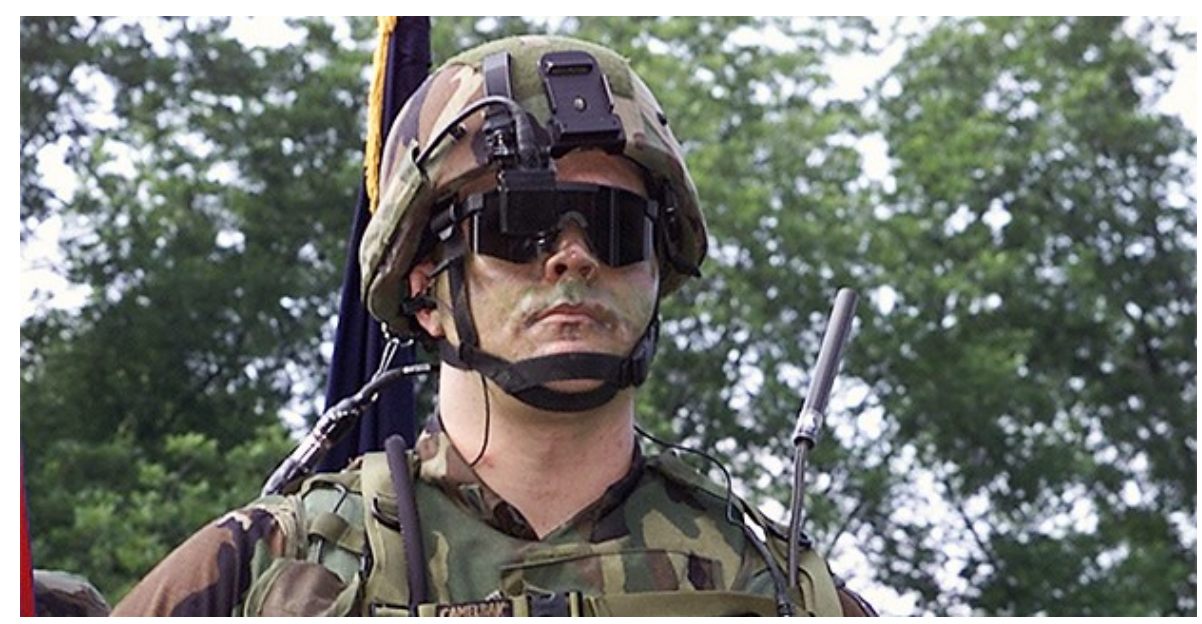

Figure 1: Head-Mounted Displays (DARPA, 2019)

Even if the early development of wearables initially began in the US military, that technology eventually became part of our daily life due to researchers focusing on developing new products that would impact people's lives (Belfiore, 2009). The remarkable advances in using technology in ready-to-wear garments are primarily in fitness and healthcare (Anzaldo, 2015). Researchers are working on integrating circuits into clothing to measure physical signals from the human body, such as heart rate (Kumar \& Vigneswaran, 2015).

Following those technological developments by DARPA, some labs began researching the use of electronics in garments. XS Labs is a design research studio that works on electronic textiles and responsive garments (XS Labs, 2010). They make a variety of garments that focus on the use of electronic textiles and materials such as conductive fibers, active inks, photoelectric sensors and shape-memory alloys as fundamental design elements. The main objective of the XS Labs is to design garments that can sense and respond to the wearers' environment to address social issues. XS Labs created the Memory Dress, which recorded acts and the time of physical intimacy, and the Reclaim Dress, that 
expanded to increase the amount of personal space - making the wearer more comfortable in crowded areas.

\subsubsection{E-Textile}

Electronic textiles (e-textiles) are fabrics that incorporate electronic elements (Aziz \& Chang, 2018) to help designers create interactive artwork with the fabric. Smart fabrics can be made from weaving, knitting or embroidering the electrical yarns on fabrics (Forster Rohner, 2019). For example, one researcher developed a design approach for smart textiles to improve the aesthetic of electronic textiles (L. Li et al., 2009). This approach used knitting technology that considered the electrical and mechanical properties as well as the aesthetics to generate a method for smart clothing. The garment is designed to fit the body shape with sufficient tightness when zipped up.

Another research project -- one that produced smart textiles -- involved both hardware and software that enabled designers to work with a printer that deposited electronic functional inks onto fabrics (Torah et al., 2019). This printer allows the designers to print out the rapid prototype smart fabrics and incorporated the functions of colour change, electroluminescence (see Figure 2), sound emission and proximity sensing. This technology allows the user to convert any type of fabric to a smart fabric. This is a good tool to help designers, who may not have the technical knowledge to create smart fabric by themselves. 


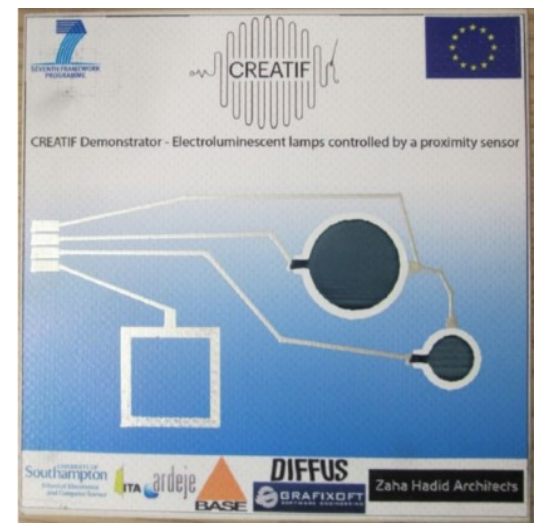

Figure 2: Printed demonstrator showing two electroluminescent lamps and one proximity sensor with associated connector at the edge of the fabric (Torah et al., 2019).

3D printing is another technology that is useful to help designers make interactive garments that perfectly fit the body form (see Figure 3) in addition to easing the incorporation of sensors into them (Farahi, 2017). Caress of the Gaze by Behnaz Farahi (Figure 3) is a 3D printed garment that explored the interaction of other people with clothing. The researcher used a cellular mesh in which synthetic fibers are woven to create a flexible and net-like fabric to achieve flexibility. This printed interactive wearable has the capacity for dynamic behaviours such as bending, folding and twisting, which makes it flexible on the body.

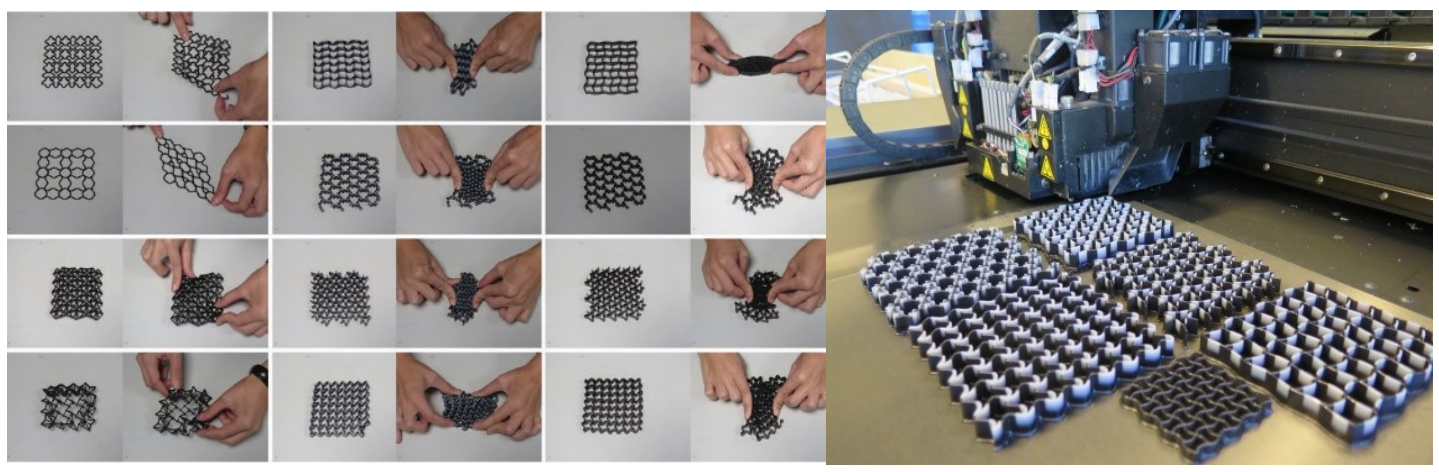

Figure 3: Fabrication of Actuating Cellular Auxetic Structures Using SMAs and 3D Printing (Farahi, 2017) 
The textile manufacturer, Forster Rohner produces illuminated fabrics with embroidery machines by braiding metal and yarn together (see Figure 4) (Forster Rohner, 2019). Their company has ready-to-use electronic fabrics that people can buy worldwide and are used for curtains, Haute Couture, ready-to-wear and lingerie. They also use lights in their designs. The illuminated fabrics by Forster Rohner are rare examples of ready-touse e-textiles that are available online for designers (Forster Rohner, 2019)

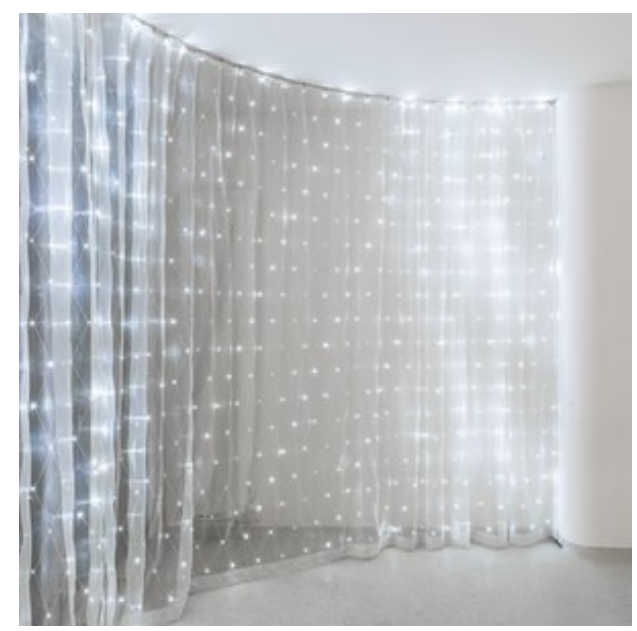

Figure 4: Forster Rohner Wearable LED \& Solar Tech Fashion (Forster Rohner, 2019)

In summary, the development of wearables began with the US Army and was eventually taken up by companies for the design of wearables for use in day-to-day life. Following that, researchers used many techniques to merge technology with fabrics or other materials in order to create smart textiles and wearables. In most cases, these materials were built for a specific research or design. 


\subsubsection{Interactive Fashion Design}

When it comes to fashion, designers need to consider many factors, such as the fabric texture, garment fit, user comfort and aesthetics (Li et al., 2019). In addition to the technical aspect of the design, they also have to take into consideration the visibility of the elements, size, and reliability of electronics (Kumar \& Vigneswaran, 2015). All these factors combined explain why it can be so complex to design interactive garments properly.

There are many interactive garments that are made from other materials such as the ones used for 3D printing, which make objects in any structure possible (Oxman, 2017). In recent years, 3D technology helped enable designers to create interactive garments more efficiently. Hiding electronics and other components used to be a challenge for designers but in the last few years, a lot of mini-size electronic boards and sensors are easier to access in the market (Kumar \& Vigneswaran, 2015).

Other literature showed that designing wearable garments requires interdisciplinary collaborations (McCann, J; Bryson, 2009). One of the reasons is that using electronic elements in textiles requires knowledge of electronics and, sometimes, programming. It is not easy for every designer to work with electronics or mechanical elements, so interactive garment designers often have an assistant who makes it possible for them (Pailes-Friedman, 2016). This is important because designers need to work with people who have computing skills in order for the e-textile system to grow more efficiently. It shows us that creating etextile is not only about designers who are willing to incorporate electronic textiles within their design, but also about building collaboration between people from different disciplines to enable high-tech creativity. 
For an example collaborations we can look at fashion designer Ying Gao who designed a collection of robotic dresses in 2017 (Pailes-Friedman, 2016). She used various sensors and programmed with Arduino components to make her famous piece called the Jellyfish dress (Figure 5). She did not accomplish that design without collaboration. Simon Laroche helped her on the technology side. It took them two years to complete the work. She said in an interview, "It's easy to have crazy ideas, but you need to have the technical knowledge to make things happen." Gao always had an assistant for technical help, and she mentioned that, "he was a great problem solver."

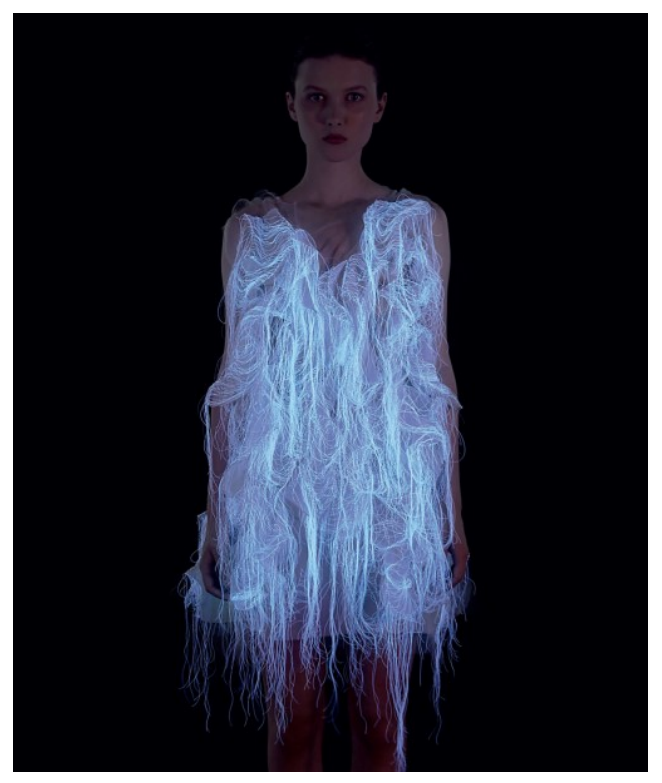

Figure 5: Jellyfish dress, one of the (No)where Now(here) dresses by Ying Gao (Pailes-Friedman, 2016)

Another example of the collaboration between garment designers and technology professionals is the work of Daan Roosegaarde, an artist and innovator who created a dress called "Intimacy" (Figure 6) to demonstrate technology as people's second skin through the use of materials (Roosegaarde, 2019). He was inspired by transparent material in a lab 
and decided to explore a fashion project with it. He explained in an interview that he was in a lab and saw a new material in a corner that it was changing from opaque to transparent. It inspired him to develop this dress. Roosegaarde and his team developed the intimacy dress with the help of the manufacturer to make it more flexible and dimmer. "The Intimacy Dress is created from a combination of smart foils, wireless technologies, electronics, LEDs, copper, and other media" (Pailes-Friedman, 2016). The dress was made from a highend technology at the time and the designer was not able to develop it without the help of the manufacturer; the collaboration was therefore important to shape his idea and achieve the dress.

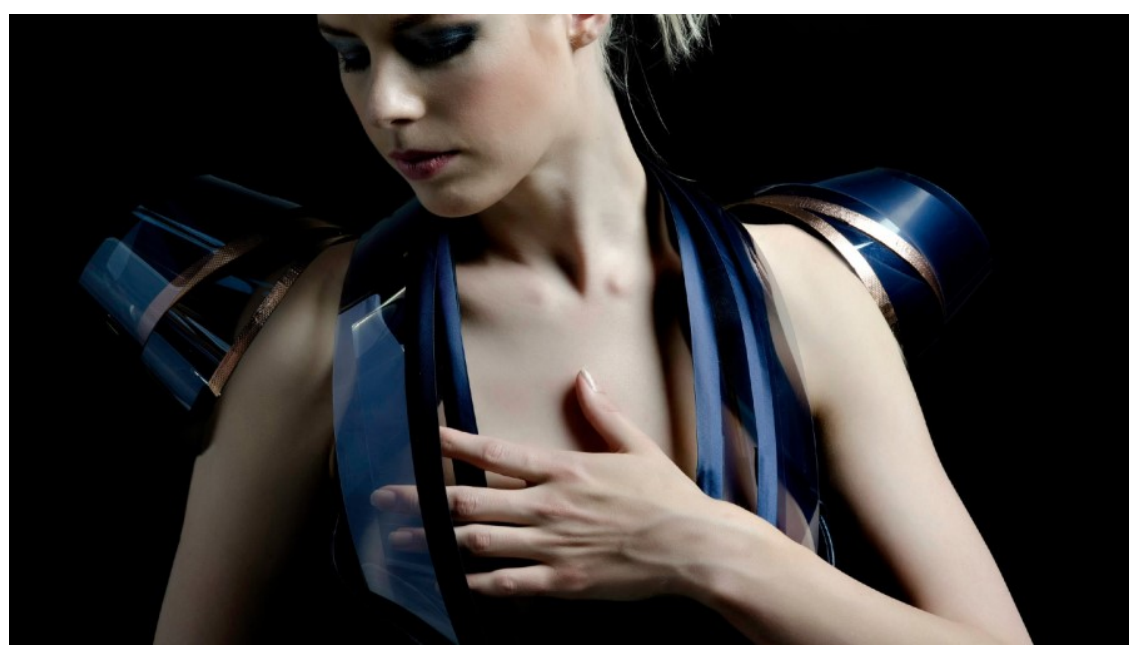

Figure 6: Intimacy dress by Daan Roosegaarde (Pailes-Friedman, 2016)

Based on examples and interviews with designers (Pailes-Friedman, 2016), in order to be innovative (and in most cases) fashion designers had to collaborate with technology professionals to implement a technology within their designs. These collaborations were necessary due to the fashion designers' lack of knowledge about electronics and the use of new technologies; this lack of knowledge was an impairment when it was time to design 
smart garments and explains why they had to team up with technology sector professionals. Meanwhile, it was not always easy to collaborate with researchers or developers because these different professionals have different visions from one another.

Some designers decided to learn by themselves instead of depending on a professional to bring their vision to life. As an example, designer Anouk Wipprecht created a 3D printed dress (Figure 7) that can sense and respond to the environment around the user (Cass, 2016). Anouk Wipprecht used sensors and motors on the garment that will react to the wearer's surroundings. The designer was interested in interactive fashion design. To be able to program her work she studied with David Cuartielles, the original creator of the Arduino, to learn how to program interactive garments. This shows us how a designer can fill the gaps in terms of technological knowledge by collaborating with a professional who has the proper knowledge and experience. In that specific case, Wipprecht was engaged in a specific work in order to learn more about how to use technology and thus she was able to create her designs. This example is important to grasp the power of sharing knowledge through collaboration.

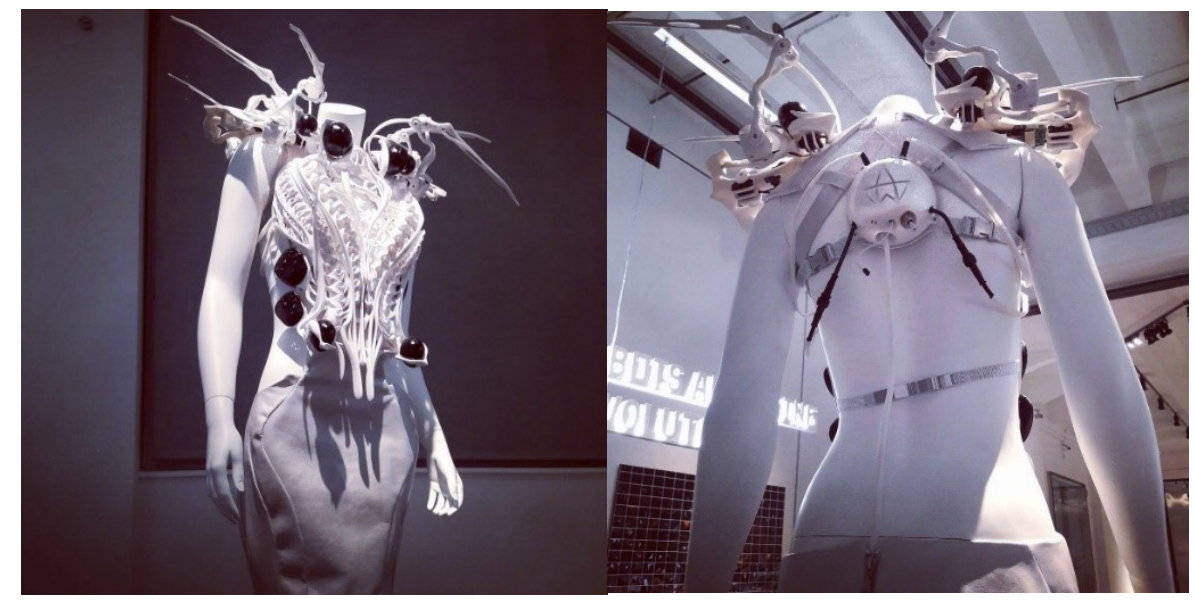

Figure 7: The Spider Dress by Anouk Wipprecht (Wipprecht, 2019) 
In the literature, we found interesting examples of designers who had a vision that required the integration of technology in their designs, but often that implied facing many challenges. For example, one designer had a view to create the feeling of a season within a dress. Despites the challenges that represent such a dress, she built that vision by creating an interactive garment called Fall (Figure 8) that simulates how trees lose their leaves and used electronics to demonstrate the leaves falling down (Ozkan, 2015). The purpose of this design is to demonstrate natural behaviour and its response to an environmental condition. The unique and complicated idea behind the mechanism is inspiring. The researcher designed a mechanism for the falling leaves such that each time the leaves fall, somebody needs to gather them again and attach them back onto the garment with wax. This example shows us that a designer can bring her vision to life by using a complicated solution that would fits her needs, such as a combination of mechanics and electronics.

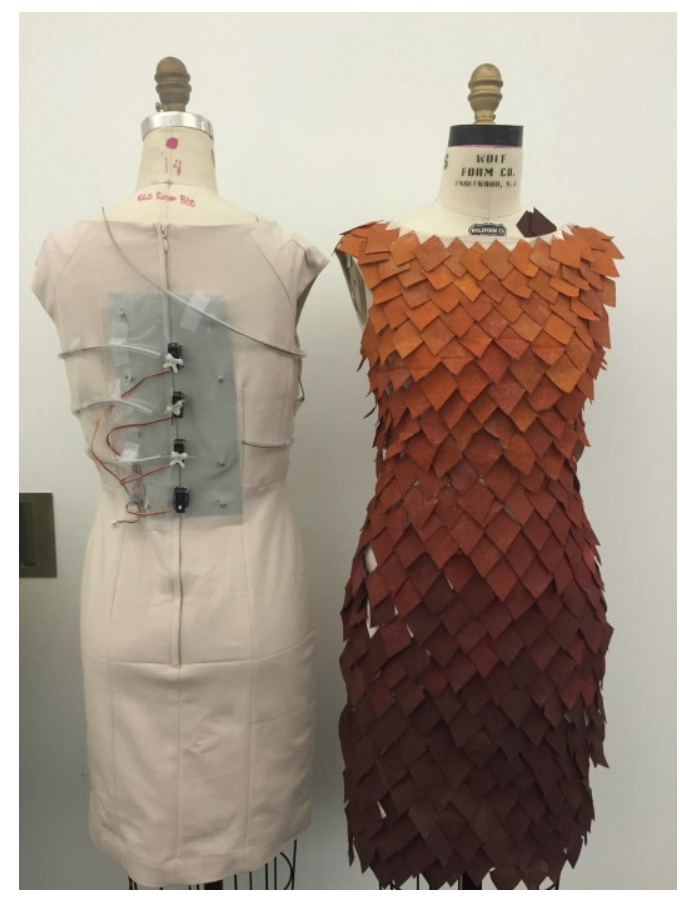

Figure 8: Inner embedded mechanism of the interactive garment (Ozkan, 2015) 


\subsubsection{Digital Arts}

TeamLab Borderless was an interdisciplinary group of technologists who built a digital art museum in Tokyo (TeamLab, 2019). They built a three-dimensional borderless world without any boundaries (Figure 9). "Artworks move out of rooms, communicate with other works, influence, and sometimes intermingle with each other with no boundaries." The intention of this artwork was to build a connection between people and link them up as they lose themselves in this artwork world. These kinds of interactive museums offer the chance for designers to learn more about interactive design and to provide them with ideas that can feed their creativity; designers love the experience and can learn from it. However, interactive museums are not present everywhere and most cities do not have any, which makes it difficult for designers to personally experience interactive digital arts.

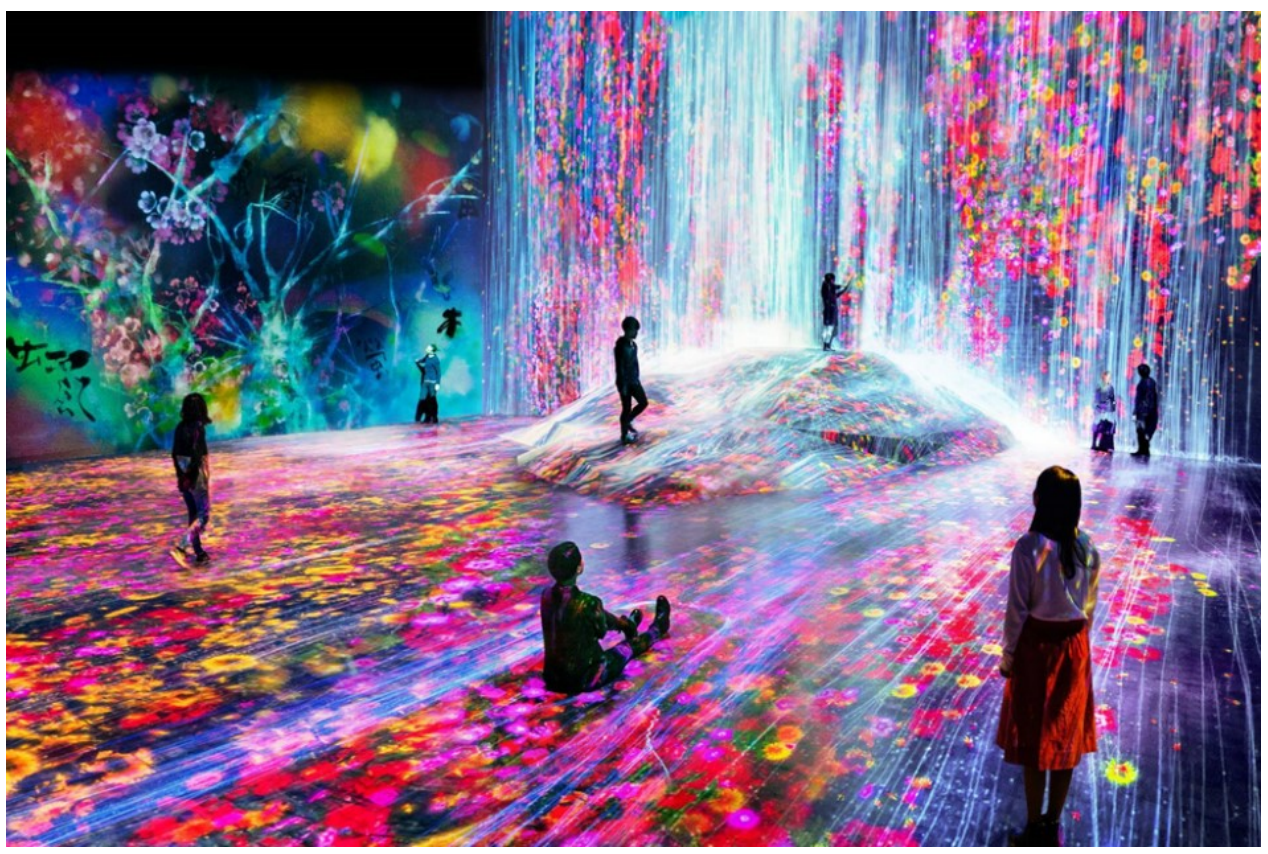

Figure 9: Borderless World, MORI Building, Tokyo (TeamLab, 2019) 
Interactive clothing and flower-inspired pods were demonstrated during the Amsterdam Light Festival (Angela Linneman, 2017) (Figure 10 ). The Living Pods project featured human surroundings in the future where everything is sensory and smart. The artists collaborated with a connected home company called Somfy, Autodesk's Fusion 360 team and LA-based concept designer Igor Knezevic. The image of the dress and its environment below is used to illustrate the future of sensory and smart environments to influence audiences and connect them to the future. As opposed to more common wearables that are used to add functionality, this dress provides a vision.

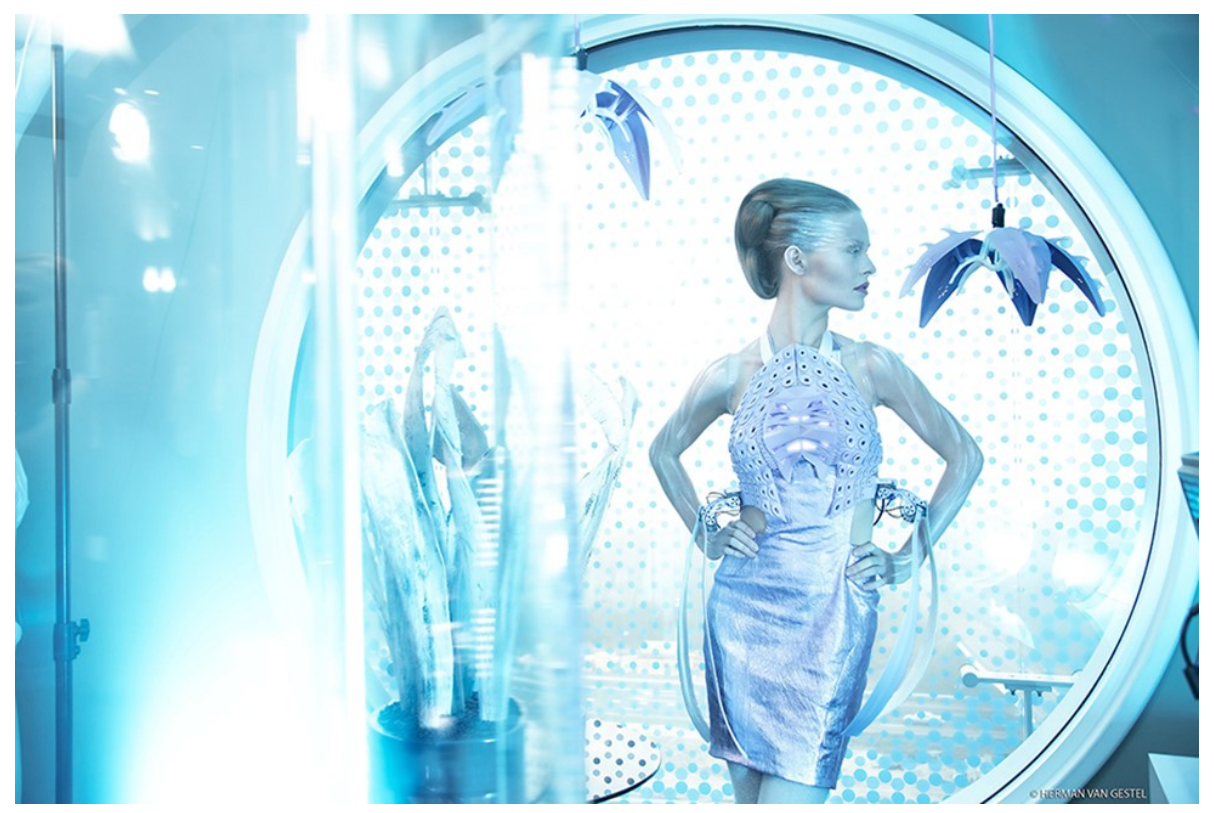

Figure 10: "A Visionary Artist Takes on the Smart Home" by Anouk Wipprecht. (Angela Linneman, 2017)

Interactive designs were incorporated into the Met Gala 2019 red carpet and provided designers with new tools to replicate a real-life version of a character (Rebecca Jennings, 2019). For example, there was a replica of Disney's Cinderella gown that transformed from black to blue and changed shape while a fairy godmother cast a magical 
spell. Another dress by Christian Siriano was a decorated gown with a deconstructed face that featured an actual blinking eye (Shapouri, 2019). The two dresses benefited from electronic elements and interactive design and made a strong impression on the audience by using a creative approach.

Most of the work done in interactive design is not used to create day-to-day wearables nor are they just to be presented in fashion shows. Instead designers use their creativity to create something special and uncommon and museums have become the place of choice to present those creative garments. Big events such as the Met Gala are where some celebrities wear interactive garments.

\subsection{Shape and Texture Changing}

The number of shape- and texture-changing devices are growing fast and there are multiple techniques to develop shape-changing surfaces (Roudaut, Karnik, Löchtefeld, \& Subramanian, 2013). An early example of developing a shape-changing garment is “Awakened Apparel" (Perovich, Mothersill, \& Farah, 2013), where the main focus of the researcher was on texture, aesthetic and robustness (Figure 11). The wearer does not need to think about their mood and plans for the day because this skirt changes its shape depending on the activity and attitude of the wearer. Another designer, Maddy Maxy, created an interactive clothing line that can change its pattern, so the wearer does not need to buy different clothes because the garment can turn transparent in sunlight (Natalie Kimani, 2016). In these two examples, a different technique was used to design a garment that can change its shape based on the wearer's needs. 

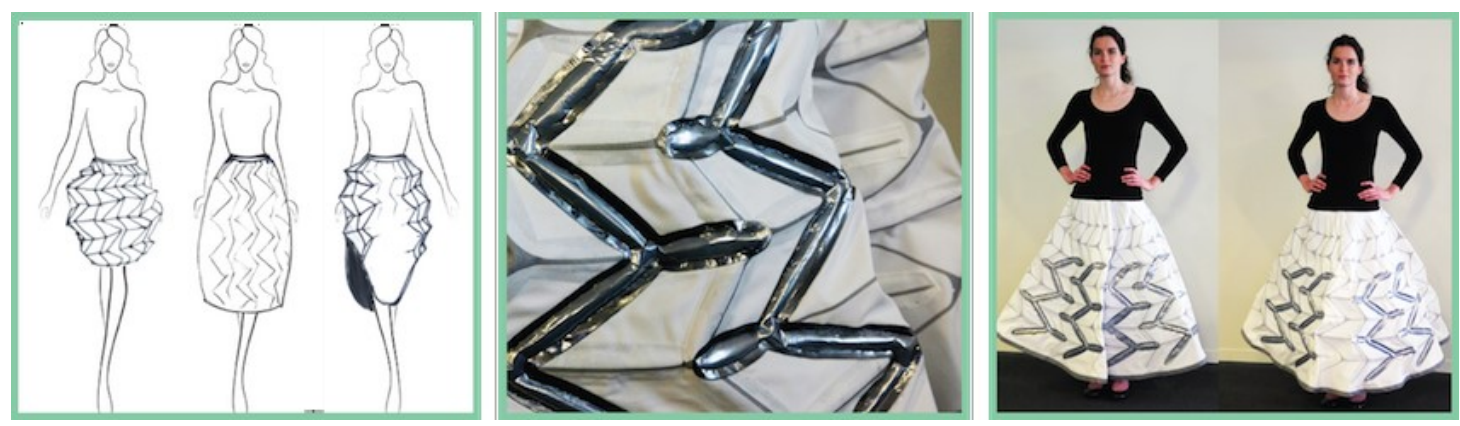

Figure 11: Awakened Apparel skirt (Perovich et al., 2013)

The intention of these two designers was very similar: they tried to make garments that transformed their shape or texture. These designers found a different solution for their idea to make the actual apparel, which depended on their knowledge and the purpose for developing their work. Awakened Apparel was made by a group of researchers that used their engineering skills and added electronics to the skirt to make it work. Maddy Maxey developed an interactive clothing line and used a pre-existing technology to change the pattern of the garment. The photochromic inks that turn transparent in sunlight were used by their design to make different looks.

\subsubsection{Origami}

Origami is a Japanese traditional art that transforms a flat sheet of paper into a 3D structure (Peraza-Hernandez, Hartl, Malak Jr, \& Lagoudas, 2014). Scientists use the function of origami in different fields, such as robotics (Hawkes et al., 2010), architecture (Nabil, Plötz, \& Kirk, 2017), self-similar interactions (Gardiner \& Gardiner, 2012) and engineering (Peraza-Hernandez et al., 2014). The origami techniques are used to produce products in different industries from food containers to engineering and even fashion (Figure 12). 


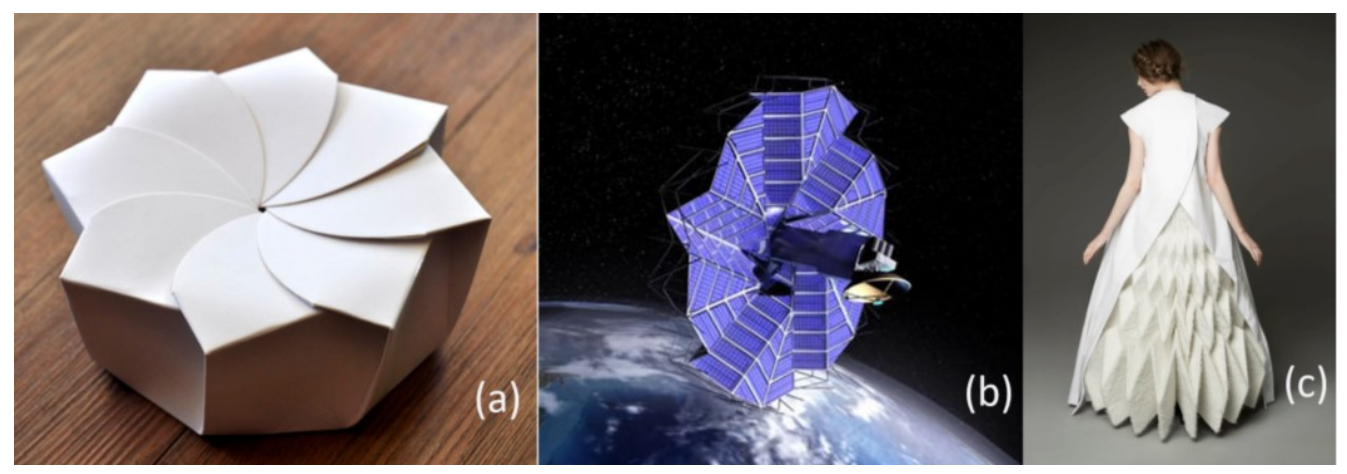

Figure 12: (a) Food Box (Derrick Lin, 2012) (b) Solar arrays (Timothy Yeung, 2017) (c) Origami dress designed by Yuki Hagino (Issam Yousef, 2015)

Oribotics (Gardiner \& Gardiner, 2012) is the combination of both origami and robotics. This technology can fold and unfold the origami paper with a robot that moves based on the hand action of a human (Figure 13). "Robots are programmed machines, and origami is programmed paper" (Huang \& Eisenberg, 2012). Matthew Gardiner took advantage of shapes by revealing the structure of origami to represent a flower as an interaction metaphor. He considered discovering the functionality and the aesthetic of the flower shape origami.

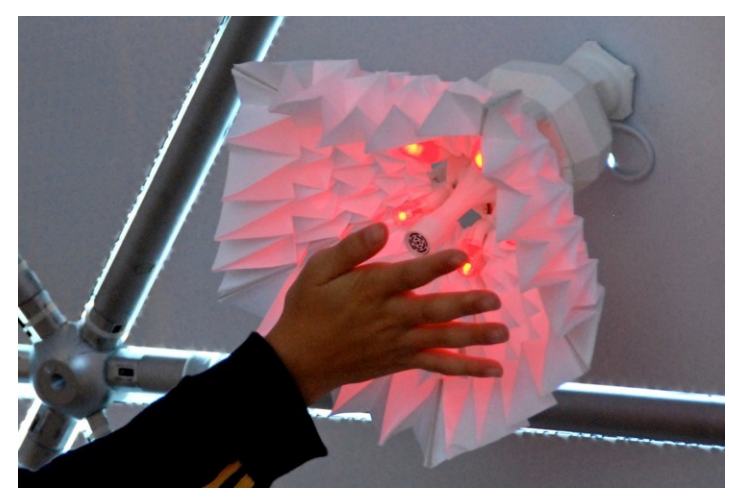

Figure 13: Oribotics, Hand push: robot opens. Hand pull: robot closes (Gardiner \& Gardiner, 2012) 
The collection called "Sculpting Mind" was a design based on origami art by Yuki Hagino that connected the field of fashion and architecture (Shivani Gohil, 2019). She believed that, "clothes are the second skin and architecture is the third skin," so she tried to connect her knowledge in both fields. This designer was interested in developing pleated forms. She brought contrast into her design by combining the hard origami pleats and the softness of fabric (Figure $12 \mathrm{c}$ ).

Origami seems popular among fashion designers as there are many examples of different types of clothes with origami patterns. Christian Dior is a famous fashion brand that designed a dress in their 2007 haute couture collection that used origami patterns (Issam Yousef, 2015).

\subsubsection{Toolkits for Shape Changing}

There are several approaches to developing self-folding mechanisms such as using Nitinol wire and shape memory (Berzowska \& Coelho, 2005) in order to produce abstract kinetic behaviour on the body. Nitinol or Memory metal is a shape memory alloy (SMA) made of nickel and titanium. The SMA can remember the geometry that was once applied to it, but the process is complex and expensive. Another approach is to use Pneumatically actuated soft composite material (Yao et al., 2013) that creates new opportunities to apply shape-changing interfaces by using responsive materials of the composites' multi-layer structures with different mechanical or electrical properties. The heat-sealing inflatable (Ou, Skouras, et al., 2016) is a bending mechanism that creates different shape-changing behaviour with the compliance of soft actuators and actuation speeds that are suitable for wearable applications, but for now this is not available in the market (Figure 14) . 
In the field of material design, inflatable fabrics are becoming popular. A shapechanging surface can be created by folding and unfolding or origami patterns and one of the ways of achieving the movement of origami can be with air pressure (Ou, Heibeck, \& Ishii, 2016).

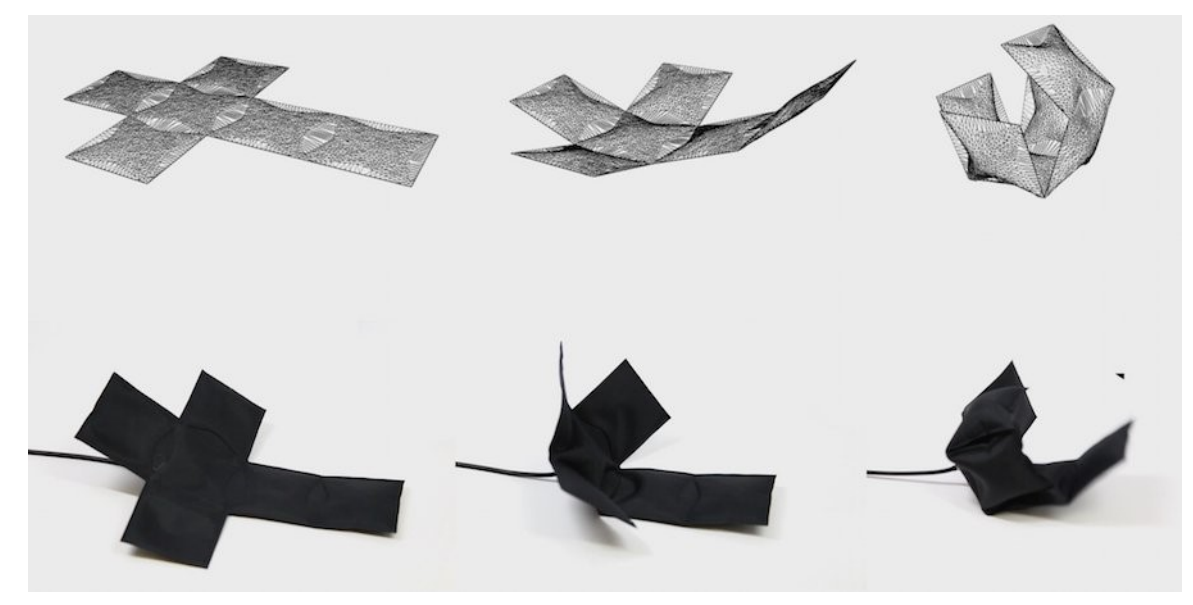

Figure 14: Polygonal Self- folding (Ou, Skouras, et al., 2016)

MIT researchers created Pneuduino, a shape-changing toolkit that works with air pressure to help designers create soft inflatable structures. This Arduino-based programmable electromechanical toolkit helps designers by allowing them to create such shape-changing structures without going through all the steps that are usually required for this kind of task. At the TEI 2016 conference, the Pneuduino toolkit was introduced to researchers who are interested in developing shape-changing and soft materials from MIT Media Lab (MIT Media Lab, 2019)(Figure 15). Some examples of the design with Pneuduino were: shape-changing packaging, Interactive crane and Haptic gloves $(\mathrm{Ou}$, Skouras, et al., 2016). This type of toolkit can constitute a step forward in the 
computerization of shape-changing materials. It can help designers to more easily design with fabrics that would change their shape for use in designing foldable structures.

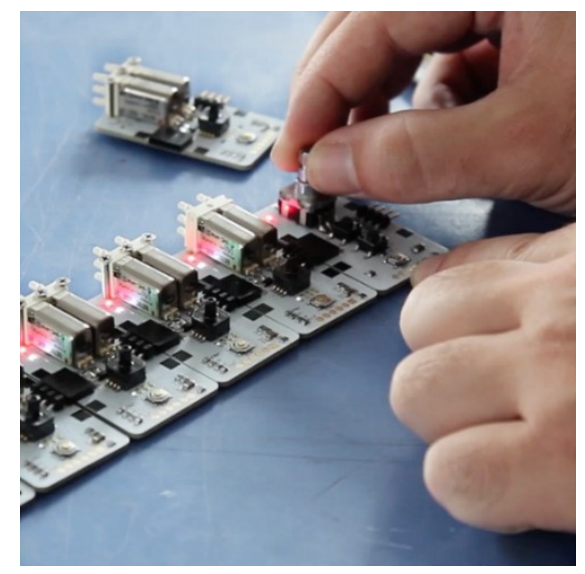

Figure 15: Pneuduino from MIT Lab (MIT Media Lab, 2019)

\subsection{Innovation}

However, mainstream adoption of innovation takes time and usually goes through multiple phases before reaching full adoption (Rogers, 1983). Previous research (Dedehayir \& Steinert, 2016) (Talukder, 2012) has shown that the adoption curve of an innovation depends on multiple factors: ease of use, the learning curve or the number of user cases. These are examples of factors that will affect the rate at which people decide to adopt an innovation. For example, Gartner has created a chart that illustrates his Hype Cycle (Figure 16) to define the different phases that innovation goes through before reaching its full potential (Gartner, 2019). According to Gartner, after the innovation is triggered, it usually reaches a peak of inflated expectations during which people's expectations are way above the true potential provided by the innovation. During that phase, success stories from early innovation adopters attracts people's attention. After this 
phase usually comes a trough of disillusionment during which people realize that their expectations were too high and that the number of user cases for application of the innovation is lower or harder to find than expected. During that phase, multiple failures to deliver the expected benefits create disillusionment and disappoint the hopeful adopters.

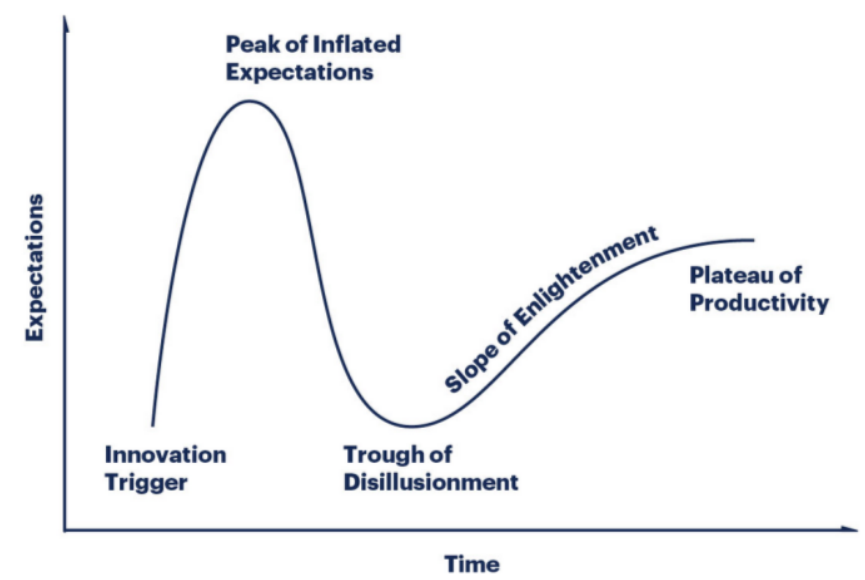

Figure 16: Gartner Hype Cycle (Gartner, 2019)

Finally, there is usually a slope of enlightenment during which education is provided about the innovation and the way of using it, in order to reach the full potential or plateau of productivity. During that phase, better understanding of both the limits and capacities of the innovation enable creation of the benefits. The important thing to understand here is that innovation will go through many phases before being adopted widely by its potential consumers. Since our research explores a new approach to provide ready-to-use samples, it is important to understand how users adopt and are educated to adopt innovation.

Another book, Crossing the Chasm was published in 1991, discussed the "Technology adoption life cycle" which is a model for understanding the acceptance of 
new products (Moore, 1991). From a marketing perspective, people's attitudes toward technology become important when estimating the potential adoption of any new technologies. Based on the paper, people were grouped into five categories, as follows:

Innovators: They seek new technology even before its release in the market. Although there are not many innovators in the market, their feedback about the new device and its properties plays an important role in the marketplace.

Early adopters: This group adopts the new technology quickly and if they find a technology that is matched with their requirements, they purchase and use it.

Early majority: This group prefers to wait to discover other people's experience with the technology and then they will buy it. "They are roughly one third of the whole adoption life cycle.” (Moore, 1991)

Late majority: This group of people would not buy a product unless it is mature enough that they see the support from large companies and the price has decreased. They include one third of total buyers.

Laggards: They do not want anything to do with new technology. The only way that they buy a technological product is when it is buried deeply inside another product.

It is also important to consider the specific characteristics of the wearable market in order to assess the potential adoption of this innovation. In the quick-growing market of wearables, the company that enters the market as a first mover usually does not gain an advantage, which is an argument for companies to wait before adopting new technology. Furthermore, there is extreme diversity of wearable devices and customers are marketconfused in their buying decisions. That could explain the resistance of some corporations 
to create more diversified products by incorporating new technologies in existing wearables (Moore, 1991).

As we discussed, the rapidity of product adoption depends on multiple factors and each product will have to go through different phases before being widely adopted. Francis Bitonti states that the fashion industry has been slow to adapt to new technologies due to their core values and culture from fashion brands and because of that technologies have not been widely adopted by the industry (Bitonti, 2016). The author does not see an extensive implementation of technology that would influence design and have a meaningful impact on fashion. The author also highlights the importance of co-creation in order for fashion to embrace technology in the future.

\subsection{Summary}

The literature review begins by noting that the first wearable computing devices were introduced by and for the US military; they provided the foundation for multiple wearable computing projects that become part of people's daily lives in specific domains:

fitness and health. Eventually, the growing pace of technology innovations encouraged researchers and designers to incorporate technology within their designs. The willingness of designers to incorporate technology has been influenced by the emergence and application of new technologies such as smart textiles, 3D printers and other techniques in the world of interactive fashion

However, designers need to have a broad range of knowledge to add technology and increased functionality to their designs. In most of the cases reviewed, the researchers with high levels of knowledge could collaborate with other researchers. In the case of 
designers, most of them did not have enough technical knowledge related to electronics and programming (Pailes-Friedman, 2016).

Based on the examples of functional apparel design presented in this chapter, fashion designers mostly collaborated with technology professionals to implement technology in order to build interactive pieces. Meanwhile, it is not always easy to collaborate with researchers or developers because there is usually a communication asymmetry between the two. Challenges exist for technical researchers in understanding designers' needs and in knowing how to solve their problems efficiently. Considering their different backgrounds, that problem requires a lot of effort and patience on both sides to understand each other. Furthermore, difficulties in communication can arise from either the lack of knowledge about fashion from the tech professional or the lack of technological literacy from the fashion designer. Those reasons may explain the reluctance of some people to engage in this type of collaboration.

A ready-to-use sample could help reduce the communication asymmetry by providing fashion designers with tools that help them build the technology by themselves without requiring the support of a technical expert. Therefore, this research aims to answer this question: How can kinetic fabric samples help designers incorporate technology in their design? This question was explored through three sub-research questions:

1. What is the designer's perception of innovative interactive garments/art piece?

2. How would designers use the kinetic fabric samples in their design?

3. Would designers be likely to use kinetic fabric samples to inspire and explore design possibilities for their work? 


\section{Chapter 3: The Prototypes}

We designed three prototypes based on findings from the literature review. In this chapter, we explain the process of designing and developing the kinetic fabric prototypes — with soft shape-changing materials - that were used in this research. The pattern of these fabrics is based on origami art that changes its shape as it folds and unfolds.

\subsection{Origami Patterns}

Origami patterns were used on fabrics in this research for three main reasons. First, the origami had a suitable structure that made it efficient for shape-changing movements by folding and unfolding an element (Peraza-Hernandez et al., 2014). Second, we wanted to use a pattern that would be easily implementable on the fabric and that would complement it in a fashionable way, so the aesthetic qualities of origami were suitable for this research.

We found different folding patterns that could be used to fold and unfold fabrics. We applied three types of tessellations: The Eight-Crease Waterbomb, the Six-Crease Waterbomb and Pyramid (Chen, Feng, Ma, Peng, \& You, 2016).

The Eight-Crease Waterbomb has a structure that enables self-unfolding with air pressure and it also looks like blooming flowers that expand (Figure 17). The Six-Crease Waterbomb changes shape from a flat piece to a ball which explains its name: the magic ball (Figure 17). The origami dress in Figure 18, by Jule Waibel (Jule Waibel, 2019) is based on the Six-Crease Waterbomb or magic ball pattern that she made for the brand Breshka to install at their stores. 

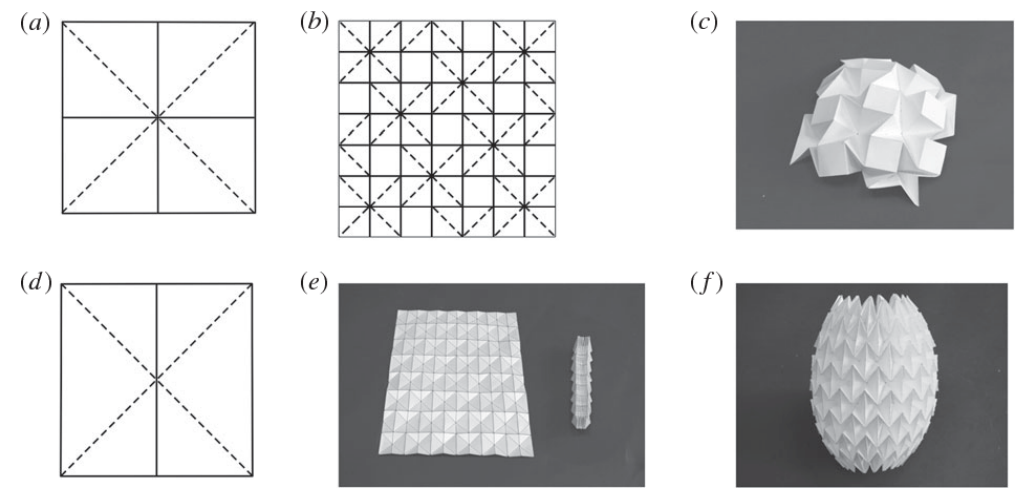

Figure 17: Two Waterbomb bases and their tessellations. (a) The Eight-Crease Waterbomb base; $(b)$ one of its tessellations forming the Resch pattern; $(c)$ partially folded Resch pattern model; $(d)$ the Six-Crease waterbomb base; $(e)$ its tessellation in unfolded and folded states and $(f)$ the tessellation can also be used to form a tube (Chen, Feng, Ma, Peng, \& You, 2016).

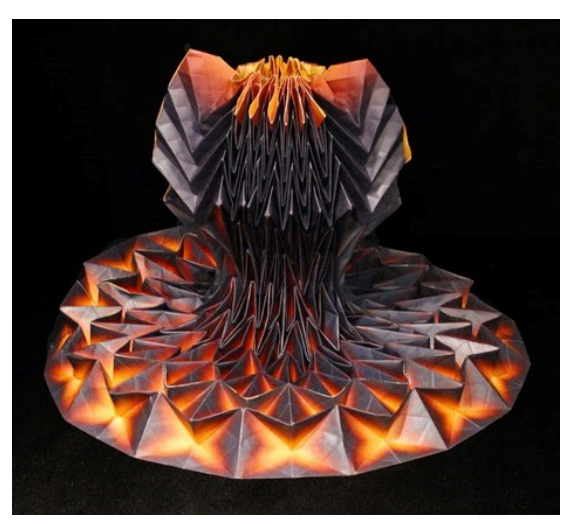

Figure 18: Origami dresses by Jule Waibel

The pyramid tessellation is a simple origami pattern that contains pleat folds of three-dimensional shapes (www.npal.cs, 2019). The crease pattern of Pyramid tessellation only contains paired mountain and valley folds (Figure 19). 


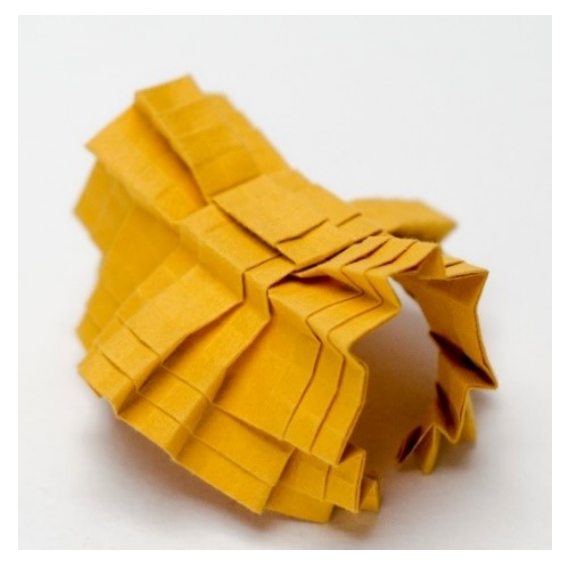

Figure 19: Photo of the folded shape (www.npal.cs, 2019)

It took us one month to iteratively build the prototypes. The Eight-Crease Waterbomb, Six-Crease Waterbomb and the Pyramid are created from square folds (Figure 17) (www.npal.cs, 2019). We made the Eight-Crease Waterbomb from a square piece of fabric that was 10 by 10 inches and each square was $3 / 4$ by $3 / 4$ inches. The Six-Crease Waterbomb was made from a piece of fabric that was 8.5 by 6 inches and each square was 1 by 1 inch. We made the Pyramid from a square piece of fabric that was 16 by 16 inches. These origami patterns can be applied to any size of fabric, by increasing or reducing the number of squares (Peraza-Hernandez et al., 2014).

The origami patterns must meet certain criteria in order to be implementable in the fabric's design. Those criteria include 3D patterns that are appealing enough to a designer to want to incorporate the pattern into their designs. We also decided to use air pressure -which does not need programming -- so we focused on creating uncomplicated kinetic fabric samples that folded and unfolded with air pressure. We also focused on choosing the right pattern with a self-folding structure based on the origami patterns that would be suitable to implement on fabrics (Ou, Skouras, et al., 2016). 
"The visual appearance of products is a critical determinant of consumer response and product success" (Crilly, Moultrie, \& Clarkson, 2004). Our goal was to make aesthetically pleasing prototypes with a clean and neat finished appearance that is suitable for fashion (Issam Yousef, 2015) and other designs. We did not want to focus only on the technology to be implanted within the garment but wanted to consider the appearance of the design in order to make a good impression on people.

We used one yard of Silk Shantung fabric to develop the three kinetic fabric samples for this study because Silk Shantung holds creases well. This fabric is stiff so it can be folded like paper and adapted efficiently to the movement of the prototypes. In addition, it is not too soft or thick and fusible web material would be attached to the back of it. The same fabric and colour was used for all the prototypes so as to not influence participants' interaction with the prototypes.

\subsection{Selection of the Origami Patterns}

We used three different origami patterns to develop the kinetic fabric samples: The two types of Waterbomb tessellations, the Eight-Crease Waterbomb in Figure 20 (1) and the Six-Crease Waterbomb (or Magic Ball) in Figure 20 (2), and the pyramid in Figure 20 (3) (Chen et al., 2016). We used these three patterns to transform a flat piece of fabric into three-dimensional structures that were suitable to bend their angles while moving them. We made the origami shape with paper first to help decide if we liked it or not. 


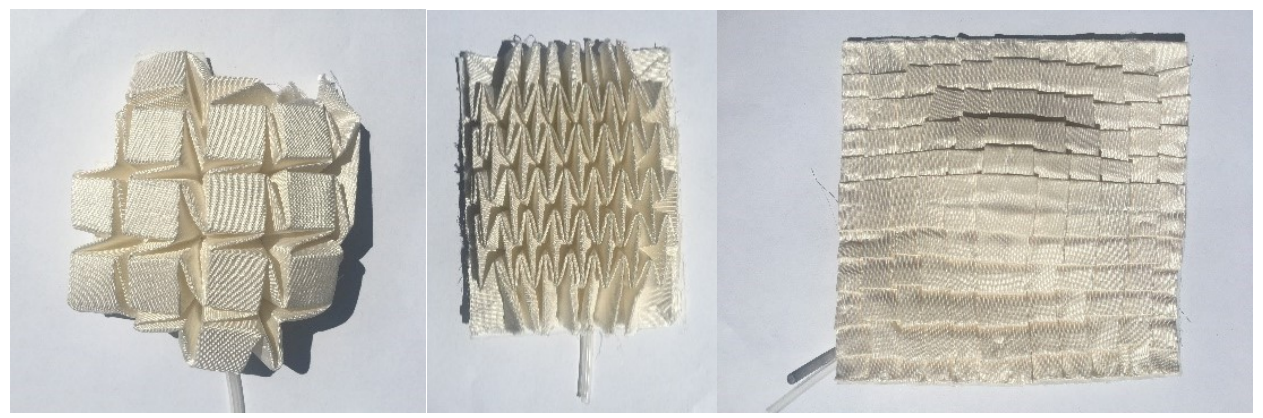

Figure 20: From left (1) Eight-Crease Waterbomb, (2) Six-Crease Waterbomb, (3) Pyramid

After finding the suitable origami pattern, we made plastic molds (Figure 21) from a transparent plastic origami sheet. We folded two transparent plastic origami sheets so that they were the same as the origami papers for each pattern. The plastic origami sheets were stronger than the papers so we could sandwich a piece of fabric between them. After sandwiching the fabric between molds, we applied heat and cold with a hair dryer to set the origami folds in the plastic molds. This method was not successful because the folds started to open up after a couple of hours. We had to find a way to set the folds so they would not open after being used.

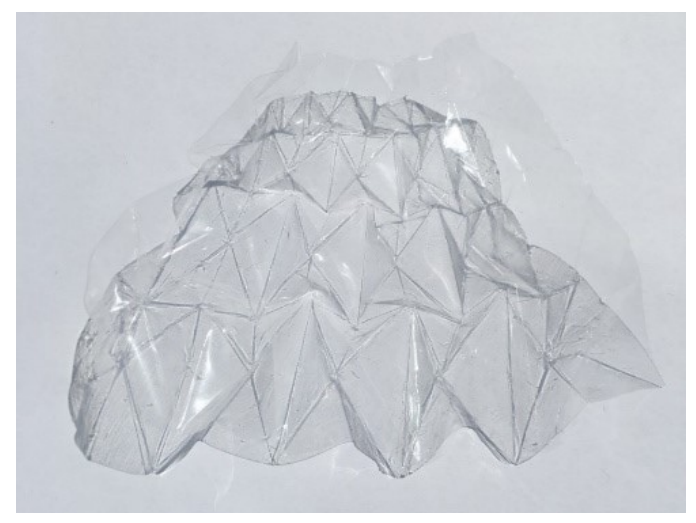

Figure 21: Plastic mold 
To set the origami folds in fabric that would attain the desired structure first required that the origami pattern be drawn on the fusible web material and cut into pieces. We ironed the pieces to the back of the fabric (Figure 22) then sandwiched the fabrics between the plastic origami sheets (mold) and secured the folds with wood clips (Figure 23). The fabric set for 2 or 3 days, as in Figure 23 and when we opened the clips, the fabric held the planned shape.

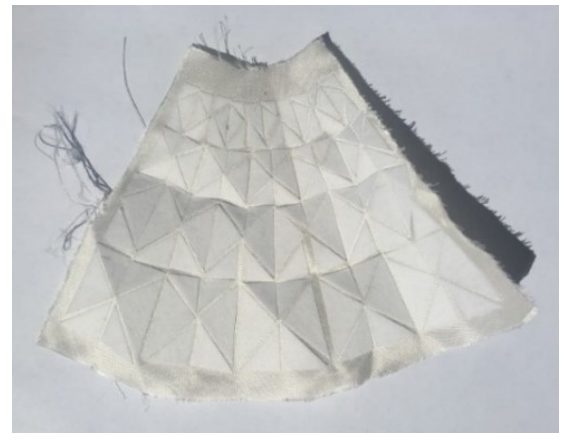

Figure 22: The fusible web cut and attached to the back of the fabric

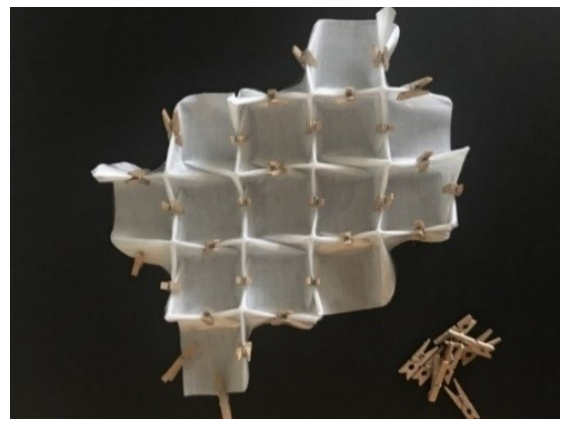

Figure 23: Secure the folds with wood clips.

We hand sewed around the pattern to an additional layer of flat fabric that had a hole in the back (Figure 24). A tube was added to the balloon with an elastic (Figure 25) after which, a balloon was placed inside the fabric, in the center (Figure 24). 


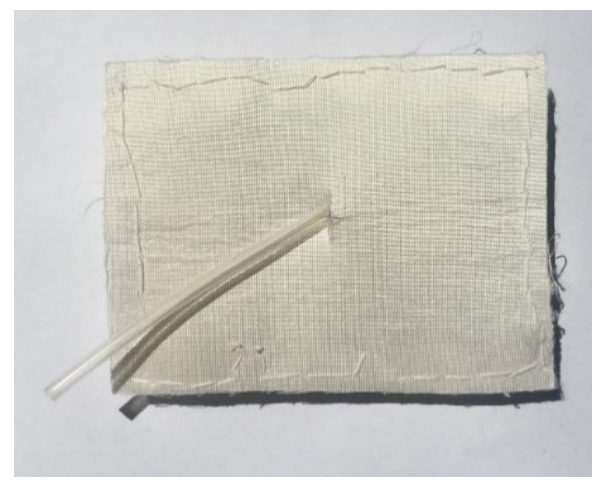

Figure 24: The back of the fabric.

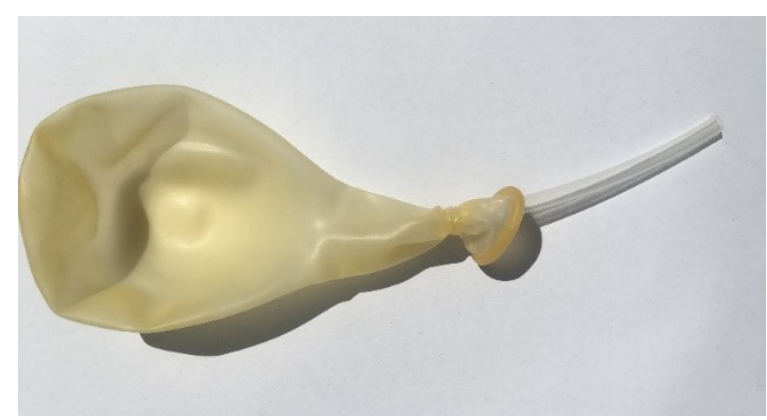

Figure 25: The balloon with a tube inside it.

\subsection{Scale of the prototypes}

The primary prototype, the Eight-crease Waterbomb, was an early sample made to test the concept and the process of the kinetic fabric samples that was the Eight-Crease Waterbomb. We built the initial prototype to a scale of seven by seven inches and it was bigger than the one used during the interviews. We changed the size of the prototypes after we learned that to create the initial prototype size for the study would require a large quantity of fabrics and additional time. We built the prototypes on a smaller scale for the design session to allow the designers to design garments on 12 inches tall mini-manikin rather than an actual human body. 
Limitations in terms of resources and time did not allow the building of human-size prototypes; furthermore, we wanted the designers to modify the garments, which would have required the building of multiple prototypes and would have used much more fabric. Therefore, the choice of size for the prototypes was mainly due to limitations in resources and time.

The final Eight-Crease Waterbomb prototype used during the design session had a scale of 3.5 by 3.5 inches. The Six-crease water bomb's scale was 3.5 by 4.5 inches. Finally, the pyramid's scale was 5.5 by 5.5 inches. All three prototypes used during the design session were smaller than the one initially built for research purposes.

\subsection{Electronics}

Based on findings from the literature review, we believed that the participants would have different levels of knowledge and experience of working with electronics and programming (Pailes-Friedman, 2016). The main goal of this study was to use a technology to create fabric samples that would be simple for designers to use. We used simple electronics to implement the shape changing of the prototypes to avoid the need for programming knowledge. Ease of use was an important attribute for our prototypes, and we wanted the prototype to be easy to modify as well.

We used a small air compressor, a balloon and tubes to blow the air under the fabric, which allowed the prototypes to change their shape by folding and unfolding. We used a battery and a switch to turn the air compressor on/off (Figure 26). 


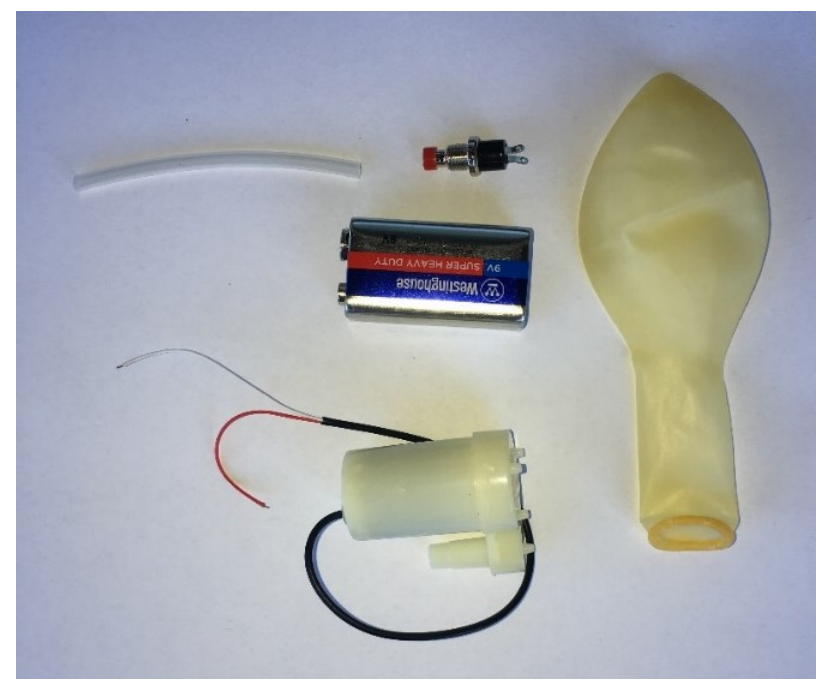

Figure 26: The material that were used to implement shape changing to the fabrics

This is a simple process for making shape-changing fabrics that would allow designers to explore designing garments or any other art pieces. The aim was to leverage the experience of working with interactive fabrics that were simple so the participants might use them without needing any special skills and knowledge about electronics.

\subsection{Final Prototypes}

The figures in this section show what the final prototypes looked like when finished and ready for the study. In Figure 27, the Eight-Crease Waterbomb at the left is closed while the one on the right is open wide and full of air. The prototype was designed to return to its normal shape when all the air was let out. The time it took to change the shape would depend on how wide the users wanted the prototypes to be opened; it could take between five seconds for the Six-Crease and Eight-Crease and ten seconds for the Pyramid to open. The participants used a button in to puff it out fully. They were instructed to deactivate the same button when they wanted the prototype to go back to its initial shape slowly which 
means for all three samples took about 10 seconds to deflate. Figure 28 shows the SixCrease Waterbomb before and after the air pressure was applied, and Figure 29 shows the Pyramid.

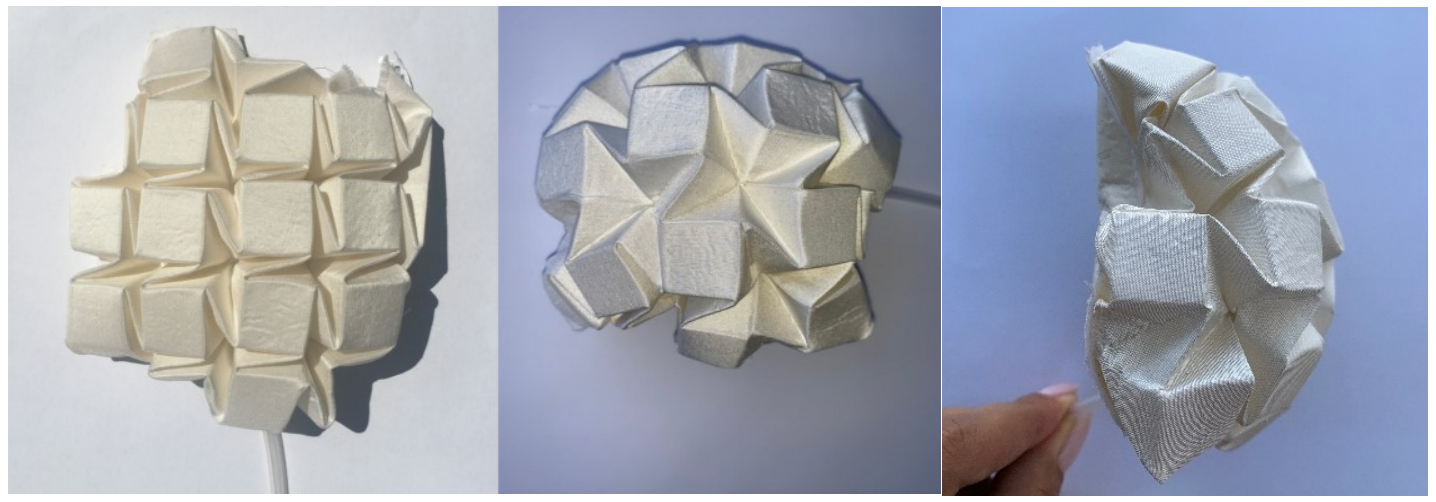

Figure 27: Eight-Crease Waterbomb before and after air pressure is applied. View from the top and side

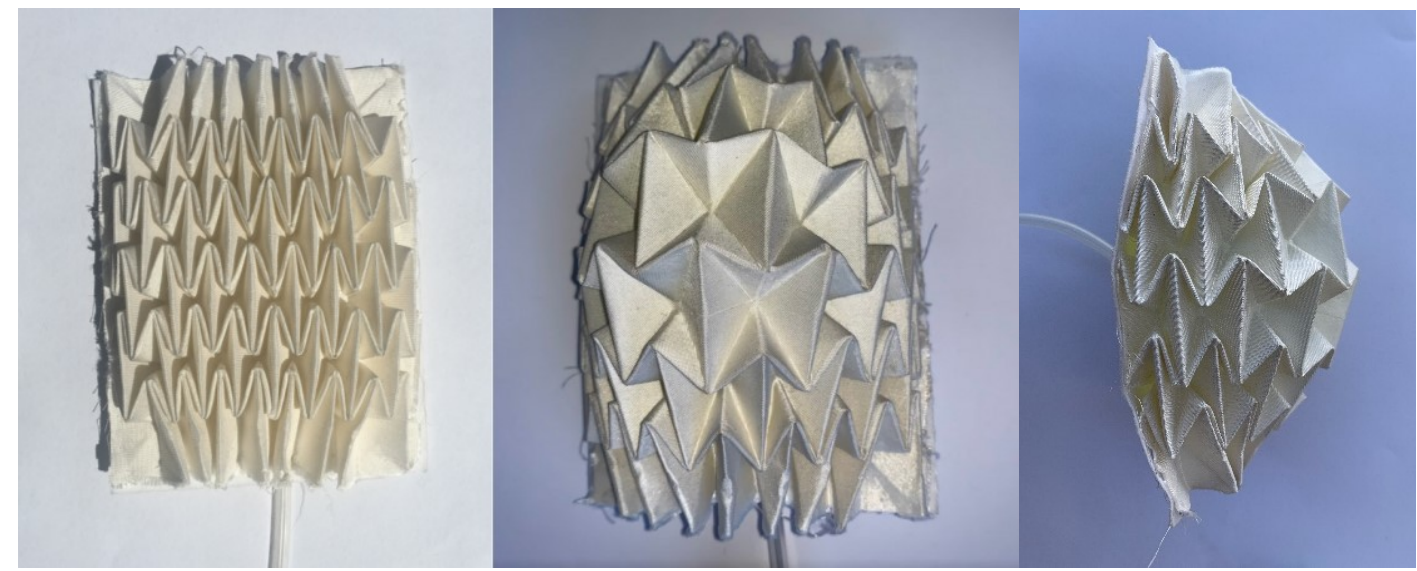

Figure 28: Six-Crease Waterbomb before and after air pressure is applied. View from the top and side. 


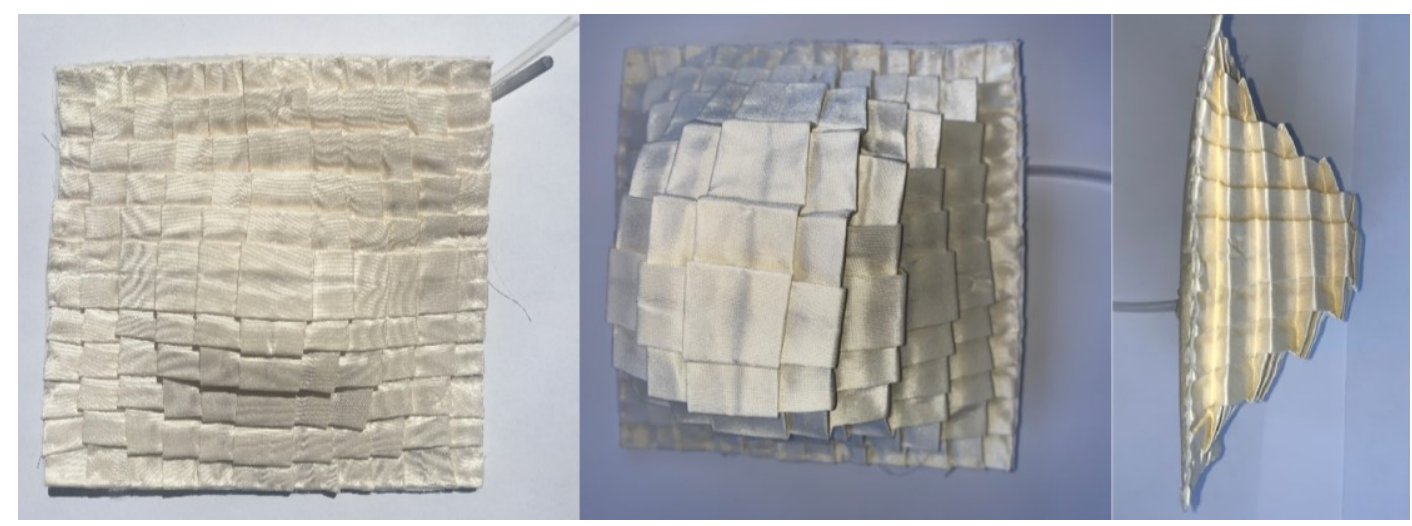

Figure 29: Pyramid before and after the air pressure is applied. View from the top and side. 


\section{Chapter 4: Methods}

As noted earlier the main study questions was: How can kinetic fabric samples help designers incorporate technology in their design? This chapter explains the methods that were used to answer the three sub-research questions that arose from the main question:

1. In order to answer the question," What is the designer's perception of innovative interactive garments/art pieces?" it was important to set up a study that explores what designers already know about interactive garments and art pieces.

2. In order to answer the question, "How would designers use the kinetic fabric samples in their designs?" it was important to make and share kinetic fabric samples so that the designers could interact with fabrics while considering design possibilities.

3. In order to answer the question, "Would designers be likely to use kinetic fabric samples to inspire and explore design possibilities for their work?" it was important to learn about the designers' points of view after interacting with the kinetic fabric samples.

This chapter explains the steps taken to set up these investigations.

\subsection{Research Design}

This study used qualitative research, combining multiple methods, to address our main research question. In this chapter, we describe the different methodologies used such as semi-structured interviews, design sessions and surveys. In order to gather the data, we introduced participants to ready-to-use, shape-changing fabrics that allowed them to explore working with these fabrics. As noted earlier, the kinetic fabric samples change their 
shape with wearers control, to fold and unfold. The patterns of these fabrics are based on origami so the fabric can be folded and unfolded. We provided the kinetic fabric samples to designers to see how they used them.

To answer our first sub-question, the first step of the study was a semi-structured interview to assess participants' knowledge and experience of innovative interactive design and incorporating technology in their design. The information gathered from this step allowed the researchers to determine the demographics of our population. We asked different questions to participants to evaluate their experience with and knowledge of interactive arts before showing them the samples. Also, we asked some questions to find out if they were interested in using technology in their designs or not. The semi-structured interview was followed by a second step, a design session in which participants were asked to interact with kinetic fabric samples to design a garment either on a mini manikin or as a design for any other kind of interactive piece.

The seven participants were given three different prototypes of kinetic fabrics to try so that their opinions could be assessed to understand the potential use case for the fabrics. The design session helped determine the level of the participants' experience and their opinion about the kinetic fabric samples. During the design session, the researcher observed and took notes of participants' interactions and feedback. That step allowed assessment of the ease of use of the kinetic fabric sample, along with the user's experience. To answer our second sub-question, we observed designers during the design session to determine how they would use the kinetic fabric samples. Finally, the last step was a survey to solicit feedback from the participants in order to obtain their insights on the kinetic fabric and their experience working with them. After analyzing the first study, we asked five 
follow-up questions from the same participants, in order to gather more information and data regarding their experience. We conducted the second interview on the phone and tried to identify both improvements that could have improved their experience in the study and to obtain a second point of view- a few months after the participants' initial experience. The second study allowed us to answer the third sub-questions and to acquire a better understanding of the use of kinetic fabric samples to inspire and explore design possibilities for the group of designers who were studied.

\subsection{Participants}

We recruited seven participants for this study. First, we emailed the designers from the Toronto Fashion Week website to recruit experienced fashion designers. Four fashion designers (P1 to $\mathrm{P} 4)$ accepted the invitation to participate in our study. We also recruited three (P5 to P7) researchers from Carleton University who had previous experience working with fabrics and whom the researcher knew personally. We tested these categories to cover the diversity of experience within the group as recommended in Nielsen \& Landauer (1993).

\subsection{Demographic}

Table 1 summarizes the participants' demographics, in terms of age. Three of them were between 18 and 30 years old, two were between 30 and 40 years old, one was between 40 and 50 years old and one was older than 50 years old. The population distribution was disproportionate in terms of sex of the participants: six were females while only P7 was male. The level of education of the population was proportionally 
distributed: three of the participants had some college degree in fashion design, the other four were currently enrolled in or had a graduate degree. However, in terms of years of experience, the distribution was disproportionate with the majority of participants: (five) had less than 10 years of experience and P2 had more than 45 years of experience (See Table 1).

\begin{tabular}{|c|c|c|c|c|c|}
\hline ID & Sex & Age & Education & $\begin{array}{c}\text { Years of } \\
\text { fashion } \\
\text { experience }\end{array}$ & $\begin{array}{c}\text { Years of } \\
\text { design } \\
\text { experience }\end{array}$ \\
\hline P1 & F & $30-40$ & $\begin{array}{c}\text { Some } \\
\text { college }\end{array}$ & 12 & 0 \\
\hline P2 & F & 50 & $\begin{array}{c}\text { Some } \\
\text { college }\end{array}$ & 45 & 0 \\
\hline P3 & F & $40-50$ & $\begin{array}{c}\text { Graduate } \\
\text { degree }\end{array}$ & 7 & 0 \\
\hline P4 & F & $18-30$ & $\begin{array}{c}\text { Some } \\
\text { college }\end{array}$ & 5 & 0 \\
\hline P5 & F & $30-40$ & $\begin{array}{c}\text { Graduate } \\
\text { degree }\end{array}$ & 0 & 8 \\
\hline P6 & F & $18-30$ & $\begin{array}{c}\text { Graduate } \\
\text { degree }\end{array}$ & 0 & 5 \\
\hline P7 & M & $18-30$ & $\begin{array}{c}\text { Graduate } \\
\text { degree }\end{array}$ & 0 & 6 \\
\hline
\end{tabular}

Table 1: Demographic of the population

All participants had experience in fabric design, four of them were fashion designers with experience in custom-made dresses, and two had experience in sewing and tailoring. P5 had experience sketching garments, without ever making any, and she had experience working with fabrics in industrial design.

\subsection{Triangulation}


In qualitative research, a combination of methods can be used to explore different dimensions of the study. Triangulation is used to collect data and analyze it from multiple perspectives and in different contexts (Creswell, 2014). The triangulation process helps researchers compare their findings from separate sources to be able to strengthen the reliability of their findings.

In this study, a combination of a semi-structured interview, a design session and a post-questionnaire survey was used to get a more complete picture of the participants' perspectives. This method helped increase the validity and trustworthiness of our findings by providing results from more than one research method. Interview questions were designed to understand the participants' insights about designing interactive garments or art pieces. In the design activity we asked participants to use the kinetic fabric samples in their design to examine the findings from multiple perspectives (Figure 30).

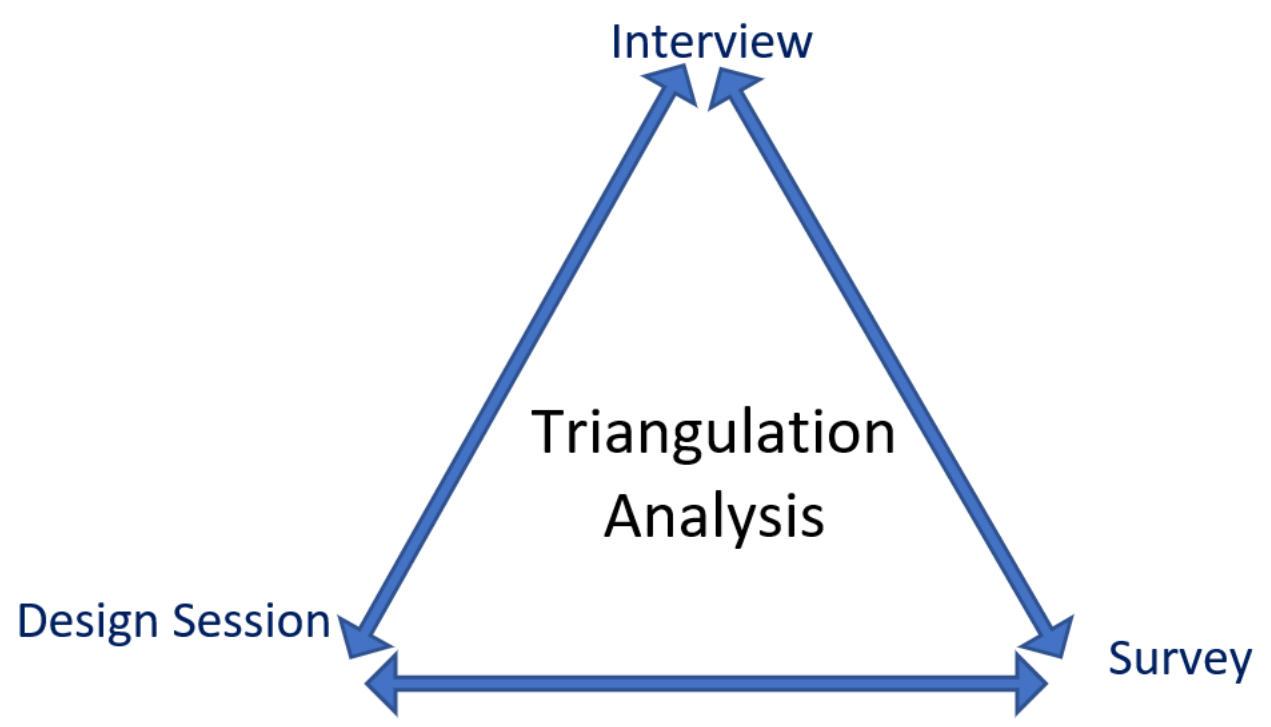

Figure 30: Triangulation brings together different data sources to enrich the analysis (Barnum, 2011) 
The triangulation process allowed comparison of our findings from these three sources: interview, observation design activity and survey. It made it possible to explore different ways to interpret the data and to check if the data from one method reinforced the data from the other methods.

\subsection{Semi-structured Interview}

The semi-structured interview is the most common of all qualitative data collection methods (Alvesson, 2000). In this type of interview, we prepared open-ended questions about different subjects to direct the conversation toward the topics (see Appendix C). The semi-structured interview is more flexible and brings more details or addresses a major concern while the interviewer can ask follow-up questions to explore responses more deeply (Qu \& Dumay, 2011).

The objective of a structured interview is to start a conversation to learn about participants' attitudes, values, beliefs and motives, using an interview guide already developed, with core questions (Richardson, Stephen A; Dohrenwend, Barbara Snell; Klein, David, 1965). A semi-structured interview was conducted to assess the participants' knowledge regarding interactive arts, leaving enough time to conduct the design session. The primary consideration of the semi-structured interview was to identify the personal histories of the sample group (Louise, Alison, Barriball, \& While, 1994).

The interview began with ice-breaking questions designed to find out more about the participants' professional experience in fashion design or other design with fabrics. We encouraged participants to talk about their experiences through open-ended questions. It allowed the researcher to have a better understanding of each designer's knowledge and 
previous experience with any interactive art pieces, smart fabrics, kinetic fabrics and related works in any other type of design. The interview helped clarify the participants' visions about the role of technology in design and their interest in using electronic elements in clothing and fabrics.

The intention of these interviews was to learn about each participant's knowledge, experience and opinion about working with any computational function in fabrics. We anticipated that the interview would improve the validity of the findings (Louise et al., 1994). For example, the designer who had been familiar with interactive art pieces may, or may not, have any interest in using electronics in their design (Louise et al., 1994). We asked ten questions during the interview that lasted an average of twenty minutes each. Those questions follow:

1. Can you tell me a little bit about yourself? How long have you been in the art industry?

2. What kind of interaction art are you interested in? Did you ever visit any fashion technology event? If so, what was your experience?

3. What role do you think technology plays in fashion today?

4. Did you ever consider using electronic elements (sensors or lights) or other technology in your designs?

5. Have you ever seen any examples of the innovative interactive garments/art piece? What inspired you?

6. What features are you interested in smart fabrics?

7. What do you think about kinetic fabrics or garments? Are you interested in designing with kinetic fabrics? 
8. How do you think using interactive electronics and other technologies would impact on the audience's experience?

9. How would you want the wearer to feel when wearing an interactive garment?

10. Has designing interactive clothing changed your perception of fashion? What are the limits of fashion materials?

\subsection{Design Session}

We conducted a design activity with our participants immediately after the initial interview that lasted an average of thirty minutes each. For all our design activities we first demonstrated our three prototypes to them. We started by initiating the prototypes to show them how these kinetic fabric samples work by changing their shapes and expanding (Figure 31). The purpose of giving this information about the structure was to prevent any confusion so the participant could focus on their design session and provide recommendations.

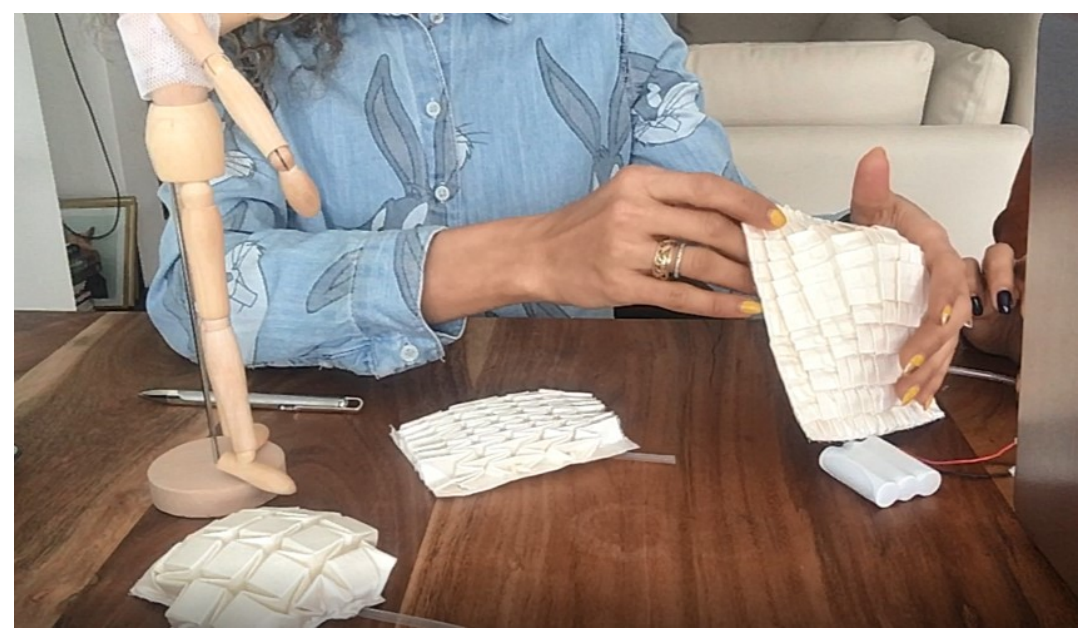

Figure 31: Demonstrations of the prototype to one of the participants 
We demonstrated three kinetic fabric samples to the participants, and provided oneyard extra fabric, along with a 12 -inch-tall mini manikin, pins and scissors. Next, we asked the participants to design a garment on a mini manikin and to actively involve themselves in generating ideas and design concepts (Barnum, 2011). Participants were also asked to give the researchers any design recommendations. While the participants were interacting with the design samples during the design session, we observed and asked them questions regarding their overall interactions during the design session.

\subsection{Survey}

Surveys have been a common research tool since the 1930s (Fowler, 2014). At the end of the study, each participant was asked to fill in a survey (see Appendix G). We gathered demographic information about age group, gender and education, from the survey, and we also assessed designer's experience with kinetic fabrics. We selected the questions in this survey to evaluate participants' satisfaction with the prototypes after finishing their design. All questions in the survey were related to the participants' experience using the kinetic fabrics during the design session. Furthermore, we asked participants to provide their opinion on the prototypes as an innovative solution as well as the likelihood of their using or recommending one of the prototypes in the future. Those questions follow:

1. How would you describe your reaction to the kinetic fabric samples at first?

2. How well, if at all, does the word "Innovative" describe this new prototype? 
3. What is your overall satisfaction with the kinetic fabric sample?

4. How likely are you consider using this prototype in your design?

5. How likely are you to recommend this prototype to another designer?

6. I found that the prototype was easy to use.

7. How do you think that this kind of technology would affect traditional couture?

\subsection{Ethics and Recruitment}

Our research methodology was reviewed and cleared by the Carleton University Research Ethics Board-B (CUREB-B). This research collected primary data from potential design experts. We selected the participants based on their experience in fashion design or related fields, and they must have had the experience of both working and design with fabrics. Eligible participants were designers that were over 18 years old and were comfortable speaking English.

A total of seven interviews were conducted with individuals who fit the target criteria of having experience in fashion design or working with fabrics. We recruited participants through email invitations to take part in the study (see Appendix D).

In this study, anonymous names were used to protect the identity of the participants. A numeric code identified each participant's video recording and faces did not show in any videos. 


\subsection{Setup}

Each volunteer participant engaged in a two-hour session held in-person at the participant's preferred location. Four participants were full-time fashion designers and we conducted their sessions at their workplaces (Figure 32); the other three were invited to the HCI $2111 \mathrm{~B}$ at Carleton University. We video recorded the interviews during the study; in order to do so, we requested that the participants sign a consent form prior to the start of the session (see Appendix E). In the beginning, we gave an introduction about the research and the main concept of the study to each participant (see Appendix F). They did not receive any direct benefit from their participation in this study.

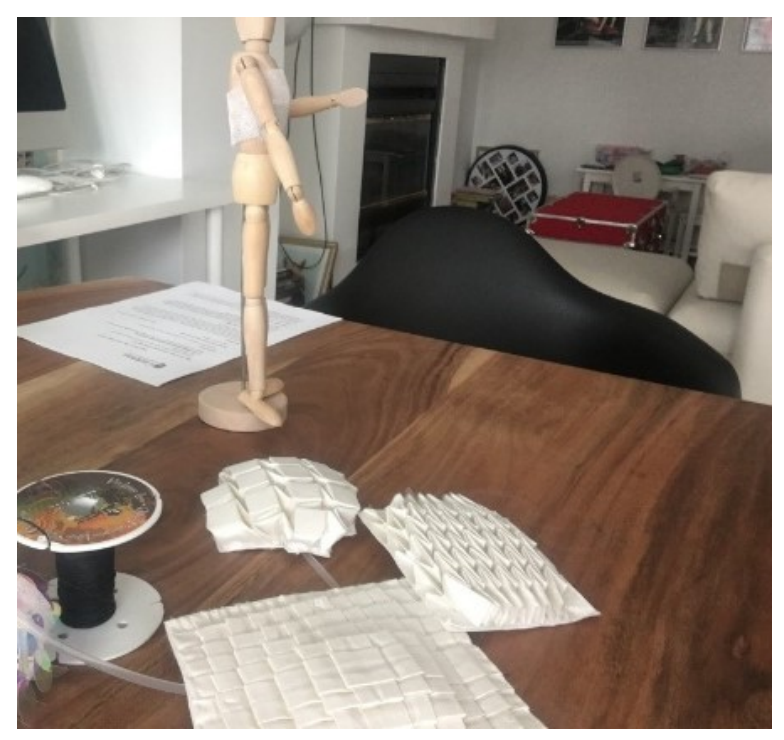

Figure 32: The study was conducted in one of the participants' office

\subsection{Second Interview}

Three months after the initial study, we asked some follow-up questions of the same participants in order to gather more information and data regarding their experience. We conducted the second interview on the phone and we audio-recorded them. The interviews 
were then transcribed for later analysis. Five of the participants agreed to participate in our follow-up study (see Appendix H). The study comprised five questions that were related to the potential weaknesses of the previous study to help identify improvements that could be made to the study and to obtain a second point of view several months after their initial experience. The questions were as follows:

1. How did the previous study of the kinetic fabrics influence your vision of using similar technologies in the design industry if it did?

2. Did you talk about the kinetic prototypes with anyone else after the design session? Did you think about them? What were some of your thoughts and/or things you said about them?

3. Thinking back to your experience in the design session, what about the kinetic samples could have been improved to inspire your ideas for design applications?

4. Would you be comfortable designing with large pieces of the kinetic fabrics? If not, why?

5. Have you had any ideas for designing with them since our design session?

The two first questions were related to the impact that the study had on the participant's vision toward and interest in technology. Those two questions were a followup to some questions that had been asked during the first interview. For example, they were asked in the first study how likely they were to recommend the prototypes to other designers. So, question 2 of the second study was used to see if they talked about the prototypes to other people following the first study. The purpose of questions 3 and 4 was to obtain feedback about what improvements could be made to the prototypes. Finally, question 5 offered a second chance to participants to give us more ideas that they might 
have regarding designing garments with the prototypes. Since one design session can offer limited opportunities for designers to be creative, we wanted to see if these designers continued to think about the prototypes and the possibilities of designs after the first study. It may also give an insight into the motivation of designers to work with kinetic fabrics. 


\section{Chapter 5: Results}

We video recorded the first study and we transcribed the interviews manually. We input our observations into Word documents to pursue our analysis. The first study, which was video recorded, comprised nine thousand eight hundred and seven words. The second study, which was audio-recorded, comprised one thousand seven hundred and thirty-two words.

\subsection{Coding analysis}

Coding is a method of analyzing qualitative data that includes interview transcripts, notes and journals. "A code in qualitative inquiry is most often a word or short phrase that symbolically assigns a summative, salient, essence-capturing, and/or evocative attribute for a portion of language-based or visual data." (Saldaña, 2016). Coding is the beginning of the search for patterns in data analysis and it enables researchers to organize their findings. Once the data has been coded, the researcher can use the coded data for analysis of specific aspects such as "pattern detection, categorization, theory building, and other analytic processes".

We transcribed and coded the qualitative answers from the interview and the design session in a Word document. We used a Descriptive coding method as suggested by Saldana to analyze the study transcript which consisted of a total of six hours. Descriptive coding is a method of analyzing qualitative data, such as interview transcripts, suitable for the beginning of the research analysis: "Descriptive coding summarizes in a word or short phrase - most often as a noun - the basic topic of a passage of qualitative data" (Saldaña, 
2016). Descriptive coding allowed us to categorize the answers come from our study in order to extract the main ideas from those answers.

We also used this method to categorize the data in the transcripts for further analytic work by looking for the same or similar concepts used in different instances. This method was the foundation of our analysis and helped us to understand what we heard and saw in general.

For example, from the design session we tried to identify how designers would use the kinetic fabric samples. Afterward, we analyzed the extracted concepts and tried to find some patterns between participants or between concepts that seemed to be related with each other and appeared multiple times within our data. Note how we categorized our findings with Descriptive Codes:

I don't think if I would use this material on the waistline

Body Parts because everybody wants to show their waistline small.

The fabrics would provide maybe a bit of insolation and Type of Apparel could be nice for an outerwear.

But I'm thinking if I use it on the top it is very difficult, Body Parts because the wearer cannot move so I will not use them close to the arms. 
Our coding process included two cycles. The objective of the first cycle was to summarize the content by identifying general topic categories discussed in the interviews. The first cycle lay a groundwork for the second cycle of coding and further analysis. In the example above, all qualitative data coded with Body Parts, for example, would be extracted from the main body and gathered together in a separate file for further analysis:

As previously mentioned, four of the participants talked about the parts of the body that are suitable for these kinds of fabrics, such as the lower body, as well as the parts of the body that are not suitable, such as the upper body, waistline, and around the arms.

\subsection{User Study with Designers}

We wanted to understand how professional designers think about interactive arts and design with the kinetic fabric samples. We categorized the interview questions into two parts; the first part is about the participants' knowledge and experience and interest in interactive fashion and arts while the second part focuses on their interest in using technology and electronic elements in their design.

\subsection{Semi-Structured Interview Results}

As part of the study, we verbally asked several open-response questions. We sorted the open-response data into three categories to meet the research objectives:

1. The participants experience in attending fashion technology events or being the witness of demonstrations of innovative interactive garments/art pieces. 
2. The role that technology plays in fashion, and whether the participant has considered using any electronic elements in their design (sensors, lights, smart fabrics, kinetic fabrics).

3. The limits and challenges of using technology in garments and the wearer experience and audience experience.

\subsubsection{Innovative Interactive Events}

First, we asked if participants had ever attended a fashion technology events or interactive art events to evaluate their experience. From the group, six of the participants indicated they had never attended any fashion/art technology events. However, those six participants all mentioned they had seen garments that used neon threads. Two of the participants had been to music and light events. P3 visited some interactive museums in Europe and London, and she stated that, "It's always exciting to go see anything when they combine two different disciplines."

Three of the participants mentioned that they were interested in attending interactive art events but indicated that those events are rare in Ottawa. For example, P7 stated that, "The problem is here in Ottawa we don't have fashion events. So that's the only reason why I'm not visiting because I need to go to another city."

\subsubsection{The Use of Electronic Elements}

Regarding the role of technology in fashion, all the participants claim that they believe technology plays an important role in fashion. All seven participants agreed that technology will change and reshape the fashion industry. 
Regarding their experience using electronic elements in their own design, six of the participants had no experience working with electronic elements in their design. One of the participants used light in an interdisciplinary project in collaboration with a professional who helped him with the coding. P2, who had forty-five years of experience in custommade clothes, stated that, "I never interacted with the technology and I just work with traditional fabrics and cut them. But I believe that technology is going to make its way to fashion as well."

Participants' knowledge about different electronic elements was limited. Four of them mentioned they are interested in lights and illuminating fabrics for aesthetic and functional purposes. For example, P3 mentioned using lights for Halloween costumes and P2 talked about the use of lights on clothes for the safety of cycling or walking during the night. Two of the participants talked about their interest in integrating 3D printing in their design but they had not yet worked on it.

Regarding their interest in designing with kinetic fabrics, all seven participants mentioned that they were interested in seeing the kinetic fabrics for the first time and looked forward to working with them.

\subsubsection{The Wearers' and Audience's Experience}

We asked participants to describe the impact of interactive electronics on the audience's experience. Four participants thought that audiences would pay more attention if they see something innovative and new, and they were happy to get people's attention. The other three mentioned that it depends on the intention of the designer and the function 
of the garment. They commented on the importance of the garment's comfort and safety with electronics and circuits.

Regarding the limits of fashion in terms of interactive fashion design, two participants think that there is no limit and mentioned that fast-growing technology will change everything.

For P2, with 45 years of experience, it was difficult to answer this question because she was not sure if people would accept interactive garments as part of their lives, but at the same time she mentioned that some people want to stand out in the crowd. She stated, "In fashion you will be surprised how people react because they have different ideas." P6 also mentioned that people would not accept interactive garments for everyday wear, highlighting a potential limitation of this technology. At the same time, he also stated, "the wearer would feel like a mystery." Two other participants mentioned that a wearer wanted, "to be on top of the world" and "stands out."

\subsection{Design Session Results}

Results from the design session were grouped into eight categories: appearance, element of surprise, type of apparel, parts of the body, preferred fabrics, functional aspect of the design, security, furniture, and other desires. The findings were categorized based on common attributes among the participants' answers.

\subsubsection{Appearance}

All of the participants talked about the appearance of the kinetic fabric samples and revealed different opinions. They commented on both specific and general patterns: "Eight- 
Crease waterbomb looks like a flower and I want to bring it to life," or "Six-Crease waterbomb is interesting and looks futuristic.”

P3 wanted to design a skirt for the purpose of both day wear and evening wear so she was considering using these samples to design a skirt that would be flat during the day and could puff up during the evening.

P4 focused on the functionality during the study and mentioned that, since these fabrics are blowing up, there is no aesthetically pleasing aspect of them to use so she just focused on the functional aspect of the prototypes. She stated, "I am not quite sure where you would go with this blowing up."

\subsubsection{Element of Surprise}

Two of the participants wanted to design a dress to surprise audiences at an event or fashion show. P1 stated, "Imagine she is taking a picture on the red carpet and she pushes the button and it will just stop traffic. People will think that there is a show, but this person is just a guest". She wanted people to be astonished and start asking questions about the dress and the technology involved so that the wearer would feel special. P7 had the same opinion and he said, "Oh my God, can you imagine how a mannequin is going on the runway? And how she is walking? The dress is becoming bigger and bigger in the public is like, wow!"

P5 mentioned that the Six-crease and Eight-Crease Waterbomb fabrics had the element of surprise because of their shape, so she preferred them.

\subsubsection{Parts of the body}


Four of the participants talked about the parts of the body that are suitable or not to use this fabric on.

P2 said she would not use these fabrics on the waistline of the garments, and she stated, "everybody wants to show their small waistline." P3 mentioned that she would not use it on the stomach, but she would use the Six-Crease Waterbomb fabric on the shoulders because she believed people do not like to show a big stomach. Three of the participants suggested using these fabrics on top of the shoulders and P3 referred to "a female Gladiator style" and she mentioned that she would use Pyramid on the shoulders.

P7 said he would have used the Six-Crease and Eight-Crease Waterbomb fabrics on the bottom of the dress rather than on the top, he would not use them close to the arms. He said that the Pyramid fabric is suitable for the top. He tried to make a pregnant lady on the mini manikin, and he stated, “It's kind of cute. I mean it's not bad. It's interesting, like a piece of art." (Figure 33). He considered designing a bra so that the wearer can puff their bra if they want. He said, "Other than that I'm thinking if you are trying to use it on top it is very difficult."

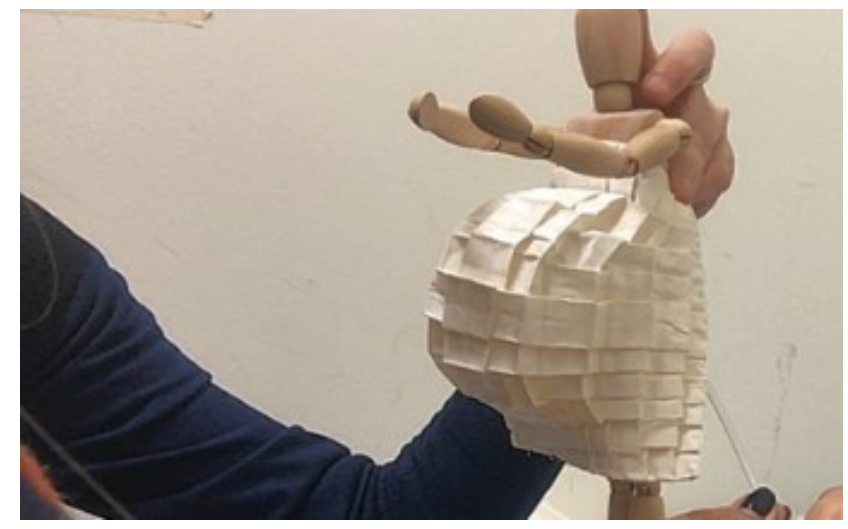

Figure 33: P7 made a pregnant lady on the mini manikin. 


\subsubsection{Type of Apparel}

All of the participants talked about the different types of apparel they would design with the kinetic fabric samples. Five of them made a skirt on the mini manikin with the Six-Crease Waterbomb kinetic fabric as shown in Figure 34.

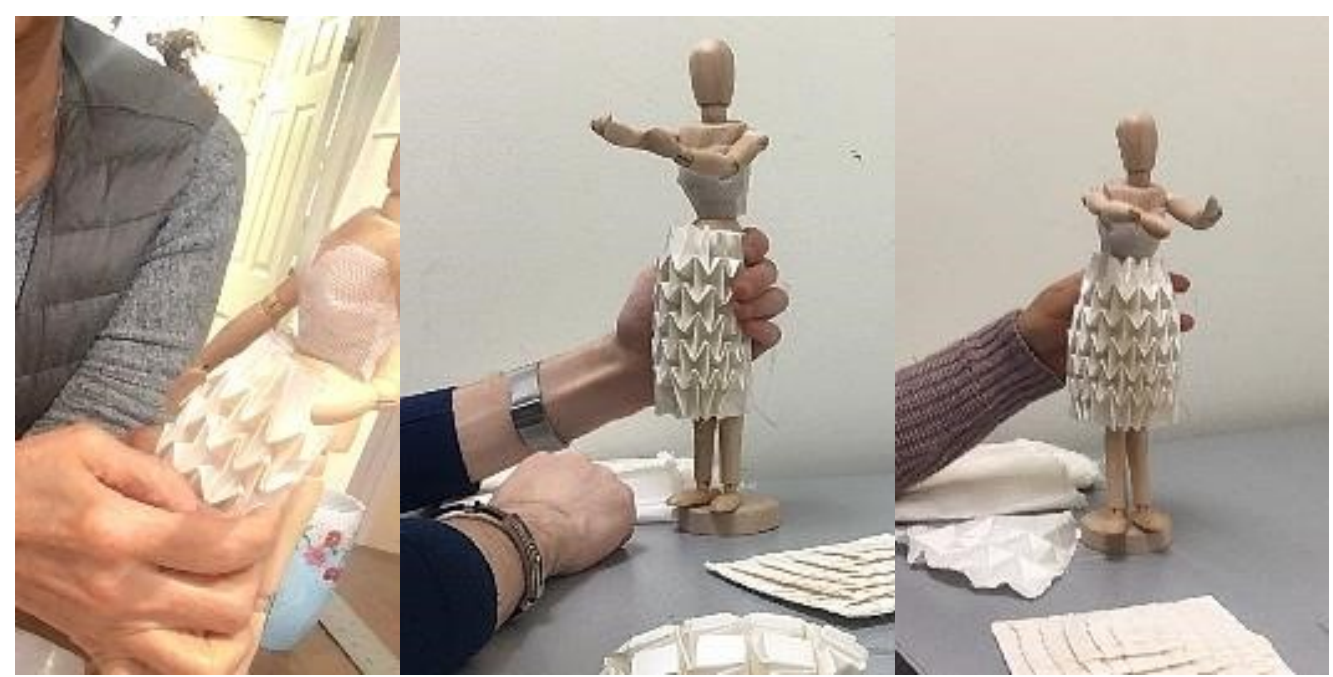

Figure 34: Participants making a skirt on a mini manikin with the Six-Crease Waterbomb kinetic fabric.

Three of the participants mentioned that they would not be comfortable using the kinetic fabrics on the top and they would prefer a simple top with a puffy skirt. One of the participants said that the Six-Crease Waterbomb was easy to work with and the first thing that came to his mind was making a puffy skirt.

Five of the participants mentioned that these fabrics are suitable to make a push-up bra. One of the participants explained that since these fabrics are light weight, they are comfortable to make a push-up bra with and the wearer can change the size of it. 
Three participants mentioned that they would not use the garments that they design for off-the-rack purposes. Only P1 and P7 stated, "I would use this material for ready-towear clothes for different events".

Some participants had different ideas. One talked about using these fabrics for outerwear and stated, "These could be nice for outerwear, it can keep the body warmer because you have a section of air in between. The reason why feathers are warm is because there's air in between. It could be the future of it, it can keep the body warmer. This would provide maybe a bit of insulation."

Another participant wanted to design wedding dresses and stated, "The wedding gown has a ring and wire inside, which makes it round and heavy. But then it gets so difficult to store them later. If there is air when you wear it and then the air goes off and then you can store it."

Other ideas they talked about included making an English hat or designing a lapel for a jacket or using it on kids' clothes and accessories.

\subsubsection{Safety}

Only one of the designers mentioned that she was worried about the safety of the wearer and she asked questions such as, "Is this detachable? The customers are not going to electrocute themselves?! Is there going to be a risk? How about if it is raining?" So, in the end she suggested that we could detach the motor when the wearer is walking outside so rain would not be a problem for the wearer.

\subsubsection{Functional Aspect of the Design}


Two participants focused on the functional aspect of the garment they designed with the fabrics. P3 wanted to use it for an outerwear garment that keeps the body warm when the fabric is inflated because there is air in between. P4 focused on using these fabrics for protective purposes. "If something bubbles up and it supports the body that would be a pretty smart way to use these fabrics. This technology can protect the wearer from a dangerous act or a stunt and having a bad fall. The person knows that he could incidentally put this on, and this can protect him. For example, people that are doing crazy stuff and they can fall and hurt themselves."

\subsubsection{Furniture}

Some participants suggested using the fabrics to design items of furniture. P4 talked about designing something outside of the body. "It is also can serve a purpose outside of the body like using it on the couch, it would be really cool as an interactive canopy or for your patio in the backyard. On rainy days have these kinetic fabrics on top for better protection. When your nice little gazebo has this fabric out when it starts raining, the fabric change their shape and they cover the roof. We can probably do a lot with these fabrics!"

For different usage three of the participants suggested making a pillow with the Pyramid fabric. Two wanted the pillows to inflate and deflate for comfort purposes and one of them wanted to use the pillow for another purpose. He stated, "People like them because they can touch it and play with it. I'm someone who always wants to do something with my hands. Kids will love to play with it, I will use it to just have fun and playing with it. For example, you know, the pillows with glitters and you're just playing with your hands." 


\subsubsection{Preferred Fabric}

Since three different prototypes were shown to the participants, we hope to determine which prototype was preferred by the participants and the reason for their preference. Table 2 shows which fabric was preferred by each of the participants: The Six-Crease Waterbomb, the Eight-Crease Waterbomb or the pyramid. Only P5 could not choose between Six-Crease and Eight-Crease Waterbombs. The following paragraphs explain the rationale behind the participants' decisions.

P2 and P5 who chose the Six-Crease Waterbomb explained their preference was due to its flexibility, which made it easy to use.

The two participants who chose the Eight-Crease Waterbomb explained their preference was due to its appearance. For them, the prototype's shape and aesthetic were the important factor in fashion design.

\begin{tabular}{|c|l|l|l|l|l|l|l|}
\hline Preferred Fabric by Participants & P1 & P2 & P3 & P4 & P5 & P6 & P7 \\
\hline Six-Crease Waterbomb & & $\checkmark$ & & & $\checkmark$ & & $\checkmark$ \\
\hline Eight-Crease Waterbomb & & & & & & & \\
\hline Pyramid & & & & $\checkmark$ & $\checkmark$ & & \\
\hline
\end{tabular}

Table 2: Preferred Fabric by Participants

The participants who chose the Pyramid as their preferred prototype explained their choice was due to the prototype's limited movement. They mentioned that the changes in 
the shape of this prototype while moving were more obvious than the two other prototypes. The Pyramid prototype provided a better impression because it allowed emphasis on the surprise effect produced by the movement that came from the prototype.

\subsubsection{Other Desires}

P1 mentioned that she expected to have a manual with the fabrics that explain the instructions on how to cut and use the fabrics.

P3 stated "I always think that we don't have enough of the combination of technology and fashion. There's not enough of it."

A participant preferred that the fabrics could change in length so she could create a skirt that could change in length (Figure 35). Two of the participants mentioned that the Eight-Crease Waterbomb fabric is too rigid for garments.

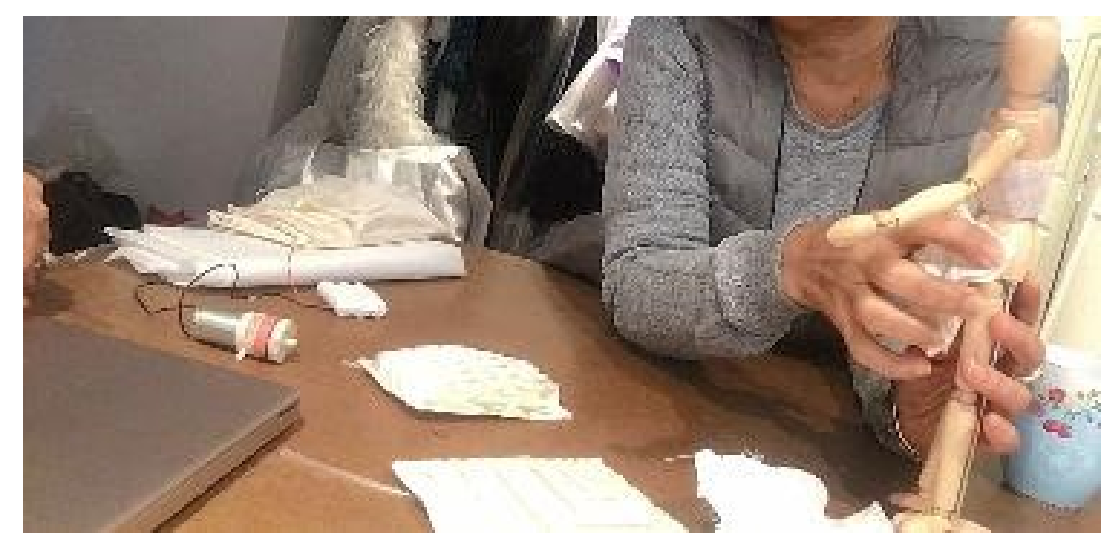

Figure 35: Participant two expected that Eight-Crease Waterbomb fabric changed the length.

\subsection{Survey Results}

We gathered the survey responses from the seven participants after each design session. In general, the responses were positive to the survey questions. Most of the 
participants' reactions to the prototype were positive and they were engaged during their session. As can be observed, most participants answers ranged between 3 and 5 on multiple questions (Figure 36).

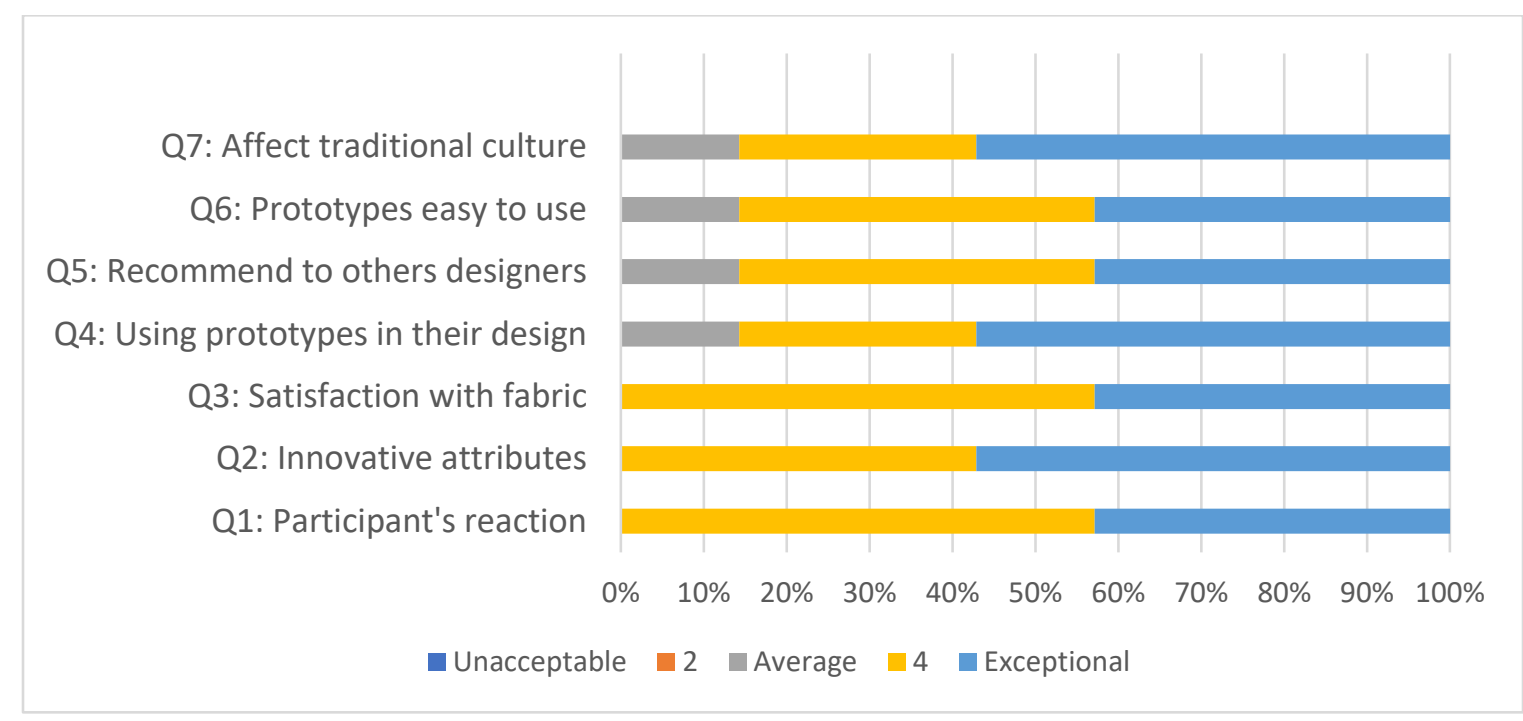

Figure 36: Survey Results

The survey results illustrate the responses for sub-question three that measure the reaction of the participants to the prototypes; three of them answered "exceptional". The remaining four participants answered that they had a good reaction to it without finding the prototypes "exceptional". Regarding Question 2, the innovative attributes of the prototypes, three of the participants answered that the prototypes were highly innovative while the other four answered "above average".

We can observe from the survey results to the first two questions that two of the three participants whose response to the prototypes was "truly exceptional" also said that the prototypes were highly innovative. In total four of the seven participants gave similar answers to those two questions. 
The participants' overall satisfaction with the kinetic fabric samples was generally positive, with all participants rating their satisfaction as "above average". Three of the participants were satisfied with the fabrics samples and they also would consider using the prototypes in their design.

P3 was the participant who indicated the lowest interest in using the prototypes in her design. She was also the one less likely to recommend the prototypes to other designers, with an answer of "average".

P1, P6 and P7 all answered that they were exceptionally likely to recommend the prototypes to another designer while the three remaining participants answered that the possibility of recommending the fabrics is above average.

Figure 36 shows that P3, P6 and P7 considered the prototypes to be exceptionally easy to use. Two of those participants (P6 and P7) were also likely to recommend the prototypes to another designer.

Most of the participants answered that this kind of technology was exceptionally likely to affect traditional couture and will have a high impact of activity on that sector. Only P2 answered that this technology would affect traditional couture on average, not expecting it to be disruptive. The two remaining participants answered that this kind of technology would affect traditional couture above average but without being exceptional.

The survey results allowed us to identify those tendencies of the participants that seemed to be different from the others. P7 is the only one who never changed his answers and answered 5 to all the questions. Participants 2 and 3 are the only ones who answered 3 to some questions. 


\subsection{Observations}

During the design session, we observed the participants' expressions during their interactions with the prototypes to better understand their overall experience. All seven participants exhibited a lot of positive attention at the beginning of the study: they showed interest in how the prototype worked, and asked questions about the technology involved in making the prototypes. Participants held and folded each kinetic fabric prototype; they touched the fabrics to evaluate their flexibility and the softness of the material.

P1 asked many questions about cutting, sewing and the mechanics inside of the fabric. She wanted to know if she could cut the fabric in the shape that she wanted and if she could sew pieces together (see Figure 37). The researcher's answers seemed to make this participant feel more comfortable to be creative after explaining how she could open the fabric and cut it. We observe from the survey result that two of the three participants who answered that their reaction to the prototypes was truly exceptional also answered that the prototypes were highly innovative.

P1 imagined making a dress for a guest and her goal was to impress the audience. She said, "I like to people ask me questions about it and being surprised or taking photo on the red carpet during a fashion show". She used her imagination about an event during the study and talked about it when she was designing. 


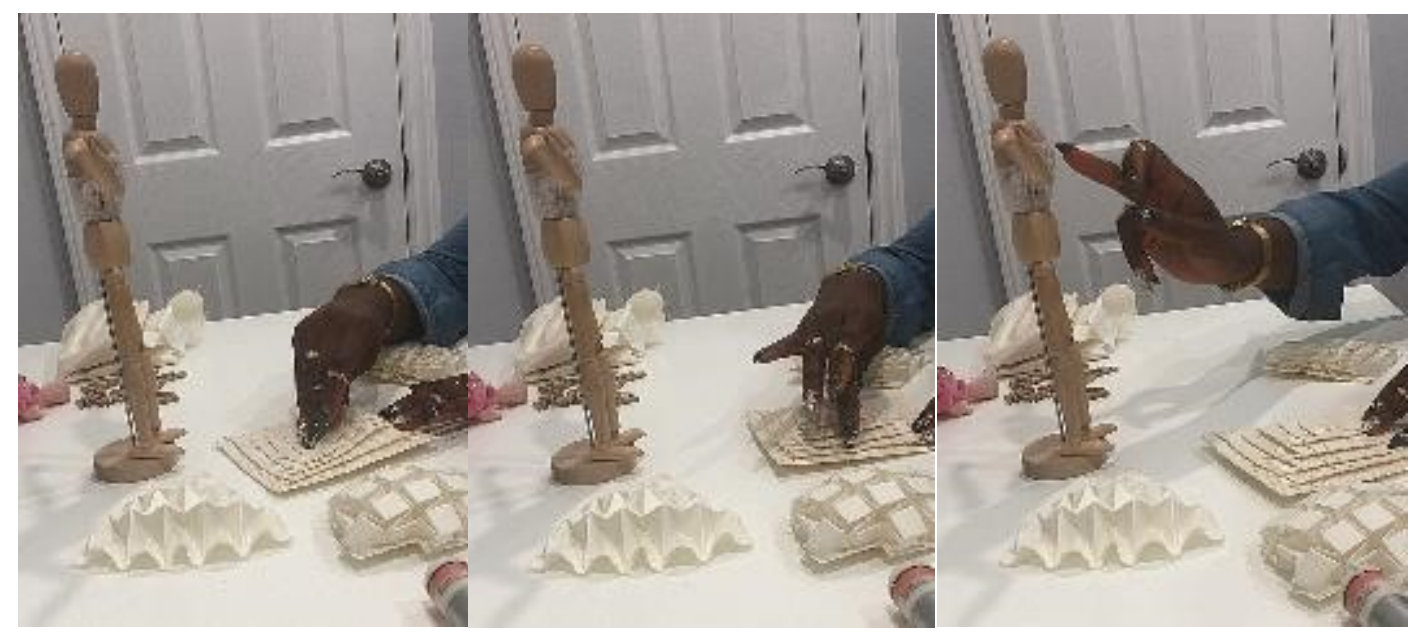

Figure 37: P1 wanted to stitch around the fabric and cut it as a corset

The participant put the fabric on her body rather than on the mini-manikin and she was trying to imagine how a jacket lapel would look and she kept it on her shoulders to see if it would look good. She was showing excitement about kinetic fabric samples and she was engaged during the session, talked about different locations of the body where she might use the samples on, for different parts of a garment.

P2 touched the fabrics and compared them with each other (Figure 38). She mentioned that she liked the appearance of the fabrics. The participant squeezed the SixCrease Waterbomb (Figure 39) in the beginning, however it took her time to start talking and think; only after a while did she give feedback to the researcher and she seemed confused. 


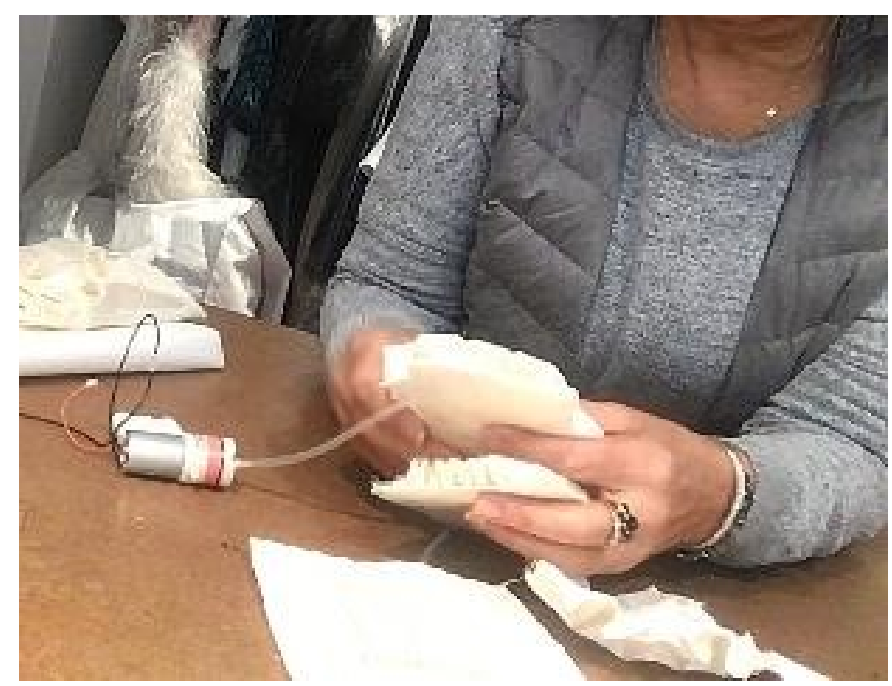

Figure 38: P2 comparing different prototypes with each other.

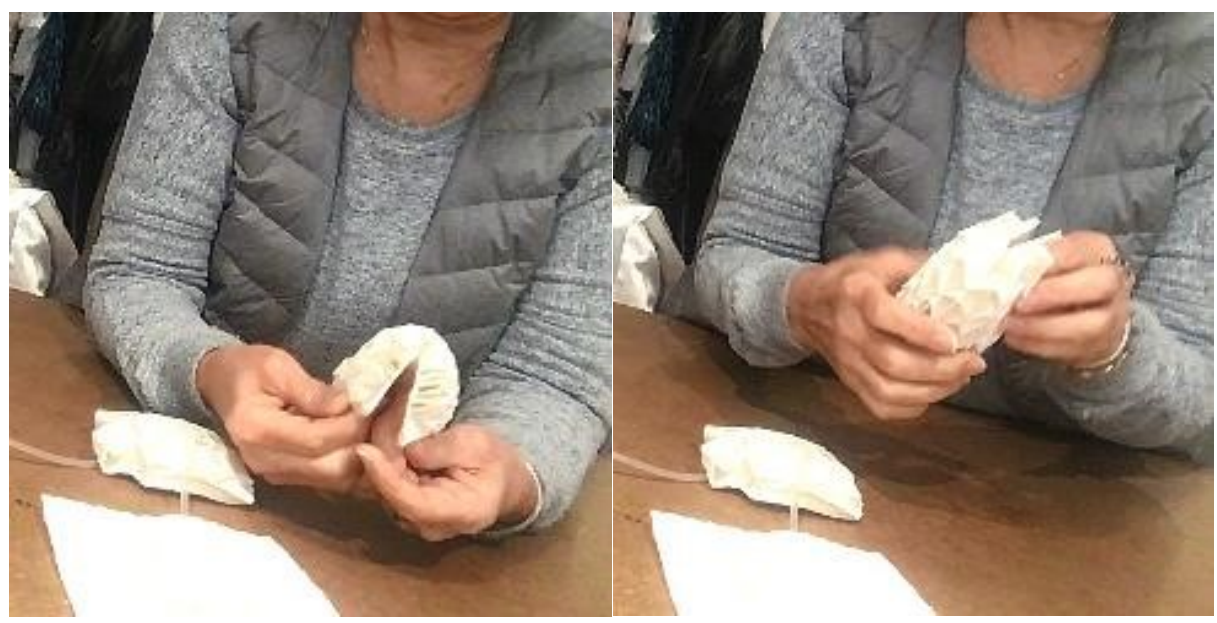

Figure 39: P2 squeezed the Six-Creased Waterbomb fabric to look at between the folds.

P2 was trying to imagine the design on her body rather than on the manikin (Figure 40). She mentioned that her expertise was on working with traditional fabrics and she preferred them to kinetic fabrics. 


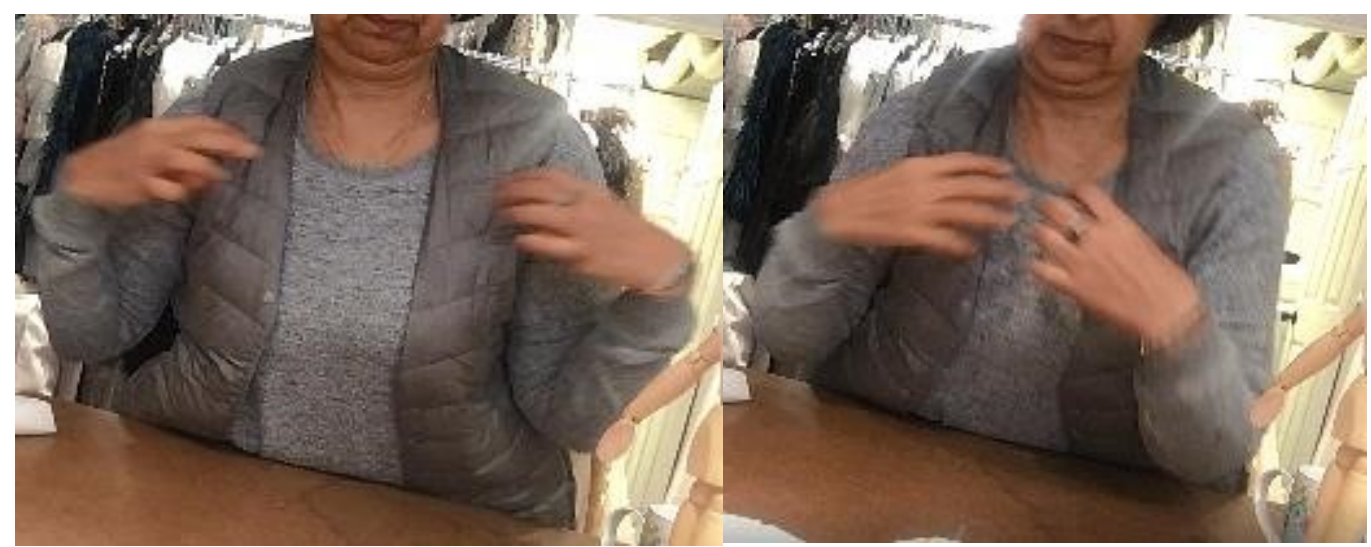

Figure 40: P2 showing the collar that she would make with the eight-crease fabric.

P3 in Figure 41 focused on Pyramid fabric and commented that she preferred this style over the other two. She touched the fabric and pulled it, but she did not ask any questions about the technology or the mechanism of the fabrics. She felt comfortable working with the Pyramid fabric, and she did not squeeze them at all. This participant talked about making outerwear with these fabrics that could keep the body warm because there is air between the layers.

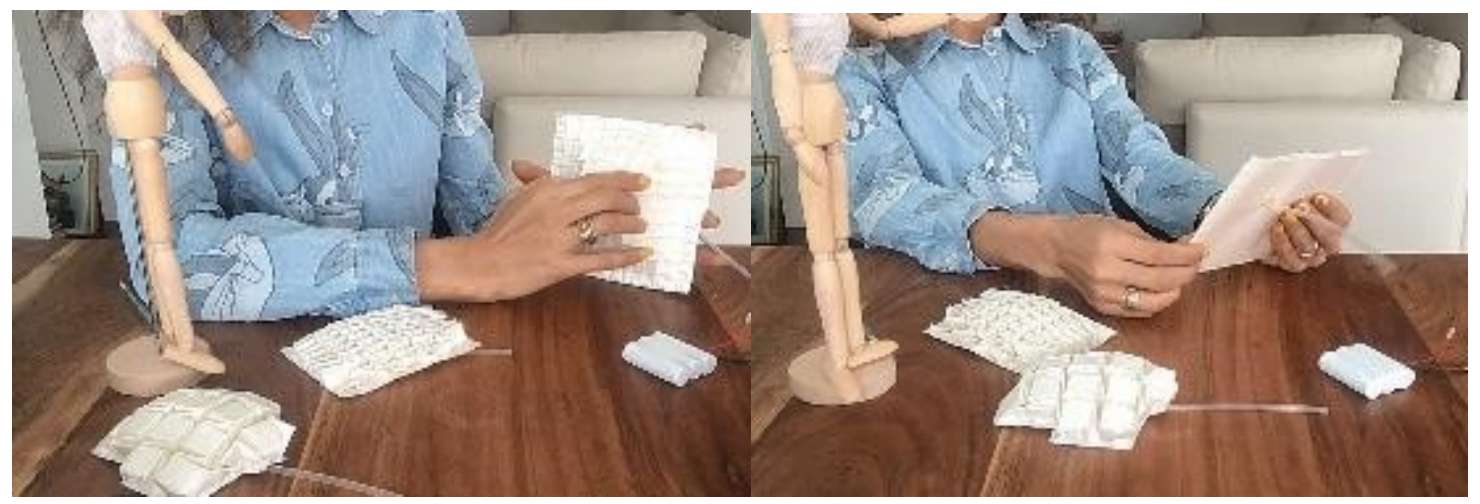

Figure 41: P3 looking between the folds and at the back of fabric. 
P4 in Figure 42 touched all of the fabrics, but she did not squeeze them at all. She observed them more than asking questions about them. She was talking about the functionality of the fabrics and mentioned that she would not use them off the rack. She mentioned that she designed a skirt with the Six-Crease Waterbomb fabric, but she said that she is not interested in wearing it, though some people might want to wear a garment like this. The participant was not interested on a shape-changing garments.

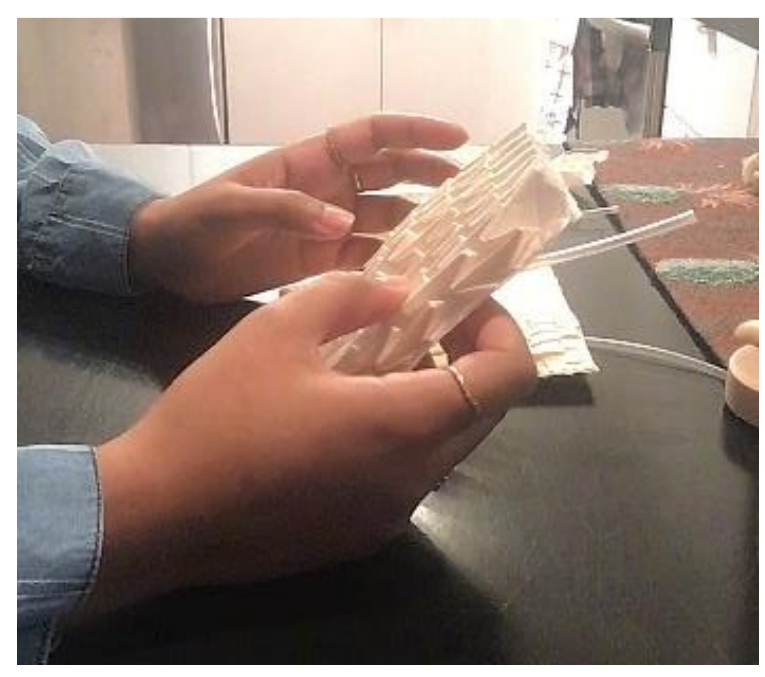

Figure 42: P4 observing the fabrics.

P5 pointed at the prototypes but did not touch them at the beginning. She stated that the Eight-Crease Waterbomb was too rigid and she expected it to be soft, so she used the Eight-Crease Waterbomb to design a hat (Figure 43). At the end of the session, she started holding the fabrics and put them on the mini manikin, and her designs seemed to be based on the flexibility of the fabrics. 


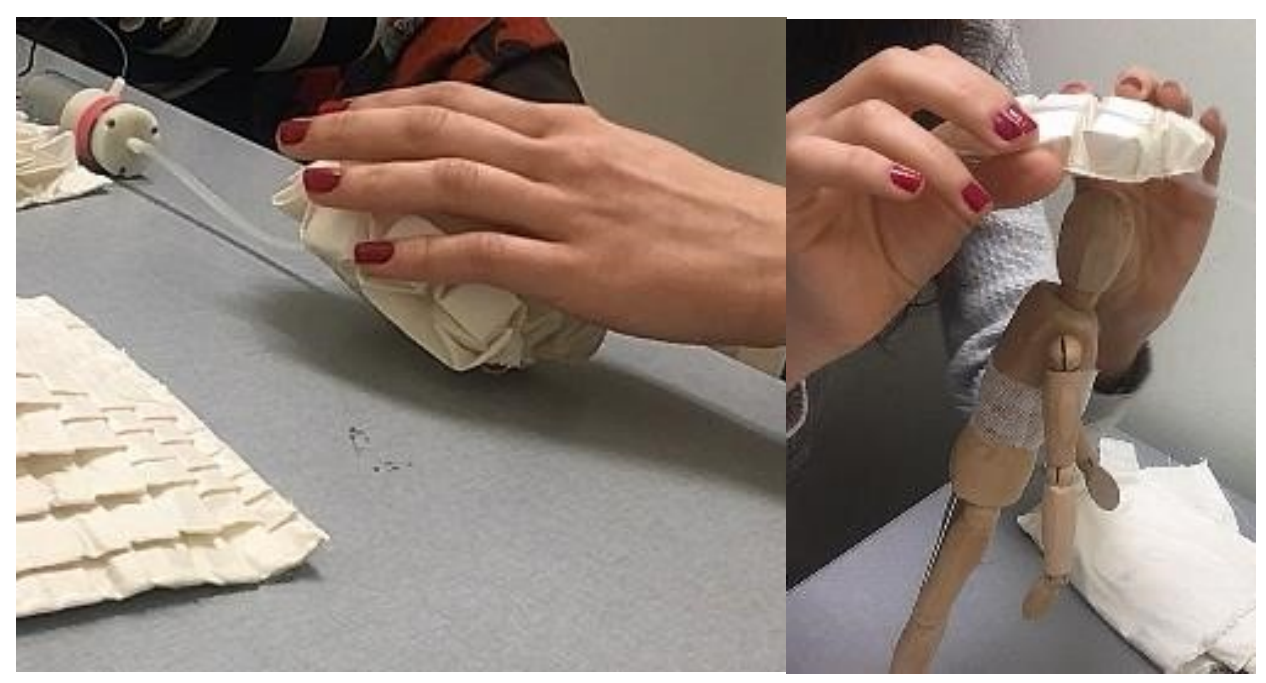

Figure 43: P5 touching the fabric and start designing based on the fabric quality.

P6 in Figure 44 was engaged from the beginning of the study. She asked several questions regarding the steps involved in the development of the prototypes. The participant mentioned several times that she would not be interested in wearing a garment that would blow up.

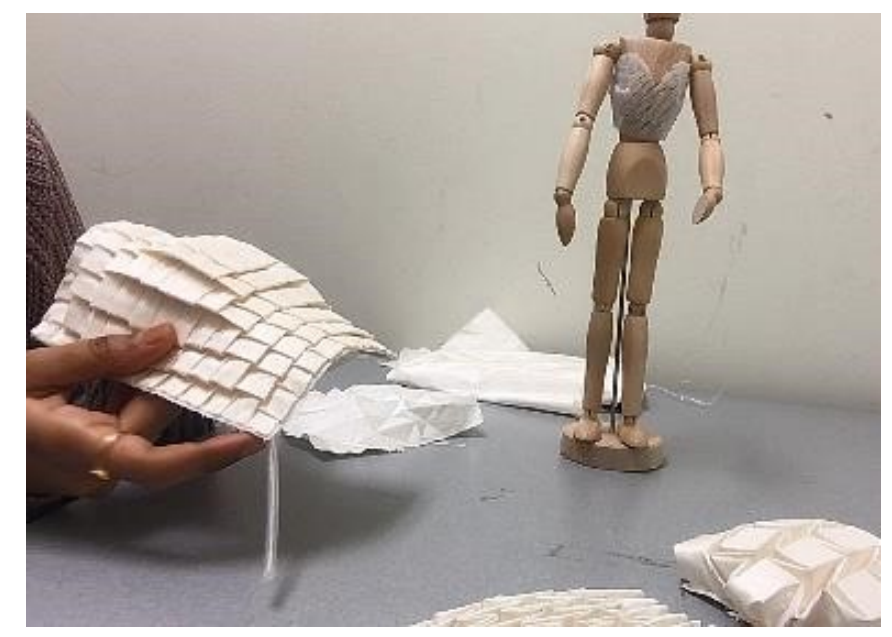

Figure 44: P6 folding the Pyramid kinetic fabric 
P7 in Figure 45 was engaged and showed his excitement when he looked at the fabrics changing their shape. At the beginning of the study, he asked several questions about the technology that we used to make the fabrics and he was interested to know about the steps of making the prototypes and comparing them with 3D printed pieces. He was pulling out the folds and talked about how he could implement the fabrics with 3D printing. He was also compared the fabrics with each other to find a suitable style for his future design.

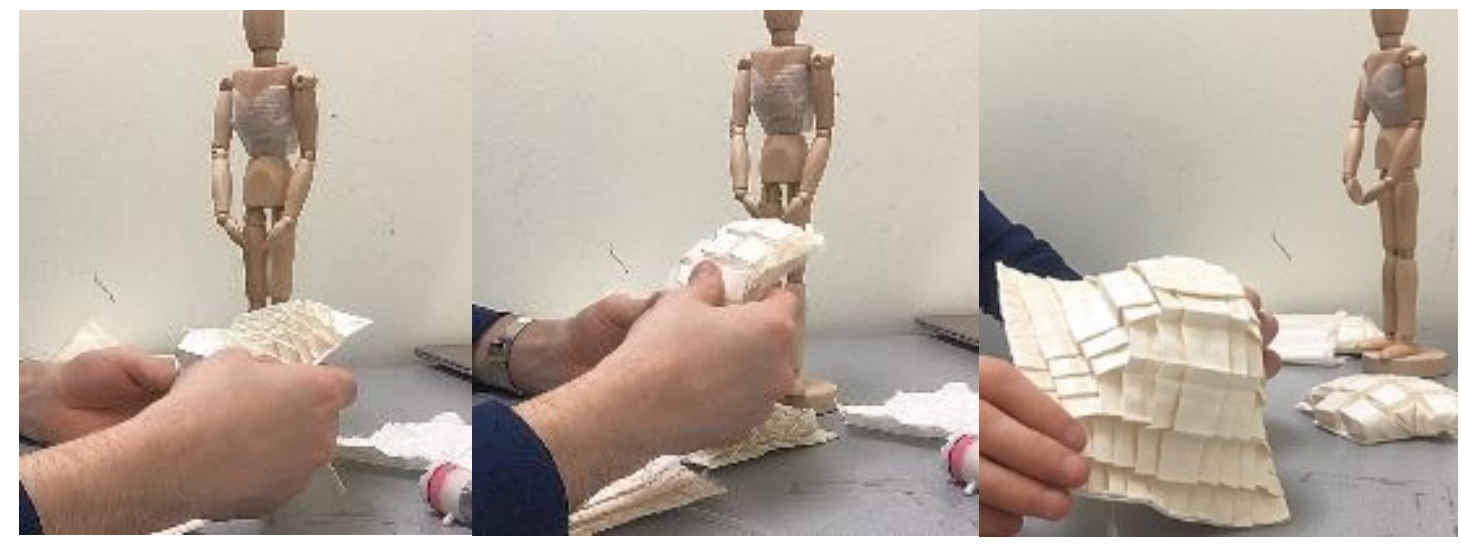

Figure 45: P7 paying attention to the detail of the fabrics

One observation that can be made is between the participant's reactions during the design session and their answers from the survey. P7, who gave the most positive answers, was the one who had engaged the most during the design session — and touched the fabric and squeezed it a lot. This participant was exceptionally likely to recommend the prototypes to other designers.

P1 and P7 drew comparisons between the prototypes and their own work; they were the most excited participants during the study and talked a lot about the element of surprise when they first saw the prototypes. During the survey these two participants answered that 
the prototypes were exceptionally innovative. P1 also asked many questions during the design session on the effects of cutting and sewing and on the safety of the components; she answered that the prototypes were easy to use. Her engagement during the design session seemed to positively affect the answers she gave us during the survey. P7 answered 5 (truly exceptional) to all the questions without ever changing his answers during the survey.

P2 was the designer with the most experience in fashion and said that she preferred to work with traditional fabrics instead of kinetic fabrics. Her answer to the survey, that the prototype was not easy to use, reflects her views. However, she stated during the survey that the technology would affect traditional fashion design, mostly traditional couture on average and that our prototypes were exceptionally innovative. These answers contradicted the answer she gave when she said that she did not expect the prototype to be disruptive.

P3 did not ask questions about the technology during the design session but was trying to figure out how the prototype worked, and she considered the prototypes to be exceptionally easy to use. P3 also showed less interest than other participants in using the prototypes in her design; she was also the participant who was less likely to recommend the prototypes to other designers.

\subsection{Second Interview}

As noted in the previous chapter, we asked the participants from the first study five follow-up questions and five of them agreed to participate in the phone interview five months after the first study. First, we asked if the earlier study of the kinetic fabrics influenced their vision of using similar technologies in their design. Three participants out 
of five answered that the technology influenced their vision about how they can incorporate technology into their design, in order to innovate and make their pieces look different.

The first of these two participants did not provide any details regarding why her vision did not change as a result of participating in our experiment; P5 stated that she did not observe enough examples during the design session so she had difficulties envisioning what the impact of the prototypes would be.

We also wanted to find out if participants talked about the kinetic fabric samples with anyone else after the design session, or if they thought about the prototypes and their functionalities. Three participants out of five did not talk about the samples with anyone; P1 surprisingly replied, "I thought I am not allowed." The other two participants talked about the samples with a friend, explaining the way the prototype worked and its functionalities.

Following this question, we asked the participants for suggestions about any improvements we could make to the kinetic fabric samples that might have changed their experience. Four of the participants said they would like to work with larger sample pieces that the scale of the pattern would not change. Designers would prefer to design on a human-sized manikin and would have wanted the opportunity to cut the fabrics into different shapes. They said that working with small samples on a small manikin was a limitation. Interestingly only one of them was concerned about the scale of the fabrics and she stated, "I don't like to have the samples in larger of the scale but if you keep the scale small and give me a large piece of fabric then I am happy." 
P1 mentioned that she would prefer the fabrics to be in different colours and textures. This could have allowed designers to be more creative by giving them more ideas of different designs through combining colours and textures.

P5 had a different idea. She mentioned the samples were limited in terms of movement and style and stated, "using different software to show the movements and more examples of 3D dimensional." P2 mentioned that the wires should be hidden.

The last question asked if they had any new ideas for designing with the samples since our design session. Two participants answered negatively, saying they had not thought about the samples since the design session. Three of them had made something new with the samples in their mind. P6 mentioned that she would like to use them on kids' wear and two others wanted to incorporate them in their designs for their customers. Those answers suggest that there was a true interest in working with our samples in the future. 


\section{Chapter 6: Discussion}

This chapter synthesizes the results into answers to the sub-questions and the main research question in this study. It relates the answers back to the information from the literature review in Chapter 2.

\subsection{Designers' Awareness and Collaboration}

Most of the participants expressed interest in interactive art and design though they had never attended an interactive events or museum. The participants had not worked with any electronic elements before participating in the study and had no knowledge about more complex prototypes. The participants' perception of innovative interactive garments/art pieces seemed to be limited to rudimentary technology with basic interactions such as lights and neon threads; they did not have much knowledge of more complex technology. Since they had never seen the potential of new technology in their design, it might have limited their understanding of the creative potential for design. This might explain why they were more conventional and conservative in their approach.

The participants who had a background in design research had considered using electronic elements in their design before; they mentioned collaborations between designers and developers that could enable designers to perform better in their design [(McCann, J; Bryson, 2009) (Pailes-Friedman, 2016)]. Other participants had not thought about working with professionals in technology fields in order to build something innovative or to incorporate technology to their design. 
The participants considered their experience working with the kinetic fabric samples exceptional. This study influenced the participants' vision regarding incorporating technology in their designs. The interview allowed us to answer the first sub-question of our study. We determined that participants lack experience and knowledge with interactive design, which influenced whether or not they would incorporate technology in their future designs.

\subsection{Participant Interest and Engagement}

Based on our observations, all the participants seemed interested in seeing the kinetic fabrics. We interpreted this by the participants' responses to the prototype demonstrations and categorized them into two groups according to their apparent engagement with and interest in the prototypes: Emotionally Oriented and Functionally

Oriented. Results suggested that the participants who were the most excited began touching and engaging immediately and asked questions about the development of the prototypes. They were intrigued by the technology behind the prototypes and the steps involved in their production. They also squeezed the fabrics and were more comfortable playing with them to discover their attributes.

Interestingly, this Emotionally-Oriented group of participants focused on the emotional and social aspects of using the fabrics in fashion design. They mentioned that the fabrics have the potential to be used on the red carpet or in a big event or a fashion show; they seemed to be interested in how the fabrics would impress people. All three responded in the survey that they were likely to recommend this prototype to another designer and would consider using them in their own design. 
The second category of participants, the Functionally-Oriented Group, who were less excited during the design session, focused on the functional aspects of using the kinetic fabrics. Such functional applications included the protection provided by the fabric while using it on parts of the body that can protect the wearer from falling down or from bad weather conditions. As another fabric functionality, participants also proposed using them for non-body purposes such as furniture. They were also more interested in working on traditional garments and fabric in more conventional ways. Furthermore, one of the main concerns of the participants in the functionality group was that the garments could not be used for everyday outerwear because of the lack of social acceptability.

This section allows us to better answer the second of our sub-questions related to the use of the kinetic fabrics by the participants during the design session. As stated, participants ended up in two groups with different traits of behavior but most of them stayed conservative in their design.

\subsection{Foldable Structure}

Based on the literature review, origami has been a favourite fashion design structure for many decades (Issam Yousef, 2015). Our results show that shape-changing was a pleasing feature based on the participants' comments and our observations. Participants also noted that the fabrics material was not flexible enough. This can be explained by the fact that we added layers of fabric in order to implement the origami shape on the soft silk fabric. The added layers made the fabric rigid and therefore less flexible for the participants who were concerned about the users' comfort. 
Participants referred to the fit of the fabric by specifying it would be suitable for the bottom parts of the body rather than the top. They explained that they would prefer not to use the prototypes on certain parts of the body --specifically mentioned the arms, waistline and stomach-- because people would not like to have clothing items bumping around those areas, it would limit movement abilities, make people look big and also decrease comfort. For this reason, participants ended up designing for a similar body part, which increased the chance of designing similar clothing items in the design session.

All of the participants had a positive reaction to the fabric samples' appearance and the origami patterns, and tried to be creative in their designs, considering user comfort as an important factor. After their experience in the design session, participants were asked about improvements that could inspire them in design and four of them expressed interest in designing with a bigger size of the fabric samples. This section also helped us to answer the second of our sub-questions by providing insights on the way that participants used origami patterns for design purposes.

\subsection{Innovation}

As noted in the literature review, when a new technology is created the first individuals to use it are usually called early adopters (Moore, 1991); the participants who took part in the study could be considered as potential early adopters of the prototyping technology. Therefore, when shown to the participants, four of them had high expectations for the prototypes and were disillusioned by the technology during the session, while the other three found the prototypes useful. The participants who were more engaged during the session provided broader ideas regarding possibilities of what to design. 
These results seem to be aligned with the literature review; people's characteristics play a major role when facing an innovation (Moore, 1991). People who are more excited about technology and love to try different things may be better candidates as early adopters of kinetic wearables. It is important to keep in mind that major adoption is something that will take a long time and will require education, publicity and support before happening (Moore, 1991). As was mentioned earlier, creating a partnership between researchers and designers could contribute to reaching full adoption earlier in the Gartner Hype Cycle (Gartner, 2019). This helped us to answer the third of our sub-questions by giving us information on how likely the participants are to explore the possibility of using samples within their designs. For example, in the second interview three participants mentioned that the design session changed their vision about the implementation of technology into their design. It influenced their perception of the relationship between technology and design in general. However, most of them did not think about the new applications in design that they could have made with the prototypes. Therefore, the prototypes may have influenced their vision about the place of technology in the design industry, but did not appear to trigger their creativity, practically, to help them consider applying the new technology within their own designs.

\subsection{Future Work and Recommendations}

The adoption curve of new technology by a population depends on knowledge and understanding of that technology; the less educated the population is, the more likely it is that their expectations will be unrealistic and produce disillusionment toward the potential benefits of the technology. Therefore, to avoid that situation and to promote better and 
faster adoption, designers should have access to collaboration spaces, samples, videos, fashion shows and interactive museums. Our observation shows that designers need to attend events related to technology and design to grasp the full potential of interactive arts.

As a result, we would like to suggest that designers pair up with engineers in order to create opportunities to implement their ideas (Pailes-Friedman, 2016). The collaboration between a designer and a tech-savvy partner can open a designer's eyes about the potential of new innovations in art and design. This allows a reduction in skill and knowledge gaps and provides better exposure to interactive design. These factors could contribute to the successful integration of new technologies within the wearable market and help designers integrate more technology into their actual designs.

We believe that providing a bigger piece of interactive sample, made with the same pattern, would provide more opportunities for designers. A similar prototype of a bigger size might have increased the participants' creativity to design with the prototypes. The same pattern and fold size, but bigger prototypes might have helped designers to modify the shape of the fabrics more efficiently by cutting and sewing them and could have even inspired them to be more creative. However, none of the participants mentioned this as being a limitation in the study. The only participant who made a comment related to the size of the fabric mentioned that she would not have liked to work with a bigger prototype.

A final recommendation would be to conduct more research on the adoption curve related to design and fashion specifically. As stated in the research, the Gartner Hype Cycle helps us understand how technology is being adopted by a population (Gartner, 2019). However, little research exists on the adoption of new technology in the design and fashion sector. It would be interesting to see if the adoption of new technology is faster or slower 
in that sector compared to others, which would help us identify gaps in the way people are working in that sector.

Another point worth mentioning is that the impact of the design and movement of our prototypes may have influenced the findings that emerged from our study. Working with prototypes that have different designs, structures and functions could perhaps have led to different findings. Therefore, it may be useful to conduct studies with different prototype patterns, functions, and movements in order to learn more.

\subsection{Limitations}

Many participants gave similar answers about the type of designs they would create with the different prototypes. One of the possible reasons for why participants would make the same kind of pieces is that they did not have the opportunity to modify the shape of the fabrics by cutting them. Therefore, they limited themselves to use the fabric as it was given to them.

One of the reasons the participants' choices were restricted is that it took time to build the prototypes; we did not have the chance to build more and/or bigger prototypes. We believe that showing participants a bigger piece of interactive sample material would inspire them to be more creative with the prototypes they were given.

An initial expectation was that designers would use the prototypes to design a piece of interactive art that would influence the audience rather than designing everyday garments. Even if most participants agreed that it would have a positive effect on the audience, only two participants introduced the idea of using the fabrics for artistic-oriented 
designs such as a pregnant lady and a gladiator lady garment. Other designs were simpler, and they did not try to create anything fantastic or original.

Furthermore, all participants answered that there was no limit in terms of using technology in fashion design. Following that, we expected them to set themselves no boundaries in their creation process and to use the prototypes in a creative way in order to design new products. However, most participants ended up being conservative during the design session and they contented themselves with deriving a product from the initial shape of the prototype. It seemed they did not use their imagination for breaking boundaries and creating new apparel designs but instead used more conventional approaches.

The highly homogeneous answers from the survey demonstrate one of the limitations of the study: since most participants gave similar answers, it was difficult to identify different patterns in their opinions.

Another limitation of our study is regarding our methodology; we observed that the possible answers to the survey were poorly designed. The three main answers ("unacceptable", "average" and "truly exceptional") were not a continuum, symmetrical or related to some of our questions. It also created issues for the results and discussion sections since it became difficult to accurately identify the opinion of the participants.

Finally, as previously mentioned in the discussion section, another potential limitation is the dependency of the findings on the types of patterns, functions and movement of the prototypes we used for this study. However, this is not something we can identify. 


\section{Chapter 7: Conclusion}

For this study, we created three kinetic fabric sample prototypes to engage designers during a design session. We asked designers to answer questions regarding their knowledge about and experience with interactive arts before being asked to design garments on the manikin. Following the design session, we asked the participants to give their feedback in a survey. The study ended with a final follow-up interview conducted several months after their design session experience where participants were asked about their perceptions and thoughts that they had about kinetic fabrics.

The responses to questions asked before the design session showed that most participants lacked experience and exposure to incorporating new technology in design. They had an interest in learning more about technology, but they expressed concerns about the lack of events hosted on the subject that would allow them to see more examples.

During the design session, we found that participants were more engaged during the time they were working with fabrics but not particularly creative; they did not try to design garments as an interactive piece and took a conservative design approach. Most of the designs focused on day-to-day wearables and most of the designers ended up designing similar pieces with the fabric samples, even though each design session was conducted at a separate time and place. In addition, we gave participants a chance to think about more designs they could have made with a bigger prototype if there was a second study.

Some participants talked about the prototypes' lack of flexibility during the design session, but they did not offer any potential improvements for the samples when asked during the second interview. Following the first study, designers seemed to not think much 
about the innovative aspect in their design and they took no initiative to subsequently develop a collaborative partnership with researchers in that field. Most of the designers did not provide any new ideas during the second interview.

The anticipated outcome of this study was to change the vision of designers in order to help them become more open-minded regarding the implementation of new technologies within their designs. However, the outcomes suggest that this group of designers in our Case study would need more time and examples in order to grasp a new technology and in order to be creative while incorporating new technologies within their designs. It would be difficult for them to become creative in a short period of time if they do not have time and resources for adapting and refining their ideas about the use of new technology. They may also need more opportunities to see the technology implemented into fashion designs and work with the technology themselves in order to become more creative.

Ultimately, this study does not quite answer the main question: How can kinetic fabric samples help designers incorporate technology in their design? The study does, however, provide a set of initial recommendations based on the findings of this preliminary Case Study.

Therefore, we recommend:

1. Adoption curve and Resources: To promote better and faster adoption it may be helpful to provide more resources for designers such as access to collaboration spaces, samples, videos, fashion shows, web sites and interactive museums.

2. Collaborations: To promote greater skills and to maximize knowledge about ematerials, kinetic resources and methods of implementation it may be helpful to promote collaborations between designers and engineers. The collaboration 
between designers and a tech-savvy partner can open a designer's eyes to ways of incorporating new innovations in art and design.

3. Changes to the fabric samples: To provide better opportunities for modifying shapes and inspiring creativity it may be helpful to provide larger and more varied patterns of interactive sample materials that could inspire participants to be more creative and make it easier to use the samples. In addition, the kinetic fabric samples could be organized into a sample that includes instructions for using the samples, shows examples of applications, and illustrates steps for sketching in three dimensions with the prototypes provided.

4. Future research: To understand the issues affecting adoption of kinetic fabrics future research. Research should include a larger population sample and study the adoption curve related to design, fashion and new technologies. 


\section{Appendices}

\section{Appendix A : Definition of Kinetic fabric samples}

Participants will be exposed to a ready to use shape-changing fabrics that allows them to explore working with soft, shape-changing materials. The kinetic fabric samples change their shape with wearer control, to fold and unfold. The pattern of these fabrics is based on folding and unfolding so the fabric can be moved when it's open and closed. We will provide the kinetic fabric samples to designers to see how they would use them in a garment design.

The samples change shape through mechanical processes but could also be electronic. However, the mechanisms are not being tested, only the concepts of changing 3-dimensional or kinetic patterns. This study explores the interaction between designers and kinetic fabrics to see how or if they would like to implement them in their designs.

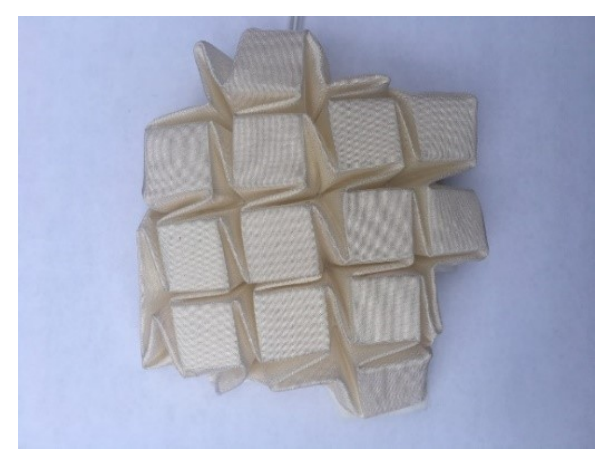

Figure 46: Kinetic Fabric Samples- The sample in this photo is closed

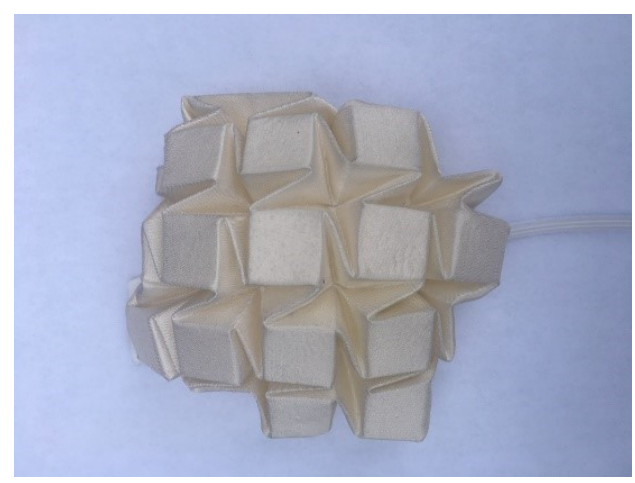

Figure 47: Kinetic Fabric Samples - The sample in this photo is open 


\section{Appendix B : Script for Activities}

\section{Introduction:}

Hello, my name is Daniela Ghanbari Vahid and I am a master student in Human computer Interaction program at Carleton university. I am conducting master's thesis research on kinetic fabric samples to understand the impact of the new prototype in interactive fashion arts from a professional point of view. The focus of this interview will be on your experience and opinions about the merging of textile and technology.

The data gathered during this interview will help us to identify the advantages and disadvantages of developing new kinetic (moving) fabric samples for designers.

This interview should take no more than two hours to complete and all your responses will be kept confidential. You will be video, and audio recorded but only your hands will be recorded not your face. If your face is video recorded, it will be blurred. Your name or identity will not be associated with the feedback provided in any way. If a comment or action needs to be referenced, you would be referred to as Test Participant 1 (for example).

Do you have any questions before we begin?

\section{The kinetic fabric samples Individual Workshop -Outline}

I. Greetings (a few minutes): Initial greeting and welcome.

II. Consent (a few minutes): Participants will be asked to sign the consent form CUREBB Clearance \#109892.

III. Introduction (5 minutes): The researcher will introduce and define the main concepts of the research for designers.

IV. Semi-structured Interview (20 minutes): The participants will be asked to answer the questions (refer to attached questions)

V. Break (15 minutes)

VI. Design (40 minutes): The participant will be asked to interact with kinetic fabric samples and try to design a garment on a mini manikin. He or she can explore any elements, sequencing and activities freely that they want to investigate and/or perform.

VII. Observation (in conjunction with the workshop phase): While the participant is interacting with the design toolkits, the researcher will observe and take note regarding the overall his/her interactions, the selection, the timing, the uncertainties and any other pertinent observations during this interactive phase.

VIII. Result and feedback (5 minutes): The participant will be asked to explain their insights or other thoughts about the kinetic fabric samples as a toolkit for designers to use. They will be encouraged to share their thoughts, knowledge, ideas about the performance as well as the benefits/drawbacks of the kinetic fabric sample.

IX. Survey Appendix F (5 minutes): In addition, participants will be called upon to fill out a survey to compile additional insight and feedback as part of the evaluation of the kinetic fabric improvements. (see attached document)

Debriefing (5 minutes): Concluding discussions will focus on the participant's key learning regarding the use and value of preparing for using kinetic fabrics in their design, as well as 
possible future considerations and any additional feedback for disseminating this knowledge.

\section{Appendix C : Semi-Structured Interview Questions}

1. Can you tell me a little bit about yourself? How long have you been in the art industry?

2. What kind of interaction art are you interested in? Did you ever visit any fashion technology event? If so, what was your experience?

3. What role do you think technology plays in fashion today?

4. Did you ever consider using electronic elements (sensors or lights) or other technology in your designs?

5. Have you ever seen any examples of the innovative interactive garments/art piece? What inspired you?

6. What features are you interested in smart fabrics?

7. What do you think about kinetic fabrics or garments? Are you interested in designing with kinetic fabrics?

8. How do you think using interactive electronics and other technologies would impact on the audience's experience?

9. How would you want the wearer to feel when wearing an interactive garment?

10. Has designing interactive clothing changed your perception of fashion? What are the limits of fashion materials?

\section{Study activities}

I would like to ask you to use these toolkits and design a garment that would incorporate one or more of the kinetic fabric samples. Please think and talk aloud at the same time.

\section{Appendix D : Email Invitation}

Subject: Invitation to participate in a research project on Kinetic fabric samples

Dear Sir or Madam,

My name is Daniela Ghanbari Vahid and I am a master's student in Human-computer Interaction at Carleton University. I am working on a research project under the supervision of Prof. Dr. Lois Frankel.

I am writing to you today to invite you to participate in a study entitled "Kinetic fabric samples". This study aims to develop kinetic fabric samples and provide them to fashion 
designers in order to enhance the opportunity for using technology in their garments. The focus of this interview will be on your experience and opinion on emerging textiles and technology. To be eligible, you must be over 18 years old and comfortable speaking English and either:

- Have been involved with fashion design

\section{and/or}

Be a designer that has worked with fabrics before

I have included information for the study below. Please let me know if you would like to participate or if you have any other questions.

We are looking for volunteers to participate in a two-hour interview and design session. These two-hour sessions will be held in-person at Participant preferred location (a library room or their workplace). With your consent, interviews will be video recorded. The recording has been transcribed and will be used in presentation without showing the faces and they will be destroyed after seven years. We will be keeping all responses confidential and you may request that certain responses not be included in the final project. If you do not accept to be video or Audio recorded unfortunately, we cannot conduct the session.

You will have the right to end your participation in the study at any time, for any reason, up until February $15^{\text {th }}, 2019$. If you choose to withdraw, all the information you have provided will be destroyed and there is no compensation.

All research data, including video-recordings and any hard copies of data (including any handwritten notes or USB keys) will be kept in a locked cabinet at Carleton University. Research data will only be accessible by the researcher and the research supervisor.

The ethics protocol for this project was reviewed by the Carleton University Research Ethics Board, which provided clearance to carry out the research. (Clearance \#109892)

If you have any ethical concerns with the study, please contact Dr. Bernadette Campbell, Chair, Carleton University Research Ethics Board-B (by phone at 613-520-2600 ext. 4085 or via email at ethics@,carleton.ca).

If you would like to participate in this research project, or have any questions, please contact me at (Danielaghanbarivahid@,cmail.carleton.ca).

Sincerely,

Daniela Ghanbari Vahid 


\section{Appendix E : Research Consent Form}

\section{Name and Contact Information of Researchers:}

Daniela Ghanbari Vahid, Department of Human Computer Interaction

Tel.: 416-414-0161

Email: Danielaghanbarivahid@cmail.carleton.ca

Supervisor and

Contact Information: Dr. Lois Frankel, loisfrankel@cunet.carleton.ca

\section{Project Title}

Kinetic fabric samples as a new approach to interactive fashion arts

\section{Carleton University Project Clearance}

Clearance \#: 109892

Date of Clearance: 29/01/2019

\section{Invitation}

You are invited to take part in a research project because you have experience in art/design/fashion design. The information in this form is intended to help you understand what we are asking of you so that you can decide whether you agree to participate in this study. Your participation in this study is voluntary, and a decision not to participate will not be used against you in any way. As you read this form, and decide whether to participate, please ask all the questions you might have, take whatever time you need, and consult with others as you wish.

\section{What is the purpose of the study?}

The aim of this research is to provide kinetic fabric samples to designers to use them in the design session. We will provide the kinetic fabric samples to designers as a toolkit to see how they would use them in a garment design and the goal is to identify the advantages and disadvantages of the samples. This information will be used to identify design guidelines for kinetic fabric samples which assist designers to use electronics in their garment design.

\section{What will I be asked to do?}

If you agree to take part in the study, we will ask you to:

Participate in an individual interview in which you will be asked questions about your knowledge and experience of working with any computational function in fabrics. You will also be asked to start designing a garment with some kinetic fabric samples that I provide. 
At the end you will be asked to fill in a survey about your design experience with kinetic fabrics.

All of the research will take place in a convenient, appropriate and comfortable neutral location. This can be either at a public location, a library room, or your workplace as agreed upon and confirmed prior to the meeting date. This study should take no more than two hours to complete and all your responses will be kept confidential. The session will be video record and photograph if you agree to be recorded if you are not agreed then the session will be cancelled.

\section{Risks and Inconveniences}

I do not anticipate any risks to participating in this study.

\section{Possible Benefits}

You may not receive any direct benefit from your participation in this study. However, your participation may allow researchers to better identify the advantages and disadvantages of the prototypes that we are developing.

\section{Compensation/Incentives}

You will not be paid or compensated for your participation in this study.

\section{No waiver of your rights}

By signing this form, you are not waiving any rights or releasing the researchers from any liability.

\section{Withdrawing from the study}

If you withdraw your consent during the course of the study, all information collected from you before your withdrawal will still be used, unless you request that it be removed from the study data.

After the study, you may request that your data be removed from the study and deleted by notice given to the Principal Investigator until February $15^{\text {th }}, 2019$.

\section{Confidentiality}

We will remove all identifying information from the study after 7 years including all the videos. We will treat your personal information as confidential, although absolute privacy cannot be guaranteed. No information that discloses your identity will be released or 
published without your specific consent. Research records may be accessed by the Carleton University Research Ethics Board in order to ensure continuing ethics compliance.

All data will be kept confidential, unless release is required by law (e.g. child abuse, harm to self or others).

The results of this study may be published or presented at an academic conference or meeting, but the data will be presented so that it will not be possible to identify any participants unless you give your consent. The interview will be video recorded but not your face. The recording will be used in presentation without showing the faces and they will be destroyed after seven years. If you are not agreeing to be recorded, then we don't video record you and the session will be cancel.

You will be assigned a code so that your identity will not be directly associated with the data you have provided. All data, including videos, will be kept in a passwordprotected file on a secure computer.

\section{Data Retention}

After the study is completed, your de-identified data will be destroyed after 7 years.

\section{New information during the study}

In the event that any changes could affect your decision to continue participating in this study, you will be promptly informed.

\section{Ethics review}

This project was reviewed and cleared by the Carleton University Research Ethics Board [B] (CUREB-B Clearance \#109892). If you have any ethical concerns with the study, please contact Dr. Bernadette Campbell, Chair, Carleton University Research Ethics Board (by phone at 613-520-2600 [ext. 4085 for CUREB B] or by email at ethics@,carleton.ca).

\section{Statement of consent - print and sign name}

I voluntarily agree to participate in this study.

I agree to be (audio/video recorded/photographed ...)

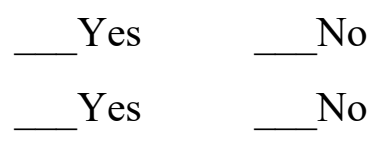




\section{Research team member who interacted with the subject}

I have explained the study to the participant and answered any and all of their questions. The participant appeared to understand and agree. I provided a copy of the consent form to the participant for their reference.

Signature of researcher

Date

\section{Appendix F : Debriefing}

\section{Name and Contact Information of Researchers:}

Daniela Ghanbari Vahid, Carleton University, Human computer interaction department Tel.: 416-414-0161

Email: Danielaghanbarivahid@cmail.carleton.ca

\section{Supervisor and Contact Information:}

Dr. Lois Frankel, loisfrankel@cunet.carleton.ca, at: (613-520-2600, ext. 5675).

\section{Project Title}

Kinetic fabric samples as a new approach to interactive fashion arts

\section{Carleton University Project Clearance}

Clearance \#: 109892

Date of Clearance: 29/01/2019

What are we trying to learn in this research? 
This research examines the kinetic fabric samples that we already developed to help fashion designers incorporate technology in their designs. The questionnaires you completed assessed your evaluation of working with Kinetic Fabric Samples. We also asked you to provide information during the design with kinetic fabrics to find out how you tend to use different samples in the design. We want to identify the advantages and disadvantages of this new approach in the fashion industry.

\section{Why is this important to scientists or the general public?}

Wearable technology and smart textiles are growing very fast and the number of designers who are willing to use the new technologies in their design is growing too. Previous research has shown a relationship between technology and garment design. Less is known, however, about the specific factors that lead designers to use emerging techtextiles in their designs.

The goal is to observe and evaluate their interaction with the tool as well as to gain the participants' perspective, advice and feedback. An additional objective is to identify the advantages and disadvantages of this new approach in the fashion industry.

Benefits can be demonstrated to designers in general with a focus on incorporating emerging tech-textiles in their designs.

\section{What are our hypotheses and predictions?}

We predict that individuals' will appreciate the kinetic fabric samples as a new approach to help designers to use them in their interactive arts. We also predict that how well they are able to interact with samples. We will also ask the participant for feedback for further improvement of this new approach in future.

\section{Where can I learn more?}

Smart Textiles for Designers Inventing the Future of Fabrics book by Rebeccah Pailes-Friedman is a great reference to explore the new materials and wearable technology.

If you found this experiment to be emotionally upsetting or if you feel any distress or anxiety after participating in this study, please feel free to contact the Carleton University Health and Counseling Services at: 613-520-6674, or the Distress Centre of Ottawa and Region at 613-238-3311 (http://www.dcottawa.on.ca).

\section{What if $I$ have questions later?}

If you have any remaining concerns, questions, or comments about the experiment, please feel free to contact Daniela Ghanbari Vahid, at: Danielaghanbarivahid@.cmail.carleton.ca , Dr. Lois Frankel at loisfrankel@cunet.carleton.ca, at: (613-520-2600, ext. 5675). 


\section{CUREB-B:}

If you have any ethical concerns with the study, please contact Dr. Bernadette Campbell, Chair, Carleton University Research Ethics Board-B (by phone at 613-520-2600 ext.4085 or via email at ethics@carleton.ca).

Thank you for participating in this research!

\section{Appendix G : Survey}

1. What is your gender?

O Female

O Male

O Other

2. How old are you?

O $18-30$

O $30-40$

O $40-50$

O +50

3. What is the highest level of education you have completed?

High school graduate

Two years associate degree or some college

Bachelor's degree

Graduate degree

Professional degree

1. How would you describe your reaction to the kinetic fabric samples at first (Truly exceptional being highly impressed by the fabric and unacceptable being disappointed by it)?

Unacceptable

$$
1
$$

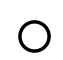

average

3

$\mathrm{O}$
Truly exceptional

5

O

2. How well, if at all, does the word "Innovative" describe this new prototype? 
Unacceptable

average

Truly exceptional

$\begin{array}{lllll}1 & 2 & 3 & 4 & 5 \\ 0 & 0 & 0 & 0 & 0\end{array}$

3. What is your overall satisfaction with the kinetic fabric sample?

\begin{tabular}{ccccc} 
Unacceptable & \multicolumn{3}{c}{ Truly exceptional } \\
1 & 2 & 3 & 4 & 5 \\
0 & 0 & 0 & 0 & 0
\end{tabular}

4. How likely are you consider using this prototype in your design?

Unacceptable

$\begin{array}{ll}1 & 2 \\ 0 & 0\end{array}$

average

3

O

Truly exceptional

5. How likely are you to recommend this prototype to another designer?

Unacceptable

$\begin{array}{ll}1 & 2 \\ 0 & 0\end{array}$

average

3

O
Truly exceptional

4

5

O

6. I found that the prototype was easy to use.

Unacceptable

$$
1
$$

O average

3

O
Truly exceptional

4

O
5

$\mathrm{O}$

7. How do you think that this kind of technology would affect traditional couture?

Unacceptable

1

O average

2

$\bigcirc$
3

$\bigcirc$
Truly exceptional

4

5

0

\section{Appendix H : Semi-Structured Interview for the Second Study}

1. How did the previous study of the kinetic fabrics influence your vision of using similar technologies in the design industry, if it did?

2. Did you talk about the kinetic prototypes with anyone else after the design session? Did you think about them? What were some of your thoughts and/or things you said about them? 
3. Thinking back to your experience in the design session, what about the kinetic samples could have been improved to inspire your ideas for design applications?

4. Would you be comfortable designing with large pieces of the kinetic fabrics? If not, why?

5. Have you had any ideas for designing with them since our design session? 


\section{References}

Alvesson, M. (2000). Doing Critical Management Research. SAGE. Retrieved from https://dx-doi-org.proxy.library.carleton.ca/10.4135/9781849208918

Angela Linneman. (2017). A Visionary Artist Takes on the Smart Home. Retrieved from https://www.shapeways.com/blog/archives/28710-a-visionary-artist-takes-on-thesmart-home.html

Anzaldo, D. (2015). Wearable sports technology - Market landscape and compute SoC trends. In 2015 International SoC Design Conference (ISOCC) (pp. 217-218). IEEE. https://doi.org/10.1109/ISOCC.2015.7401796

Barnum, C. M. (2011). Usability Testing Essentials: Ready, Set....Test! (Barnum, C.M.; 2011) [Book Review]. IEEE Transactions on Professional Communication, 54(3), 336-337. https://doi.org/10.1109/TPC.2011.2159642

Belfiore, M. P. (2009). The department of mad scientists: how DARPA is remaking our world, from the internet to artificial limbs (1st ed.). New York, Washington, D.C.: Smithsonian Books.

Berzowska, J., \& Coelho, M. (2005). Kukkia and Vilkas: Kinetic electronic garments. Proceedings - International Symposium on Wearable Computers, ISWC, 2005, 8285. https://doi.org/10.1109/ISWC.2005.29

Bitonti, F. A. (2016). When Matter Becomes Media: How Our New Tools Are Reinventing Physicality. Architectural Design, 86(5), 100-107. https://doi.org/10.1002/ad.2095

Cass, S. (2016). Anouk Wipprecht: dynamic dresses merge high fashion and technology [Resources]. IEEE Spectrum, 53(2), 19-20. 
https://doi.org/10.1109/MSPEC.2016.7419790

Chen, Y., Feng, H., Ma, J., Peng, R., \& You, Z. (2016). Symmetric waterbomb origami. Proceedings of the Royal Society A: Mathematical, Physical and Engineering Science, 472(2190), 20150846. https://doi.org/10.1098/rspa.2015.0846

Creswell, J. W. (2014). Research design: qualitative, quantitative, and mixed methods approaches (4th ed.). SAGE Publications.

DARPA. (2019). Head-Mounted Displays. Retrieved from https://www.darpa.mil Dedehayir, O., \& Steinert, M. (2016). The hype cycle model: A review and future directions. Technological Forecasting and Social Change, 108, 28-41. https://doi.org/10.1016/j.techfore.2016.04.005

Forster Rohner. (2019). Collections by Forster Rohner Textile Innovations. Retrieved from https://www.architonic.com/en/collections/forster-rohner-textileinnovations $/ 3105100 / 0 / 1$

Fowler, F. J. (2014). Survey research methods (Fifth ed.). Los Angeles: SAGE.

Gardiner, M., \& Gardiner, R. (2012). The functional aesthetic of folding, self-similar interactions. In Proceedings of the Sixth International Conference on Tangible, Embedded and Embodied Interaction - TEI '12 (p. 19). New York, New York, USA: ACM Press. https://doi.org/10.1145/2148131.2148134

Gartner, I. (2019). Gartner Hype Cycle. Retrieved from https://www.gartner.com/en/research/methodologies/gartner-hype-cycle Hawkes, E., An, B., Benbernou, N. M., Tanaka, H., Kim, S., Demaine, E. D., ... Wood, R. J. (2010). Programmable matter by folding. Proceedings of the National Academy 
of Sciences, 107(28), 12441-12445. https://doi.org/10.1073/pnas.0914069107

Hodges, N. J., \& Link, A. N. (2019). Innovation by design. Small Business Economics, 52(2), 395-403. https://doi.org/10.1007/s11187-018-0098-1

Huang, Y., \& Eisenberg, M. (2012). Easigami. In Proceedings of the Sixth International Conference on Tangible, Embedded and Embodied Interaction - TEI '12 (p. 41). New York, New York, USA: ACM Press. https://doi.org/10.1145/2148131.2148143 Issam Yousef. (2015). Origami Fashion. Retrieved from http://www.uttutextiles.com/origami-fashion/

Jule Waibel. (2019). Jule Waibel. Retrieved from http://julewaibel.com/

Kumar, L. A., \& Vigneswaran, C. (2015). Electronics in Textiles and Clothing. Electronics in Textiles and Clothing. CRC Press. https://doi.org/10.1201/b19358

Li, Y., Zhang, J., Chen, M., Lei, H., Luo, G., \& Huang, Y. (2019). Shape based local affine invariant texture characteristics for fabric image retrieval. Multimedia Tools and Applications, 78(11), 15433-15453. https://doi.org/10.1007/s11042-018-6936-y

McCann, J; Bryson, D. (2009). Smart clothes and wearable technology. Woodhead Publishing.

MIT Media Lab. (2019). Pneuduino. Retrieved from https://tangible.media.mit.edu/project/pneuduino/

Moore, G. A. (1991). Crossing the Chashm.

Nabil, S., Plötz, T., \& Kirk, D. S. (2017). Interactive Architecture: Exploring and Unwrapping the Potentials of Organic User Interfaces. Proc. TEI '17, 89-100. https://doi.org/10.1145/3024969.3024981

Natalie Kimani. (2016). INTERACTIVE CLOTHING: The future of fashion is all for 
connectivity. Retrieved from http://tdsblog.com/interactive-clothing-future-fashionconnectivity/

Ou, J., Heibeck, F., \& Ishii, H. (2016). TEI 2016 Studio. In Proceedings of the TEI '16: Tenth International Conference on Tangible, Embedded, and Embodied Interaction - TEI '16 (pp. 766-769). New York, New York, USA: ACM Press. https://doi.org/10.1145/2839462.2854119

Ou, J., Skouras, M., Vlavianos, N., Heibeck, F., Cheng, C.-Y., Peters, J., \& Ishii, H. (2016). aeroMorph - Heat-sealing Inflatable Shape-change Materials for Interaction Design. In Proceedings of the 29th Annual Symposium on User Interface Software and Technology - UIST '16 (pp. 121-132). New York, New York, USA: ACM Press. https://doi.org/10.1145/2984511.2984520

Oxman, N. (2017). Dermi-Domus: A Grown Wardrobe for Bodies and Buildings. Architectural Design, 87(6), 16-25. https://doi.org/10.1002/ad.2233

Ozkan, B. (2015). Fall. In Proceedings of the 2015 ACM International Joint Conference on Pervasive and Ubiquitous Computing and Proceedings of the 2015 ACM International Symposium on Wearable Computers - UbiComp '15 (Vol. 0, pp. 617621). New York, New York, USA: ACM Press. https://doi.org/10.1145/2800835.2801675

Pailes-Friedman, R. (2016). Smart Textiles for Designers. London: Laurence King Publishing Ltd.

Peraza-Hernandez, E. A., Hartl, D. J., Malak Jr, R. J., \& Lagoudas, D. C. (2014). Origami-inspired active structures: a synthesis and review. Smart Materials and 
Structures, 23(9), 094001. https://doi.org/10.1088/0964-1726/23/9/094001

Perovich, L., Mothersill, P., \& Farah, J. B. (2013). Awakened apparel. In Proceedings of the 8th International Conference on Tangible, Embedded and Embodied Interaction - TEI '14 (pp. 77-80). New York, New York, USA: ACM Press. https://doi.org/10.1145/2540930.2540958

Qu, S. Q., \& Dumay, J. (2011). The qualitative research interview. Qualitative Research in Accounting \& Management, 8(3), 238-264. https://doi.org/10.1108/11766091111162070

Rebecca Jennings. (2019). No Title. Retrieved from https://www.vox.com/thegoods/2019/5/6/18531523/met-gala-2019-red-carpet-lady-gaga-kendall-kylie

Roosegaarde, D. (2019). Intimacy. Retrieved from https://www.studioroosegaarde.net/project/intimacy

Roudaut, A., Karnik, A., Löchtefeld, M., \& Subramanian, S. (2013). Morphees. In Proceedings of the SIGCHI Conference on Human Factors in Computing Systems CHI '13 (p. 593). New York, New York, USA: ACM Press.

https://doi.org/10.1145/2470654.2470738

Shapouri, B. (2019). No Title. Retrieved from https://www.usmagazine.com/stylish/news/met-gala-2019-best-dressed-our-top-5gowns-and-outfits-of-the-night/

Shivani Gohil. (2019). SKIN AND BONES. Retrieved from https://shivanigohil.wordpress.com/

Talukder, M. (2012). Factors affecting the adoption of technological innovation by individual employees: An Australian study. Procedia - Social and Behavioral 
Sciences, 40, 52-57. https://doi.org/10.1016/j.sbspro.2012.03.160

TeamLab. (2019). About teamLab. Retrieved from https://borderless.teamlab.art/ Timothy Yeung. (2017). Unfolding Origami Engineering. Retrieved from https://quarkmag.com/unfolding-origami-engineering-5bbee7fa0e13

Torah, R., Wei, Y., Grabham, N., Li, Y., de Vos, M., Todorov, T., ... Tudor, J. (2019). Enabling platform technology for smart fabric design and printing. Journal of Engineered Fibers and Fabrics, 14, 155892501984590. https://doi.org/10.1177/1558925019845903

Wipprecht, A. (2019). Spider Dress 2.0. Retrieved from https://twitter.com/anoukwipprecht/status/880018696042926082 www.npal.cs. (2019). www.npal.cs. Retrieved from http://www.npal.cs.tsukuba.ac.jp/projects/2014/pleat_tessellation/index.html XS Labs. (2010). Xs Labs Design Research. Retrieved from http://www.xslabs.net/ 